\title{
ANSWERING THE "CALL OF THE MOUNTAIN" \\ co-creating sustainability through networks of change in Colombia
}
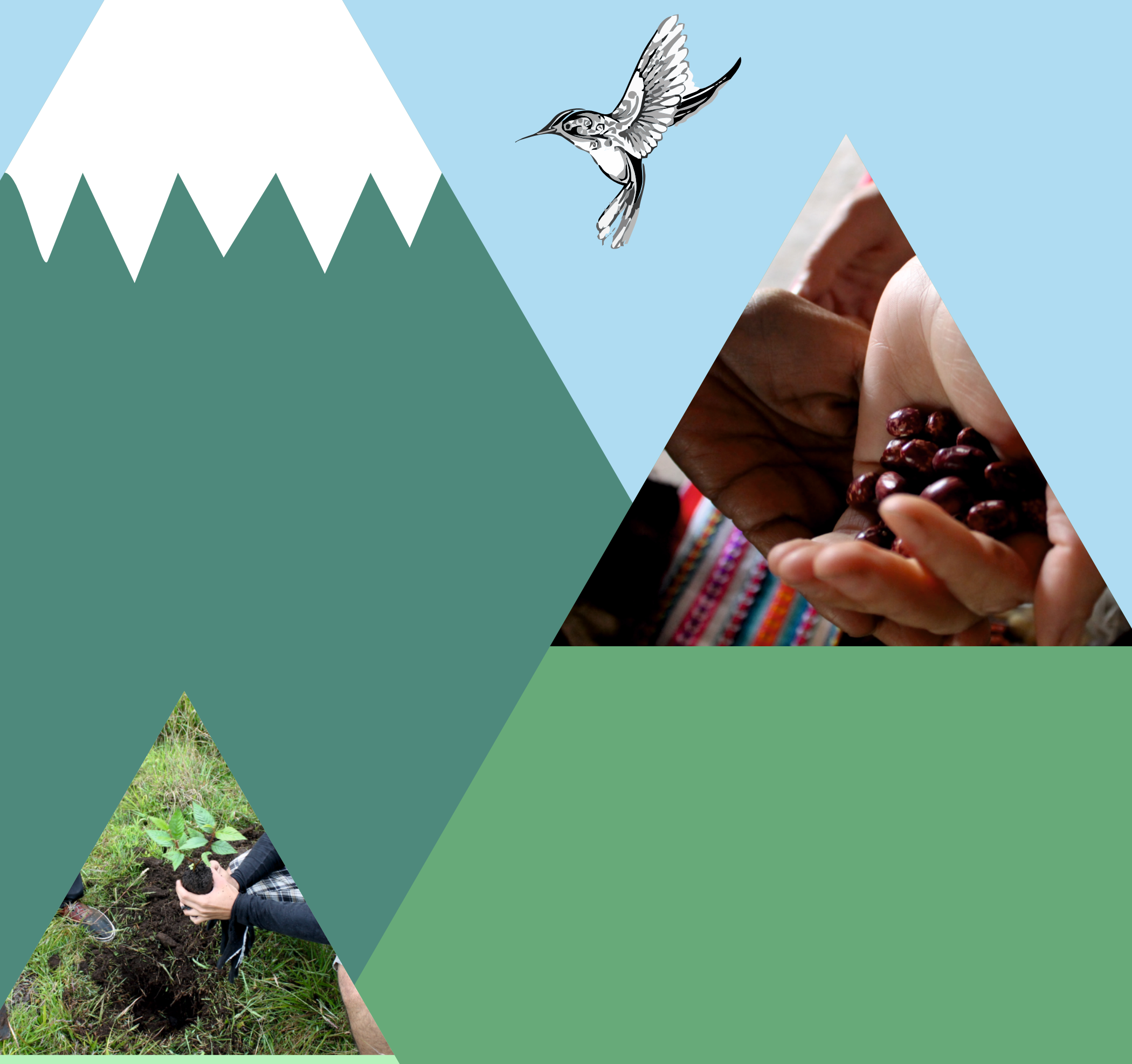


\section{Answering the "Call of the Mountain": Co-creating sustainability through networks of change in Colombia}

Martha Cecilia Chaves 


\section{Thesis committee}

\section{Promotor}

Prof. Dr A.E.J. Wals

Personal Chair at the Department of Education and Competence Studies

Wageningen University

\section{Co-promotor}

Dr G.M. Verschoor

Assistant professor, Sociology of Development and Change group

Wageningen University

\section{Other members}

Prof. Dr M.N.C. Aarts, Wageningen University

Prof. Dr R. Boelens, Wageningen University

Prof. Dr H. Lotz-Sisitka, Rhodes University, South Africa

Prof. Dr D. Wildemeersch, University of Leuven, Belgium

This research was conducted under the auspices of The Wageningen School of Social Sciences 


\title{
Answering the "Call of the Mountain": Co-creating sustainability through networks of change in Colombia
}

\author{
Martha Cecilia Chaves
}

\section{Thesis}

submitted in fulfillment of the requirements for the degree of doctor at Wageningen University.

By the authority of the Rector Magnificus

Prof. Dr A.P.J. Mol,

in the presence of the

Thesis Committee appointed by the Academic Board

to be defended in publicon

Tuesday 22 November 2016

at 11 a.m. in the Aula 
Martha Cecilia Chaves

Answering the "Call of the Mountain": Co-creating sustainability through networks of change in Colombia

152 pages.

PhD thesis, Wageningen University, Wageningen, NL (2016)

With references, with summaries in English, Spanish and Dutch

ISBN: 978-94-6257-725-1

DOI: $10.18174 / 394399$ 
This thesis is dedicated to my golden hummingbirds who inspire me to construct a better world for all... 


\section{Acknowledgments}

This has been not just a personal research journey, but a family endeavour in exploring 'other ways' of critically facing an increasingly unsustainable world. I give special thanks to my husband Thomas and son Mateo for their support, patience and accompaniment, as well as my parents and sisters who have always given me support when I needed it.

I gratefully acknowledge the Administrative Department of Science, Technology and Innovation of Colombia (Colciencias), not only for financing this PhD project, but for their great effort in promoting science and research in Colombia, and giving Colombians the opportunities for improving their professional careers.

I also give special acknowledgement to my co-researchers who made this research a lot more interesting and meaningful: To the C.A.S.A. network for allowing me to be part of their team and opening the doors to this research; To Jorge Calero and Eliana Riano for their efforts in making alternative worlds viable and for sharing their experiences and learning processes through their stories; to Thomas Macintyre for sharing my interest in learning about alternative lifestyles and this emergent network movement - his critical and analytical contributions have improved this thesis immensely; A profound thanks to all those people in the communities I have visited, and the people I have met along the way, for discussions and experiences; Last, to the organizers and participants of the network gathering El Llamado de la Montaña for engaging in the collective social experiment of enacting a community of learners. You give me hope!

Also a warm thanks to all my friends who have helped refine the ideas of this thesis, aided with fieldwork logistics and given me emotional support. A special thanks to Thomas van Gurp and Tatiana Villarroel for helping translate the thesis summary into Dutch.

Finally, a heartfelt 'gracias' to my two supervisors: Gerard Verschoor for believing in my ideas, for being open-minded to 'worlds otherwise' and for his courage in being less mainstream and more of a boundary researcher; and to Arjen Wals for being an inspiration, an innovative academic rebel who is transforming structures and bridging the gap between academia and practice. Thank you for opening up opportunities for me beyond the thesis, I'm looking forward to continuing breaking hegemonic structure in collaboration with you. 


\section{Table of Contents}

Chapter 1. 'Other Ways or the Highway': An Introduction to a Research Journey .................. 1

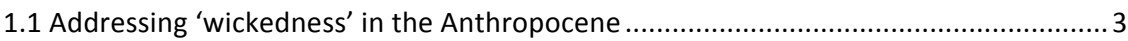

1.2 Mi C.A.S.A. es tu CASA: The context of C.A.S.A. Colombia.............................................. 5

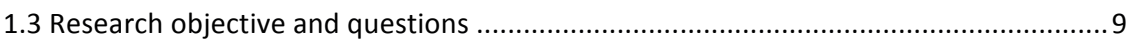

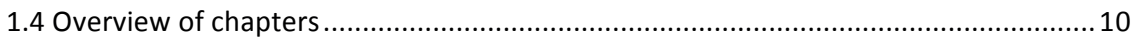

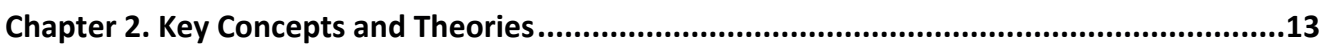

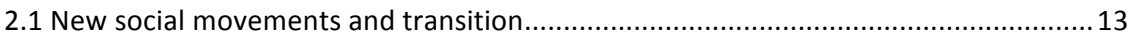

2.1.1 C.A.S.A. as a New Social Movement ...................................................................... 15

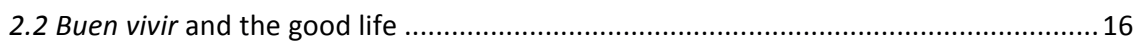

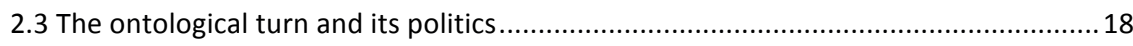

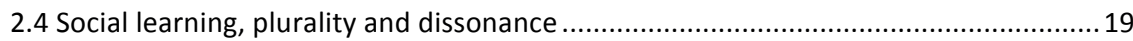

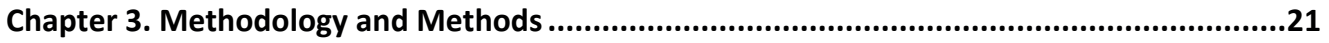

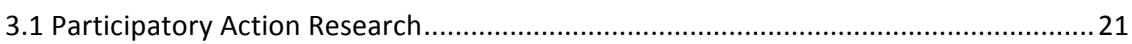

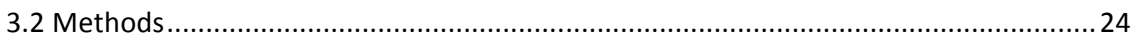

3.3 Reflection on methodological process and fieldwork challenges ..............................26

Chapter 4. Death and Rebirth of Atlántida: The Role of Social Learning in Bringing about Transformative Sustainability Processes in an Ecovillage ...................................29

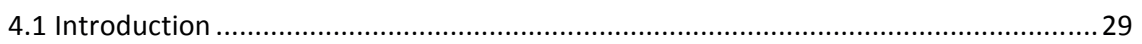

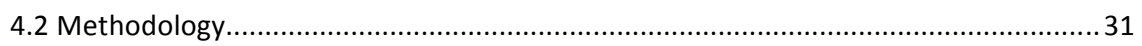

4.3 From horizontal dreams to circular realities: Atlántida's multi-loop learning journey 31

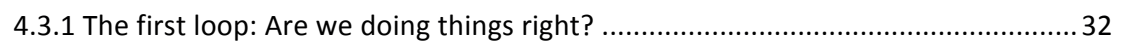

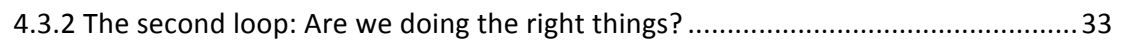

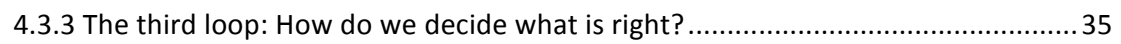

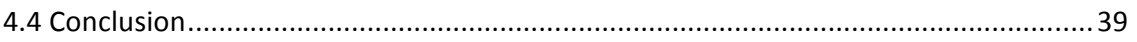

\section{Chapter 5. The Radical Ruralities of Buen Vivir in Practice: Negotiating Territo-realities in a}

Colombian Network of Sustainability.............................................................41

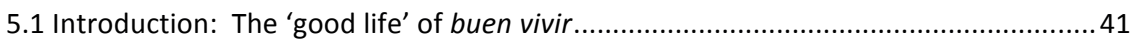

5.2 A Trial for space: Radical new ruralities and their Territo-realities..............................45

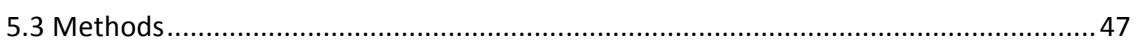

5.4 Building territorial relations through envisioning and enacting buen vivir................... 49

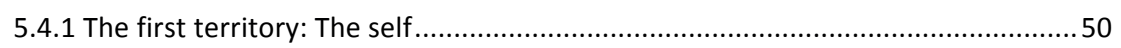

5.4.2 The second territory: family and communal living ..........................................5 
5.4.3 The third territory: connection to nature and the non-human ............................57

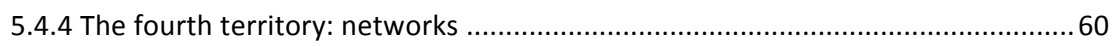

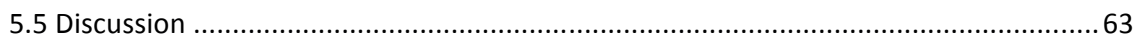

5.5.1 Plurality, territo-realities, and an intercultural platform of buen vivir ....................64

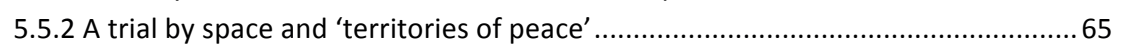

5.6 Conclusion: An alternative to modernity, or a modern alternative? ............................68

Chapter 6. Towards Transgressive Learning through Ontological Politics: Answering the "Call of the Mountain" in a Colombian Network of Sustainability ............................69

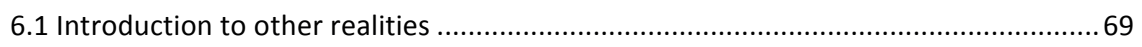

6.2 Theory: Transgressive learning and the ontological politics of the pluriverse .............71

6.3 Methodology: Auto-ethnography and a New Materialist Ontology ............................ 74

6.4 Enacting a learning pluriverse: The collective process of El Llamado .............................75

6.4.1 A glimpse into El Llamado de la Montaña, 2015 ................................................ 76

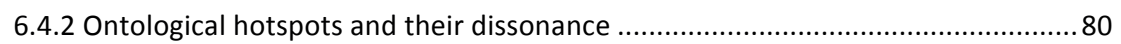

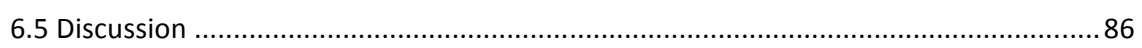

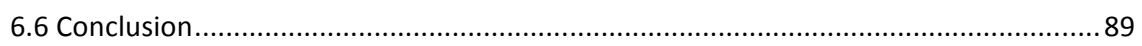

Chapter 7. The Nature of Transformative Learning for Socio-ecological Sustainability ...........91

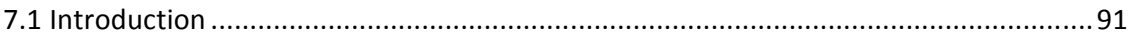

7.2 Design principles for transformative learning............................................................ 94

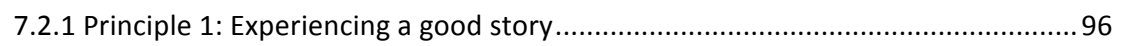

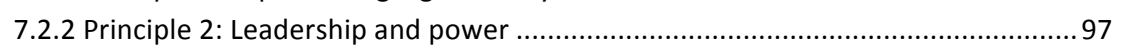

7.2.3 Principle 3: Embracing uncertainty and organic processes .................................. 98

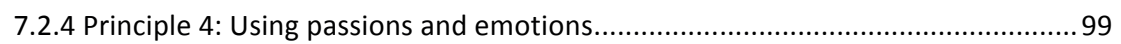

7.2.5 Principle 5: Plurality as a driver for change ........................................................... 100

7.3 Designing and expanding transboundary spaces for CEP ........................................ 101

7.3.1 A city in transformation - the emergence of civic society in Bogota, Colombia .. 101

7.3.2 Up-scaling transformational CEPs through bioregional networks....................... 105

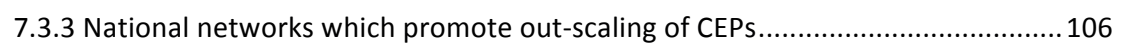

7.4 Reflections for designing and expanding transformative learning and CEP ..............109

Chapter 8. General Discussion and Conclusion.............................................................111

8.1 New social movements as sources for alternative paradigms ..................................112

8.2 Social learning for addressing 'wicked' problems..................................................... 115

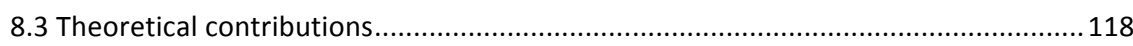

8.3.1 Political strategies of C.A.S.A. as a New Social Movement ................................. 118

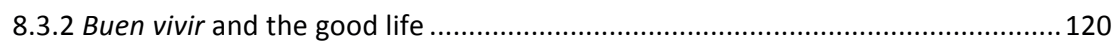

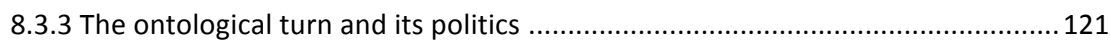

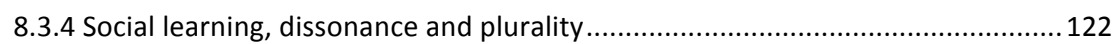


8.4 Research Implications and new directions

References.

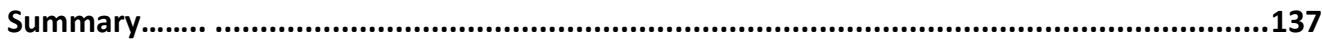

About the Author 


\section{List of Tables}

Table 1. Location and characteristics of communities which participated in the participatory photo methodology.

\section{List of Figures}

Figure 1. Different foci towards which the C.A.S.A. network is attempting to articulate 7

Figure 2. National C.A.S.A network in Latin America connected to the Global Ecovillage Network (GEN)

Figure 3. Action-research loops carried out empirically by the organizing committee of El Llamado de Montaña.

Figure 4. Buen Vivir vision of Tatiana from Aldeafeliz.....

Figure 5. Collage of buen vivir of Taita Trino from Misak University and Ever from Community of Rosario Islands

Figure 6. Collage of buen vivir visions of David from Kunagua and Ever from the Community of Rosario Islands 54

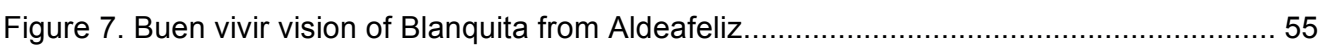

Figure 8. Buen vivir vision of María Yibi from Nashira.................................................. 56

Figure 9. Collage of buen vivir visions of Liliana from Misak University and Eliana from Altántida

Figure 10. Buen vivir vision of Anonymous from Pachamama ............................................. 58

Figure 11. Collage of buen vivir visions of Brahama Putra Das from Varsana and Julián from Atlántida

Figure 12. Buen vivir panel during the Call of the Mountain 2015....................................... 61

Figure 13. Diagram of triple loop learning ....................................................................... 93

Figure 14. Resonance levels for the principles of transformative learning according to the

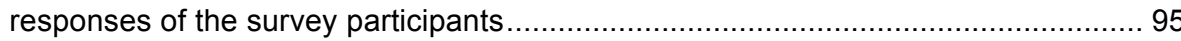

Figure 15. Collage of photographs from Eco Sembrando Barrio experiences ........................ 102

Figure 16. Collage of photographs from Carnival of Maize and Native Quinoa experiences ... 103

Figure 17. Collage of photographs from Foundation Naturaleza y Patrimonio experiences .... 104 


\section{Chapter 1.}

\section{'Other Ways or the Highway': An Introduction to a Research Journey}

Since I was a child, I have been exposed to nature and its delights. I would spend every vacation with my family (which in Colombian standards is at least 30 people) in natural areas around Colombia - fishing, catching shrimp, running after fireflies and grasshoppers, and listening to stories and songs from the places we visited. My goal ever since has been to be close to Nature: To enjoy it, to study it, to conserve it, to defend it. This was my plan when I started studying Biology at La Universidad del Valle in Colombia in the year 1997. In those days it was difficult and even dangerous to leave the city to visit natural places in the countryside, as 'las pescas milagrosas' (miraculous fishing expeditions) were a common activity of the left-wing guerrilla movement (FARC). FARC members would stop cars on highway roadblocks and randomly kidnap people to ask for ransoms. I therefore carried out little fieldwork during my Bachelor studies, instead concentrating on learning about nature through classes, books and theories. I graduated as an entomologist, specializing in social insects (e.g. ants and bees) whom I feel are fascinating creatures who have a lot to teach human societies.

The type of scientist I was taught to be was that of the 'expert': always objective, relying only on what can be measured, replicated, and deemed statistically significant. This meant working in areas where this type of expert knowledge was in demand. When I started working as an entomologist, I quickly realized that rather than working with nature to increase knowledge into natural ecosystems, in practice my job was to work against nature: specifically, how to control the 'pest' problem of ant colonies on agricultural farms. It slowly dawned on me that nature and society were at 'war.' Against the trend of my biologist friends at that time (2004), I decided to 'leave the forest' and work with people to raise awareness of the tragedies taking place in nature. To pursue this I carried out an MSc in Forest and Nature Conservation, at Wageningen University, The Netherlands, specializing in policy and community based conservation. During my studies I learnt about such concepts as Climate Change, Payment for environmental services (PES), UN-REDD+ Programme (Reducing Emissions from Deforestation and Forest Degradation), Forest Stewardship Council (FSC), and many other market-based and community-based conservation strategies. For my MSc thesis I was determined to save the 
Amazon rainforest through FSC schemes with Indigenous communities in the Peruvian Amazon, as part of the bigger EU project ForLive: Smallholders, Forest Management and Rural Development in the Amazon. However, my hopes and high expectations were dashed after living in an Indigenous community for two months and realizing how these schemes were culturally invasive and unrealistic in a context of widespread illegal activities and a tough capitalist environment. I became increasingly convinced that even though these 'green' initiatives and products could be short-term means of reducing nature degradation, they (un)intentionally promote the same 'rationality' of development based on raising commodity production and consumption, and hence encourage the false idea that unlimited economic growth is possible on a finite planet.

What I did find during my Master studies were rich intercultural experiences, which helped open my mind to the ways other people understand and experience the world. I naturally began questioning my own assumptions of the world. Disillusioned with science-, government- and market-based conservation strategies, I returned to Colombia with my MSc diploma and a bag full of unanswered questions on how best to help 'nature.' By coincidence or fate, I met a biologist friend from my Bachelor days who I remembered as one of the 'hippies' of the University. He invited me to visit his project in the south of Colombia: The Ecovillage Atlántida. In theory, Ecovillages are grass-root initiatives striving to design human-scale and full-featured settlements (food, leisure, social life, education, business, residence) of low ecological footprints promoting self-development (Gilman 1991). In practice, what I met was a group of friends growing food in the garden, cooking and eating meals together, and attempting to create another set of ethics by which to live by. Importantly, they were not just talking; they were talking as well as doing. I was inspired as this type of community seemed to answer many of my questions. I decided to become an ecovillager; I joined the community with the determination of exploring grass-root innovative solutions - those that endorse deep personal changes through putting into practice a sustainable lifestyle and leading by example.

I had initially disregarded this type of movement as being made up of esoteric and elitist 'New Agers' who merely opt for an 'alternative lifestyle' as many others do (Ray and Anderson 2000). To my surprise, living in Atlántida and working with RENACE (the Colombian Ecovillage and alternative communities network of Colombia) I perceived the movement as a network of very diverse communities and people trying to make a difference. Through trial and error, they were constructing relations not only between themselves, but also with their peasant/Indigenous 
neighbors and local communities. I decided to once again unleash my researcher curiosity, but this time I was determined to do it differently: I would conduct research not for the 'experts' who would read my work, but instead for the people with whom I was living. Instead of myself as the objective expert observing and participating in the community, I would instead be a resident and stakeholder: In this way I would attempt to bridge the gap between discourse and action, not just at the level of the research, but also at a personal level. The question I asked myself was whether I could live up to my own discourse in practice?

At the time of starting this $\mathrm{PhD}$, a research with these characteristics would have been impossible in the field of natural science; so I turned to the social sciences for help. After learning a whole new language of the social 'experts' and questioning even more my way of understanding/constructing the world, I have learned that there is no nature apart from society, and vice versa, and that our ways as a consumerist society will only mean the highways. We thus need to 'take other ways' or we will end up on the 'highway' that leads out of existence! By this I mean making other ways of being in the world more visible - to learn and get inspired in what we can do differently. Consequently, we need (yes, in a very normative way) to place more attention on critically researching the elite, consumerist, mainstream society and its systemic effects on people and nature, while voicing the alternatives to this with the same passion we currently study the 'poor', marginalized and underdeveloped people and their effects in nature. The content of this thesis is the result of my journey towards taking 'another way' by critically attempting to construct the personal and collective realities that I/we want to live in.

\subsection{Addressing 'wickedness' in the Anthropocene}

We are living in the age of the Anthropocene and its 'best practices for sustainable solutions.' In what many perceive as the peak of our scientific knowledge, we have, paradoxically, sufficient hard data to confirm the adverse effects of human activity on the planetary system (Steffen et al 2011). However, we hardly have a clue as to what to do about them. Despite twenty-five years of global efforts in the international policy arena to address the situation - from the 1992 UNCED/Earth Summit until the follow-up Rio +20 in 2012 and Paris COP21 in 2015 - positive change appears elusive. In fact, environmental and social crises seem to be increasing and worsening wherever we look. 
In addition, although discursively powerful, the concept of sustainability ${ }^{1}$ and its 'best practices' have become insufficient and often empty in practice (Kates et al 2005; Parr 2012). On the one hand, such discourses encourage dis-connective thinking and dis-integrative practices in our society (Sterling 2009). On the other hand, many proposed sustainable solutions continually perpetuate the illusion that infinite growth is still a possibility regardless of a finite global carrying capacity $^{2}$ (Rees 2003, Ivanova 2011). In line with this illusion is the promotion of the type of development and culture of modernity which favors the autonomous rational individual over the connection to a particular place or community; the primacy of expert knowledge above other forms of knowing; the separation of nature and culture, the economy from the environment and society; and the search for material and individual satisfaction over any other goal (Escobar 2011a). This type of illusory development has led us to encounter the 'wicked' sustainability challenges of today, such as climate change, food insecurity, land degradation, and indigenous marginalization, amongst others. We can call them 'wicked' in that their complexity makes them highly resistant to solutions and change, and because they are unstable, multi-causal, difficult to define and have unforeseen consequences. Their possible solutions therefore demand more innovative approaches to motivate individuals and organizations to actively cooperate in achieving sustained behavioral change (APSC 2007; Krasny 2013).

To address the complex nature of wicked problems there are therefore increasing calls towards a more radical learning-based sustainability. This involves deep transformations in individuals and communities, so as to transition towards a more reflexive, integrative and process-oriented society (Wals 2009, Krasny 2013, Sterling 2009, Capra 1996). According to Lotz-Sisitka et al. (2015) one approach to these pedagogical processes can be found in the change-oriented and transformative learning of social movements that are currently dealing with the social-ecological justice nexus through counter-hegemonic logics. For more than ten years, several authors have been demonstrating the existence of a growing sector of society that is making significant changes in their paradigms, sensibilities, values and worldviews (Ghisi 2008, Rifkin 2005, Dussel 2006 Rodriguez-Magda 2004, Altejevic, 2013). Ray and Anderson (2000) have described these movements as 'cultural creatives' who are characterized by a focus on internal

\footnotetext{
${ }^{1}$ In this thesis we value the term sustainability when backed up with consequent practices.

${ }^{2}$ For example, currently the most popular strategies being proposed are market-based strategies such as PES, REDD, certification schemes, fair trade and sustainable development. Despite this apparent diversity of approaches, all are to some degree top-down and entail similar limitations: they are highly decontextualized; when implemented they tend to create local conflicts of resource access; imply high transaction and maintenance costs as they necessitate infinity financing to maintain their effectiveness; and promote externalization of direct responsibility from implementers, consumers and producers.
} 
growth, are socially sensitive, strive to protect the planet, promote peace, social justice, spirituality and self-expression, and to reinvent public governance. Hawken (2007) calls it 'the silent or nameless movement,' made up of "ordinary people willing to confront despair and power in order to restore, redress, reform, rebuild, recover and re-imagine justice, happiness and beauty in the world" (p.6).

According to Castells (2012), it is these new kinds of social movements, based on social networks driven by information technology and the development of autonomous horizontal communication, that are ultimately building the 21 st century. Consequently, we have been introduced to the primacy of simultaneity, where the internet has blurred territoriality, and the global and the local coexist in shaping the 'glocal' (Rodríguez-Magda 2011). This brings an ethical and political commitment to the necessary consideration that a global reality is also being constructed through massive knowledge exchange and unstoppable global communication. Hardt and Negri (2004) state that it is essential to understand the subjectivities of subjects capable of creating a new world. Subjectivities, they argue, being the subjects and their perspectives, feelings, beliefs, and desires.

\subsection{Mi C.A.S.A. es tu CASA: The context of C.A.S.A. Colombia}

Stereotyped by its associations to drugs, crime and insecurity, Colombia stands on the verge of a historic turning point: As of June 23, 2016, a peace treaty was signed between the left wing guerrilla group FARC-EP and the government, effectively ending over 50 years of internal war which has killed over 200.000 people and resulted in over 5 million internally displaced people. Many see this as the beginning of a new chapter of stability for the country, where deep wounds can begin to heal, and the country can move towards a better future for all its inhabitants Brodzinsky and Watts (2016).

Yet signing a peace agreement will not in itself solve the myriad of other 'wicked' problems which the country faces. At the heart of these challenges is an entrenched logic of neoliberal development based on opening up the country's resources to foreign investors, as well as significant social inequality - both socio-economic as well as between different cultural groups (Escobar 2012). This can be witnessed through environmental degradations due to (often illegal) mega-mining (Sierra-Camargo 2014) and infrastructure projects that are defacing the 
landscape and upsetting the balance of nature and the livelihoods of local populations (Sánchez 2008). There is also the example of the privatisation of seeds, brought about by the free-trade agreement with the United States (TLC), which is perceived as a serious infringement on the autonomy of campesino farmers (Forero and Urrea 2013).

In response to these challenges is the growing resistance of initiatives, NGOs, innovative municipalities and some Indigenous and afro-Colombian communities seeking to make grassroots changes. These movements are often place-based, situated in biologically rich regions, and with marginalised populations. A good example of this work is that of Colombian anthropologist Arturo Escobar $(1998 ; 2008)$ who writes about the articulation between afroColombian social movements and biodiversity-environmentalist discourses. With a focus on territoriality and the (re)definition of cultural and ethnic identities, Escobar shows the political strategies of these actors in claiming biodiversity alongside those of other national and international actors.

Beyond such place-based movements are the more networked and horizontal social movements described above by the new social movements. The objective of this research is to explore one such emergent Colombian movement called C.A.S.A. (Council of Sustainable Networks of the Americas), which brings together a wide range of people, communities and initiatives around shared sustainability challenges so as to co-create solutions through annual gatherings and other network events. Established in 2012, C.A.S.A. Colombia has the goal of "seeking to coordinate and strengthen efforts of national and regional networks that promote, form, investigate and disseminate sustainable and regenerative lifestyles" (C.A.S.A. 2015). With roots in the ecovillage network, C.A.S.A. has evolved into a broader network of initiatives, seeking to articulate diverse visions and practices of sustainable living (See Figure 1). 


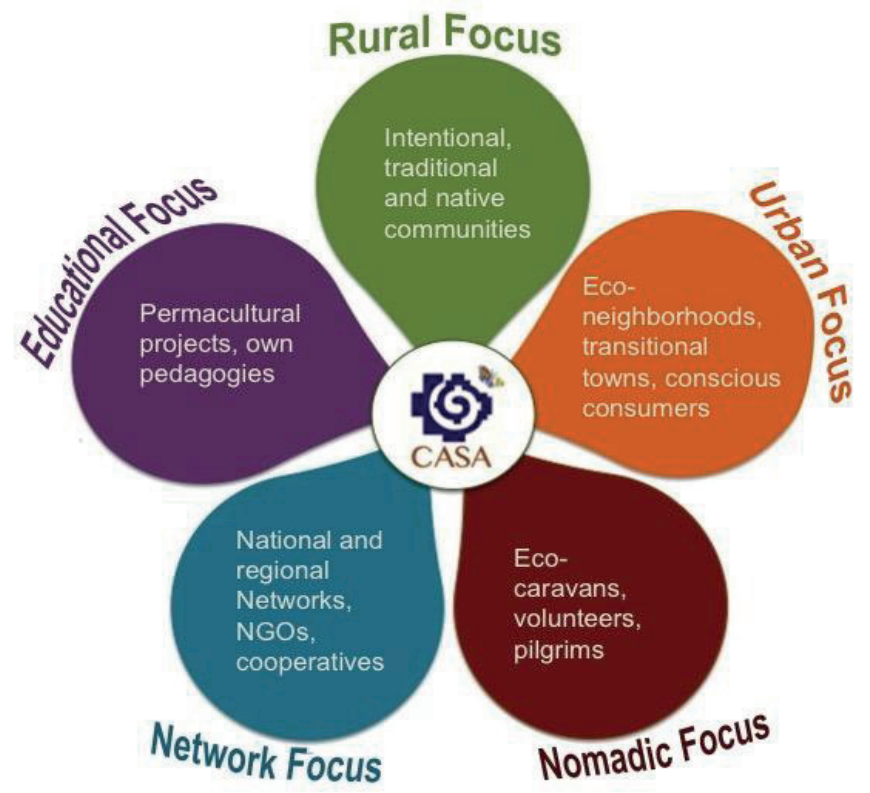

Figure 1. Different foci towards which the C.A.S.A. network is attempting to articulate

Organized through the governance system of sociocracy, ${ }^{3}$ representatives of all member initiatives meet in a yearly General Assembly to make collective decisions, plan the yearly activities, and elect the organizing committee called la cocina (the kitchen). The C.A.S.A. network also hold events, the most important of which is the annual Llamado de la Montaña (the Call of the Mountain) which is a five to seven-day intercultural event bringing together people and initiatives from all over Colombia and beyond, around pertinent sustainability issues. This network is connected to a growing broader network of national C.A.S.A. networks in Latin América. Up until the writing of this thesis, C.A.S.A. Colombia and C.A.S.A. México are the strongest C.A.S.A. networks, followed by Chile, Brazil and Peru, which are still in early stages of development. These national C.A.S.A. networks come together in the C.A.S.A. Latina continental network, which is represented in the board of the Global Ecovillage Network (see Figure 2).

\footnotetext{
${ }^{3}$ Sociocracy is an organisational arrangement for governance, which includes horizontal and vertical structures of decision-making to improve effectiveness while maintaining participation (cf. Romme and Van Witteloostuijn 1999).
} 


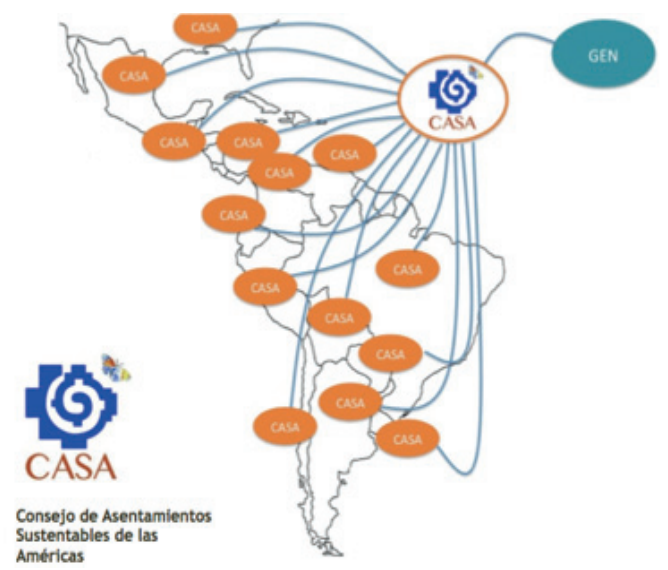

Figure 2. National C.A.S.A network in Latin America connected to the Global Ecovillage Network (GEN)

C.A.S.A. Colombia is interesting to research for two reasons. First, the network is in the process of increasing its diversity of initiatives, having moved beyond its ecovillage base towards a more intercultural network including Indigenous communities and urban initiatives. Such interculturality opens up the opportunity for experiencing a range of visions, practices and narratives that promote peaceful relations and meaning-making, and which will be important in post-conflict Colombia. Important in respect to this is the concept of territo-realities, which I have coined so as to engage with the contradictions between these territorial visions and the realities of putting them into practice. Second, the focus on learning in the network through participatory, collaborative, and collective evaluation, with a focus on decolonial justice between diverse knowledge systems which is quite novel and under researched. Through this learning focus we want to explore the link between the emerging approach of decolonial thinking and social movements, and the relationship to forms of social learning, as put forward by Lotz-Sisitka et al. (2015). 


\subsection{Research objective and questions}

This research explores how Colombian grassroots initiatives are collectively articulating alternative paradigms of responsible good lives, through new social movements such as manifested in C.A.S.A. Colombia. Fundamental to this is the objective of exploring the dynamics of the social learning processes involved in bridging the value-action gap which is vital for generating global-local (glocal) solutions to 'wicked' sustainability challenges (Glasser 2007). This I achieved by actively participating in the organizational committee of C.A.S.A., and by following the struggles, negotiations and attempts at articulation and multiplication of different ideas of responsible good lives within and between member initiatives of the C.A.S.A. network.

This thesis answers the following research questions:

1. How are new social movements such as the C.A.S.A. network self-organizing and articulating visions and practices on alternative paradigms of socio-ecological, responsible good lives?

a. What are the everyday sustainability challenges of individuals and communities who make up the C.A.S.A. network?

b. How are notions of plurality dealt with in the network?

2. To what extent does the enactment of socio-ecological, responsible good lives within the C.A.S.A. network lead to 'glocal' social learning processes?

a. Are social learning processes being promoted within and between initiatives in the C.A.S.A. network? If so, what types of learning processes are being promoted and how are they expressed?

b. To what extent are these processes confronting wicked socio-ecological problems? 


\subsection{Overview of chapters}

Chapter 2 introduces the key concepts and theories that underpin this work. These are concepts such as new social movements, transition discourses, the good life and buen vivir, the ontological turn, and social transformative learning. Following this theory chapter is chapter 3 , which outlines the methodology and methods which are grounded in action research and ethnographic participatory methods. The subsequent chapters 4-7 are the backbone of this thesis, each representing self-contained empirical research. Chapter 8 summarizes my main findings by responding directly to the research questions, and highlights the theoretical contributions to the debates that this thesis has engaged with. I end the thesis by reflecting on research implications, provide new directions for future research, and conclude with some final remarks.

To provide a taste of what is to come, I provide below a summary of each of the empirical chapters.

In chapter 4, Death and Rebirth of Atlántida: The Role of Social Learning in Bringing about Transformative Sustainability Processes in an Ecovillage, I explore the role of social learning in bringing about transformative sustainability processes among individuals and communities. At a time when sustainability is being seriously questioned in terms of what it is and how it can be implemented and evaluated, there are increasing calls to focus instead on sustainability processes. Drawing on 12 months of action-oriented research, including interviews and community-reflection meetings, and with contributions by two co-researchers from the community studied, this paper explores the triple-loop learning process of an ecovillage in Colombia called Atlántida. The findings show that disruptions in the community provided the opportunity for members to enter into a process of deep learning, due to their willingness to reflect collectively on their process. This, however, took place in a tough reflective environment in which it was realised that differences in worldviews, ethics and leadership among members had contributed to the 'death' of the community, while their acknowledgement and acceptance of these differences were contributing to a process of transformative 'rebirth.' I therefore conclude that, when we talk about social learning as a deep transformative process, it is vital to remember that, though it may be necessary, nobody said it was going to be easy. 
In the next results chapter 5, The Radical Ruralities of Buen Vivir in Practice: Negotiating Territo-realities in a Colombian Network of Sustainability, I address the emerging concept of buen vivir (integrative and collective well-being), as it is being envisioned and practiced by a network of sustainable initiatives in Colombia. As an example of a transition narrative currently taking place in Latin America and beyond, buen vivir represents a turn towards a more biocentric, relational and collective means of understanding and being in the world. Yet despite the many discourses into buen vivir, many of which tout it as an alternative to neoliberal models of development, there is a general lack of research into its varied forms of application, especially in terms of lived experiences. Drawing on new ruralities literature, this chapter sets out to present concrete examples of how buen vivir is being envisioned and practiced, and the challenges in negotiating these new relations. Data were collected from individuals and ecological communities in predominantly rural areas who are members of the Council of Sustainable Settlements of the Americas (CASA network) Colombia, a network which promotes many of the principles of buen vivir. Through participant observation, participatory photography, interviews conducted during annual network gatherings, and discussion circles, results demonstrate that buen vivir visions in CASA are based on building new relations between people and territory through intercultural knowledge exchange, which we argue, positions it as an alternative paradigm to the modern development narrative. In terms of lived-experiences, however, there are strong contradictions between these territorial visions and the realities of putting them into practice. Coining the term territo-realities to conceptualise this value-action gap, we show, however, that buen vivir promotes the idea and expression of pluralism which opens up the opportunities for people to cohere around shared principles of good living, while at the same time having the freedom to live whatever variation of the good life which the context permits. Although buen vivir may therefore not always be so 'radical' in practice, its adherence to cultural plurality provides the potential to act as a platform for articulating people and communities around visions of integrative and collective well-being.

Following these ideas, and in line with the increasing calls for more transformative and transgressive learning in the context of sustainability studies, I present chapter 6: Towards Transgressive Learning through Ontological politics: Answering the "Call of the Mountain" in a Colombian Network of Sustainability. In this chapter I explore how intercultural encounters between different ontological positions can lead to more radically confronting and overcoming our unsustainable habits. With the dominant one-world universe increasingly coming under attack by those who advocate the existence of many worlds - a so called pluriverse - there lays 
the possibility of not only imagining other realities, but engaging with them in practice. Moving towards an understanding of plural worlds, however, entails the need for negotiations between people with often very different ontologies, in what I will call ontological politics. Based on the new materialist ontology, and auto-ethnographic and narrative methods, data were collected from three consecutive Llamados de la Montaña. By actively participating in these plural gatherings, which include Hare Krishna, Indigenous peoples, ecovillagers, and urban dwellers, results show how encounters between different ontologies can result in transformative and potentially transgressive learning in terms of disrupting stubborn routines, norms and hegemonic powers which tend to accelerate unsustainablity. I conclude, however, that such learning environments also lead to conflicts as inflexible, rigid ontologies and power relations within and between communities must be addressed if sustained learning is to take place.

The last empirical chapter 7 is more conceptual: 'The nature of transformative learning for socioecological sustainability'. In this chapter I use what I have learnt in the four-year trajectory of my research to conceptualize principles for generating transformative learning spaces. I present them as 'design principles' for creating spaces that facilitate boundary crossing and transformative learning for socio-ecological sustainability, inspired by my learning experiences in El Llamado de la Montaña, and fieldwork in various communities. I validated these principles through an online survey completed by academics and practitioners with extensive experience in community-based environmental stewardship. This chapter then poses the question as to what extent such principles can help people develop the reflexive capacities needed to transform and transgress resilient patterns and systems that contribute to 'glocal' systemic dysfunction. This is addressed through exploring civic ecology practices (CEPs) in the city of Bogota, many of which are led by individuals who are part of the process of El Llamado de la Montaña. The chapter finishes with strategies for upscaling and outscaling these capacities through bioregional and national networks, one of which is the C.A.S.A. network and its annual gathering El Llamado de la Montaña. 


\section{Chapter 2}

\section{Key Concepts and Theories}

This thesis engages with two academic fields that address social movements: Sociology of Development and Change (SDC) and Social Learning for Sustainability (SLS). I bring these together by weaving concepts from theories on new social movements, narratives of the good life (buen vivir) as an alternative paradigm to development, the ontological turn, and social learning. The red thread which binds these concepts together is the focus on transitioning towards a more sustainable world, and the deep learning processes needed for such a transition to take place. Below, I briefly introduce the main concepts, followed by the specific debates this thesis will address.

\subsection{New social movements and transition}

In the context of the distinct contemporary social formation of post-industrialism, capitalist markets, and postmodernity that provides the emergence of collective action in specific response to these conditions (Buechler 2016), this study is situated in the theoretical current of new social movements (NSM) theory. Castells (2012) argues that, from the safety of cyberspace beyond control of governments and corporations, citizens of 'the information age' are able to invent new programs for their lives. According to Hardt and Negri (2004) the production of ideas, knowledge and affects, for example, do not merely create means by which society is formed and maintained, but also directly produce social relationships, taking a social form of networks based on communication, collaboration, and affective relationships. Using this self-configurable autonomous communication they become self-expanding, non-hierarchical and self-organized participatory movements. Such NSM engage in the exchange of their suffering, fears, dreams and hopes through multimodal (including online and offline social networks, and pre-existing and/or emergent action networks) and interactive digital networks of horizontal communication. These new types of networked social movements, Castells (2012) states, will ultimately make societies in the twenty-first century by engaging in conflictive practices rooted in the fundamental contradictions of our world. These types of new network movements are calling 
for a significant paradigmatic or civilizational transformation, through radical transitions in society. ${ }^{4}$

Apart from social movement literature, there is also the emergence of transition discourses in the fields of sustainability transitions (see Markard et al, 2012, for an overview). These focus on the socio-technical transformations that take into account user-practices and institutional structures which influence sustainability. Whereas this field has previously focused on marketbased technological innovations, an emerging branch of research is looking into communitybased transitions (see Seyfang and Haxeltine, 2012), which highlight the role of the social innovation and adaptive learning. According to Christakis and Fowler (2009) and Castells (2012), it is imperative to study how these networks are assembled and how they negotiate the diversity of interest and values present in the network, to be able to understand how they affect and relate to the society at large.

This thesis engages with above issues, as well as the longstanding and ongoing debate on the most effective political strategy for social movements to catalyze change (Meyer 2014; Buechler 2016; Barnes 2016). On the one side of the fence are those who advocate do-it-ourselves collectivist strategies, based on the tradition of communitarian anarchism, social ecology and horizontal forms of political organization (Bookchin 1982; Fotopoulos 1997; Scott 1998). On the other side of the fence are those that seek to generate enough political influence to shift public policies by engaging with powerful political authorities to more effectively and efficiently generate change (Bullard and Johnson 2000, Paehlke and Torgerson 2005). In line with the categories used by Barnes (2016) who explores this debate from the perspective of grassroots transition initiatives, I will call the initial do-it-yourself collectivist strategy a 'secessionist politics,' and that which engages with formal governance structures as 'confrontational politics' respectively. My interest lies in engaging in this debate through exploring how the C.A.S.A. Colombia network - with secessionist tendencies - is striving for increased socio-political impacts by creating alliances with different partners who use more confrontational political strategies.

\footnotetext{
${ }^{4}$ As Escobar (2015) explains, transition refers to different types of multilevel radical transformations.
} 


\subsubsection{C.A.S.A. as a New Social Movement}

This research positions the C.A.S.A. network as part of an emergent NSM. Buechler (2016) argues that there is no one single theory of new social movements but numerous variations of arguments on the topic. Nevertheless, he identifies several characteristics that are prominent in most if not all versions of NSM theories. By connecting these characteristics with my case study, I will build up the argument that C.A.S.A. is part of an emergent NSM in Colombia. The following are characteristics of NSM, summarised from Buechler (2016):

1. A prominent feature of NSM is that they are fundamentally social and cultural rather than political. They encompass new forms of collective action whose cultural, spiritual, or symbolic elements have displaced more conventional political struggles.

2. There is a causal claim linking the response of NSM to the contemporary social formation of advanced capitalism, instrumental rationality, scientized relationships, new colonialism, post-industrialism and postmodernity.

3. The social base of NSM is more complex than conventional class-based activism, because these movements are no longer rooted in a class structure, or other clear statuses of race, ethnicity, gender, age, sexual orientation or citizenship. Rather, ideological consensus over values and beliefs is more important.

4. New social movements have a constructed nature of diverse social identities, challenging old ones and valorizing new ones as part of their socio-cultural struggles. Thus, the social construction of a shared collective identity becomes essential in defining the ability to engage people in collective action.

5. Intimate and private aspects of everyday life become major arenas for political action (lifestyle politics) as the relation between the individual and the collective in NSM is blurred.

6. They promote a pluralism of values and ideas, but framed in postmaterialist values which emphasize quality of life, autonomy and democratization, while resisting conventional strategies of cooptation via material rewards.

7. New social movements use cultural and symbolic forms of resistance, which for many involves a philosophical or spiritual rejection of conventional goals, tactics and strategies based on instrumental rationality and social control.

8. Organization is a symbolic expression of the movement's values, thus activism is preferably organize through decentralized, participatory and prefigurative ways. As 
Melucci (1996) argues, these NSM function as cultural laboratories alternating between visibility for specific battles and latency as they revert to politicized subcultures that maintain movement values.

Rather than based on political struggle, the C.A.S.A. network emerges from a social and cultural questioning of the mainstream status quo in Colombia and its unsustainable nature. Its main focus is on achieving societal change through changing the materialist and consumerist culture responsible for current environmental and social crises. The contention of C.A.S.A. is that by claiming control over their relations to territory and place (including humans and nonhumans), they will be able to collectively (re)construct a more inclusive, plural and just world. To achieve this they have established an activism based on practical examples of lifestyle choices, characterized by more non-conventional values, giving space for a mixture of customs and knowledges from other groups of society such as of those of Indigenous communities. Their day-to-day practices become in themselves activist actions in which emphasis is placed on a quality of life based on biocentric and community relations with low carbon footprints. These everyday practices are shared and discussed during gatherings of the network, such as El Llamado de la Montaña. Central to this activism is claiming a holistic understanding of the world where spirituality and self-development play an important role, and where no single dogma is followed. In this approach, no programmatic schemes are put forward for collective actions, instead relying on participatory and sociocratic tools of organization.

\subsection{Buen vivir and the good life}

While transition in the global North is characterized by the desired movement towards a postfossil fuel society, ${ }^{5}$ the main characteristic in Latin America is the call for a 'civilizational transformation' with a focus on decolonization (Escobar 2010). A leading transition narrative is that of buen vivir which can roughly be translated as 'the good life', but which incorporates a deeper understanding of integrative and collective well-being. Buen vivir is a hybrid concept that owes much to Indigenous cosmologies of the Andes, but also to the writings of mestizo (colonial descendant) academics and others (Gudynas 2011). Representing a turn towards a more

\footnotetext{
${ }^{5}$ For example degrowth, which admonishes a reduction of the economy so as to live better within our means (Miller 2010; Escobar 2015); transition town initiatives, which seek to increase resilience through addressing peak oil and energy use (Hopkins, 2008); and the Global Ecovillage Network (GEN) movement, which attempts a more holistic way of living with a strong spiritual focus (Kasper 2008).
} 
biocentric, relational and collective means of understanding and being in the world, buen vivir represents a departure from the modern development narrative towards more interconnected and relational ways of living. Buen vivir has been included in both the Ecuadorian and Bolivian Constitutions, and is increasingly being used as an articulating concept linking Indigenous and non-Indigenous communities in (mostly Andean) Latin America. Buen vivir also takes the form of an academic project put forward as an alternative paradigm to that of modern development (Acosta, 2008; Escobar, 2011a).

Yet despite buen vivir being perceived as a Latin American development paradigm, a major debate taking place is the extent to which buen vivir really represents a novel paradigm, or whether it is being (or has been) co-opted by the neoliberal paradigm (Villalba 2013; Walsh 2010). Employing the division of Escobar (2010), I contribute to the debate of whether buen vivir is an alternative modernity or an alternative to modernity? Examples from Ecuador show that although the rights of nature are guaranteed under the new Constitution in 2008, the government's approval of a Mining Law and the proposal of a Water Law arguably contradict the principles of buen vivir by placing economic development over that of the rights of nature (Walsh, 2010). This is one of many examples which demonstrate the paradoxes and challenges involved in reconciling in practice buen vivir principles (such as the rights of nature) with national policies such as income generation (through extractive mining, for example). Many authors therefore point to the need for more research into the practices of buen vivir to highlight these dilemmas (what I call territo-realities), and means to addressing them (Gudynas 2011;Walsh 2010). What I will address in particular is the under-researched lived experiences of buen vivir by individuals and communities attempting to put into practice more sustainable lifestyles. This also addresses the debate initiated by Gudynas (2011) into whose buen vivir we are talking about. Although most buen vivir literature refers to Indigenous concepts and peoples, Gudynas (ibid) makes the point that if we see buen vivir as an inclusive and plural concept, then we need to continue exploring how other groups envision it and how this can be articulated as a bigger movement, for example, through what he visualizes as a platform for alternatives to development. 


\subsection{The ontological turn and its politics}

The focus on decolonialization of knowledge as a major characteristic of buen vivir (Gudynas 2011) necessarily brings us into the somewhat confusing but important realm of ontology, where we go beyond the epistemological questions of ways of knowing towards the common understanding of ontology as what it means to be. From the start it is worth noting, however, that although there may have been an 'ontological turn' in social theory (Escobar 2007), there are various interpretations of what ontology means. As Holbraad et al (2014) note, we can distinguish between ontology as 'what there is' (a philosophical notion of what exists as an absolute truth); 'what should be' (a sociological interpretation which critiques such essentialisms for their inherent political nature); and last, 'what could be' (a view of ontology where a multiplicity of forms of existence are enacted in concrete practices, and where politics brings about the potentialities of these forms).

This thesis addresses the debate into this last interpretation of ontology as 'what could be,' a debate defined by those who endorse the possibilities of plural ontologies (Holbraad et al 2014; Viveiros de Castro 2015) and those who perceive such thinking as idealist and more a form of 'radical constructivism' (ibid:20), for example (Graeber 2015). This is an important debate because it has become clear that the dominant paradigm (or perhaps we can say ontology?), which the modern world operates under, is placing monumental strains on the environment and society through the idealisation of the consumerist modern lifestyle and domination over nature (Gudynas 2011a). If there exist other ontologies then what can such alternatives teach us? I address this by engaging with the concept of the pluriverse, which encourages us to move away from the notion of a universe and towards idea of overlapping and entangled multiple worlds (Blaser 2010; Escobar 2012).

As urgent as the need to explore other ontologies is research into how such ontologies interact. By engaging with 'ontological politics' (Mol 2002) we explore how the essentiality of ontology, and the processes of negotiation as human collectives (politics) come together to make other worlds possible. This will be accomplished by exploring how to create and facilitate spaces where different ontologies can meet together as equals, share points of view, and together attempt to co-create strategies for addressing sustainability challenges. 


\subsection{Social learning, plurality and dissonance}

Central to the three concepts above is the importance of diverging perspectives, values and knowledge systems for generating forms of learning which challenge normalised unsustainable behaviour. With respect to this, I will enter the debate into what types of learning are needed to address such (un)sustainability challenges. On the one hand is the predominant 'instrumental learning,' which through law and order conditions human behaviour towards set sustainability goals. On the other hand is more 'emancipatory learning' which promotes a self-actualization of society members through critical participation in problem solving and decision making (Wals and Jickling 2002). In terms of social learning to promote these different types of learning, Glasser (2009) notes that there is a breadth of interpretations and definitions of what social learning is. Based on the grassroots nature of the C.A.S.A. network with its focus on plurality and participatory decision-making, I have decided to explore the interpretation active social learning, provided by Glasser (ibid), which brings together different ideas and actors within an interactive environment, characterised by being critical, reflective and participatory. Such 'emancipatory learning' can be contrasted to passive social learning, which relies on the perceived wisdom of others, whose top-down, expert knowledge transmission relates better to 'instrumental learning.'

The question then arises as to how to go about generating emancipatory learning? Although plurality and diversity are often put forward as means for transformative learning to take place, such processes do not happen by themselves. In line with Wals (2015) I argue there must be a 'dissonance' brought about by tensions or conflicts which transform the points of reference of an individual or community, and contribute to deep processes of reflection and potential change. Although dissonance is a poorly conceptualised term (ibid) I see it as the disruptions caused in our minds through exposure to new values and worldviews which challenge our beliefs and mental frameworks. This often takes place through 'boundary crossing' between different domains of knowledge and practices (Akkerman and Bakker 2011a; 2011b).

My contribution to the above debates is to explore how to create and facilitate an 'optimal dissonance' of social learning. For although dissonance is an acknowledged trigger for learning (Wals 2015), it can act as a double-edged sword. One the one hand, some people are comfortable with leaving their comfort zones, and are energised by challenges to their basic beliefs. Such dissonance can also be the catalyst for those who do not like leaving their comfort zones to experience a transformative experience, and gain an appreciation for other points of 
view. On the other hand, some individuals may react adversely to such dissonance, lashing out and/or retreating further into their own comfort zone. My research will thus address how to design and facilitate learning processes which have enough diversity to promote dissonance, but maintains enough social cohesion to not push people over the edge. 


\section{Chapter 3}

\section{Methodology and Methods}

Researchers enter the field carrying not just a laptop, pen and paper, but also a fairly rigid set of ideas and values of how things are and how they should be. Research will therefore always be partial, and even performative (Law and Urry 2004) with the worldview of the researcher affecting the research process. Rather than this being an inescapable problem, however, knowledge production can be conceptualized as a research 'assemblage' that has its own effects on the event researched and which comprises researchers, data, methods and contexts (Mol 2002). Following this logic I have employed the New Materialist Ontology (NMO) in which agency is conceived as not only tied to human action but to relational networks or assemblages of human and non-human actors who affect and are affected (Fox and Alldred 2015). 'Affects' used in this way refers to the Spinozist notion of there being no 'object' or 'subject', but instead a process of 'becoming' that represents a change of state or capacities of an entity (Deleuze and Guattari 1988). Keeping in mind that these affects are dynamic, unpredictable and always in flux around actions and events (Fox and Alldred 2015), in this thesis I present 'pictures' of this research assemblage in specific time frames.

To operationalize the NMO logic and to respond to the performativity of research, I based my methodology on action research with a focus on ethnographic participatory methods of data collection and analysis. In the first part of this section I explain how action research was used in this study (section 3.1); this is followed by an explanation of some of the participatory methods used (section 3.2). Finally, I provide a self-reflection on the methodological process (section 3.3), problematizing the role of the researcher and the difficulties encountered during fieldwork.

\subsection{Participatory Action Research}

One way of visualizing affections and giving voice to researchers and research subjects in the research assemblage was through participatory action research. According to Reason and Bradbury (2001) and Valkenburg et al. (2009) action-research is an interactive inquiry process that balances problem-solving actions implemented in a collaborative context (actively engaging with research subjects) with data-driven collaborative analysis to understand the actions of 
people, their underlying interpretations, knowledge and strategies. What makes it Participatory Action Research (PAR) is the added involvement of the researcher in what Fals Borda (2006) describes as 'praxis-inspired commitment' whereby the researcher goes through a process of decolonization from the dominant expert-based institutional logic, and instead assists intellectual and political movements for people's self-reliance and empowerment. This is achieved by directly getting involved in processes of collectively re-interpreting and constructing knowledge for the improvement of practice together with research subjects. This focuses on collaboration through iterative cyclical processes of action and reflection, which brings a greater awareness of a participant's situation to thus improve chances of achieving the ultimate goal of personal or collective change (Kindon et al. 2007).

In this research, I participated actively in various ways. First, I joined the community of Atlántida where I conducted one year of ethnographic research, participating in community reflection sessions and decision-making processes as a resident. Second, I became increasingly involved in the organizing body of C.A.S.A. Colombia, participating in vision-making and decision-taking processes. This culminated in my role of co-organizing the network gathering El Llamado de la Montaña of 2016, which took place in the ecovillage Anaconda del Sur in the province of Putumayo (30 June - 7 July). By taking active part in the processes I was studying, I gained a deeper understanding of the dynamics of community interactions, the feeling of taking responsibility for decisions and actions in the community, and the emotive aspects of seeing change happen (or not). My attachment to the community was vital for engaging research subjects as co-researchers, which can be seen in chapter 4, which is co-authored by two members of the community Atlántida.

Action learning loops have also been very important to the processes of social learning during the yearly network meetings. In the case of El Llamado de la Montaña, these loops have been established empirically. As a self-organized event, El Llamado de la Montaña has necessitated the engagement of dedicated volunteers in contributing to the logistics of planning, organizing and carrying out the event. There is a core group of up to seven organizers who work for several months before each Llamado, fostering connections with the host community and organizing logistics. The other organizational level is the dinamizadores who act as leaders facilitating the workshops and activities of the vision councils. As many of these organizers have been part of the Llamado for a long time, and because there is a strong focus on personal development and reflection within the network, a natural result has been the coming together of 
organizers after each event to evaluate outcomes, reflect on assumptions, and generate learning points.

After El Llamado de la Montaña of 2012, when the C.A.S.A. network was established, a collective question emerged and has remained constant throughout the years: How can we unite in a plurality of peoples and visions so as to co-create sustainability actions while learning from each other? Since 2013, I became progressively involved in the organizing committee and in their yearly processes of reflection. After the second year, I recognized this process as an action-research loop, and became fully involved in following, participating and contributing to this process. With the above question in mind, I developed more detailed research questions (outlined in chapter 1), which in essence are the academic versions of this collective question. El Llamado de la Montaña has then become an experimental space for answering this question. After each event, the core group of organizers and facilitators go through a process of reflection, evaluation, re-designing of strategies according to lessons learned, and hence develop new ideas for improving the following event (See Figure 3 below). This connects to the theory of action research cycles: 1) formulating a collective research question; 2) a diagnosis of the problem; 3) intervention design; 4) evaluation/reflection; and 5) implementation to bring about a desirable change (Beukema, 2009). Some of the findings of these social learning cycles are presented in chapters 4 and 7 .

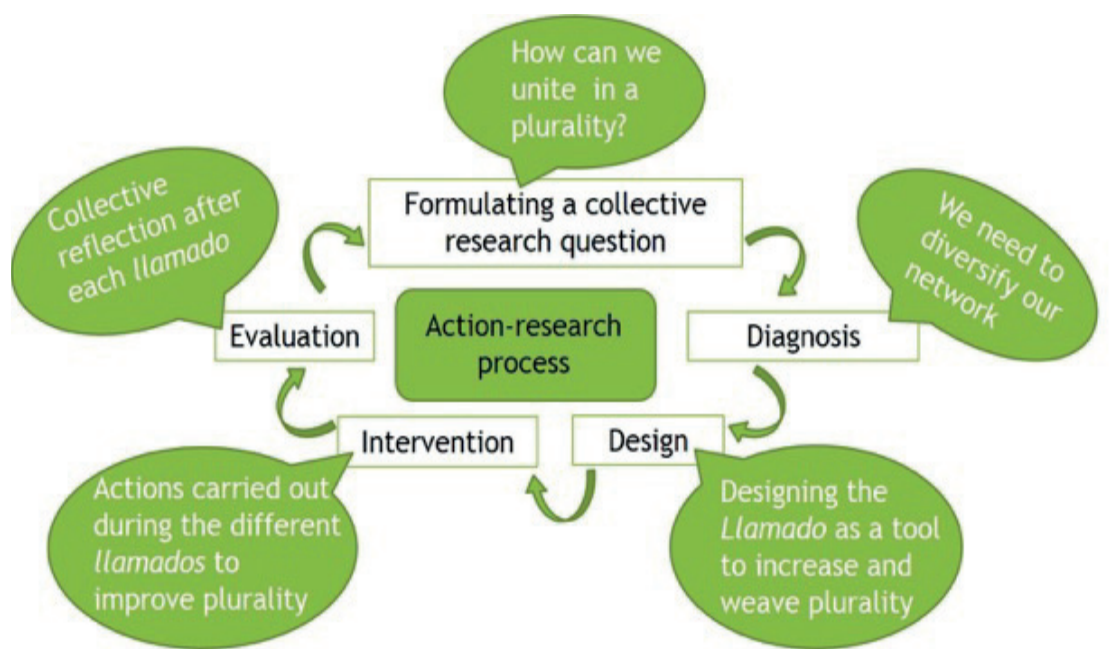

Figure 3. Action-research loops carried out empirically by the organizing committee of El Llamado de Montaña (Based on Beukema 2009) 


\subsection{Methods}

Within this framework of action research and collaboration, I chose certain methods of inquiry with which to represent the methodological logic:

(Active) Participatory Observation: Fundamental to the development of this research was in depth ethnographic research conducted in the community of Atlántida at the start of my $\mathrm{PhD}$ fieldwork. When I arrived to begin fieldwork in 2013, major changes had taken place in the community. From having been a thriving community in 2011, almost half of the residents had left the project and the community was in a deep conflict. Living in the community (and being part of the community) through the latter part of the conflict allowed a window into the lives and realities of Atlántida residents going through major changes, as well as glimpses into the challenges and learning points gathered from 10 years of community life through intense community reflection sessions. Although this was a tough experience as both a researcher and resident, this contributed greatly to the thesis and my understanding of communal living. I also was able to experience the greater 'community of life' which Atlántida represented. From the animals and plants on the farm, to the temperamental communal washing machine, to infestations of lice, participating in everyday activities gave me a much better appreciation of day-to-day sustainable living - the joys and the challenges. As a scientific method, it also provided a means of reflecting on the processes taking place, and although the active aspect was very important, participatory observation methods also allowed me moments to take a step back to observe what was happening as an outsider/researcher, thus providing some perspective before reentering the role of a community member. In this sense I was inspired by the idea of 'observation of participation' (Tedlock 1991) whereby stepping in and stepping out of the researcher role, the ethnographer can both experience and observe their own and others' coparticipation within the ethnographic encounter.

Auto-ethnography as a narrative method of representation: Normally when we read an academic text we have little idea of what the author(s) went through during their research. Did they enjoy the fieldwork? Was it difficult? Or did everything just seem to fall into place? This is normally not included in academic work so as not to make the work appear subjective; yet as researchers we all know the emotional roller coaster involved in investigation. One way of including the researcher in the written representation is through narrative methods of autoethnography. In what Goodall (2000) describes as the 'new ethnography' the author reflects on 
their own research position - creatively incorporating feelings and impressions into the written representation. This method is employed in chapter 6 where I provide a personal account of the process of co-organizing El Llamado de la Montaña of 2015, at the Indigenous University of Misak. It felt good to be able to share the more emotive aspects of my research with the reader, as well as hopefully providing the reader with a deeper and more honest look into the processes that took place.

Circular participatory photography: Beyond words, images have the potential to inspire and trigger the mind in novel ways, as well as presenting knowledge through a different medium. However, to break with the idea of the researcher as the expert in terms of producing and representing knowledge, I decided to use a form of Participatory Photography (PP) as a way of generating processes of reflection, as well as a visual means of representing the visions and practices of buen vivir (the good life) in the C.A.S.A. network. PP (also sometimes referred to as photovoice) is a participatory action strategy whereby subjects record and reflect on a topic by taking photographs and explaining the photographs to the researcher. I took this process one step further by creating a PP exhibition which I presented back to participating communities, thus catalyzed discussion circles whereby participants sat in a circle and shared ideas and reflections on the photographs of themselves and those of other communities (see chapter 5 ). In this way I deepened the reflexivity of the process as well as generated valuable data.

Participatory video: Participatory video is a set of techniques to involve a group or community in shaping and creating their own film (Lunch and Lunch 2006). It was employed to explore collective meanings, understandings and impacts in social learning in the C.A.S.A. network. This method leads to a dynamic process of community-led learning and exchange (Lunch and Lunch 2006). In a similar way Witteveen (2009) and Witteveen and Lie (2009) have used filmbased methodologies for analysis of social learning processes when addressing complex problems concerning sustainable rural development between different stakeholders.

Online Survey: As a collaborative means of validating principles of transformative learning (in chapter 7 ), an online survey was sent out to 16 academics and practitioners in the field of civic ecology and socio-ecological well-being. Respondents were asked to rate the resonance level of five 'design principles' for transformative learning, choosing between the options of: highly resonates; resonates somewhat; hardly resonates; and does not resonate. Respondents were 
also given the option of providing suggestions to these principles, with the suggestions being woven into the chapter.

\subsection{Reflection on methodological process and fieldwork challenges}

A strong ethical consideration of performative research is that if we are influencing the specific event that we are researching, then we have a responsibility to help create the realities we want to realize. Focusing on participatory and action research has been a rewarding process in which I have learnt about the importance of including other researchers and subjects into the research process, as well as the importance of research having an activist element in trying to push boundaries of normalized habits towards more sustainable outcomes. That said, such a process involves many challenges - some of which I discuss below.

During my 12 months of ethnographic research in the community Atlántida, I made important connections and friendships with the residents. Particularly two residents were interested in my work from a more academic perspective as both held Master degrees. I asked them if they wanted to act as co-researchers for the article I was writing, and they were both enthusiastic. Both smart and intelligent, they wrote reflections on their experiences, which I managed to weave into my article. However, one of the co-researchers did not speak English, so it proved a lot of work translating what was written, as well as contextualizing my article to the coresearcher as the article was being written in English. I also found that weaving the stories of the co-researchers into the article meant making changes to what was written, which at times created tensions with what the co-researcher(s) wanted to communicate. The next time I produce an article with co-researchers I will from the start plan the article with them and decide together on what we want to present and how. This of course is difficult because one does not always know from the start what the focus of an article will be.

One method which did not work so well was the Participatory Video (PV), which I used with two indigenous students from the Indigenous University of Misak as a means to provide feedback from the host community Misak about the network event El Llamado de la Montaña, of 2015. My hypothesis was that the reserved Misak people would be more willing to share their insights if their own people undertook the research. PV would also provide the potential of empowering the two students into new ways of carrying out research. Although enthusiastic, the students found it difficult to ask critical questions to the local community, especially to Indigenous elders 
whom are held in high respect by the Misak people. I also believe the camera effected the critical responses of the interviewees, with responses tending to repeat positive outcomes. I encouraged the students to carry out informal interviews to complement the video footage, but this was not carried out.

In my opinion, there was a lack of planning from my part, where I should have invested more time in accompanying the students and their research process. This would have led to the opportunity of co-producing an interesting product, rather than the end video product, which I feel did not turn out to be a good representation of the local impact of the event. Moreover, it would also have given me a better opportunity to learn their ways of researching and assembling knowledge.

On the other hand, I had a better experience carrying out a PV with the participants of the 'Youth Council' of El Llamado de la Montaña, 2015. It was a mixed group of Indigenous and urban youth, and through the participatory process of making the video we explored their different ideas of what territory signified, and the role of young people in strengthening their relations to nature and spirituality. Although it was an enriching experience for all parties, and the end video product (in my view) was representative and of high quality, I was unable to use it for two reasons: First, it had sensitive footage from a sacred lagoon of the Misak people where some participants went to make an offering together to Mother Earth. Although the Misak youth gave me permission to share the footage, I was hesitant at the time to use the video as it could cause conflict with other members of the Misak community. The second reason was that the data collected from this process did not contribute substantially to the main topics of this thesis. I intend to return to the Misak community and continue exploring the territorial processes they are going through, and perhaps use the material later on. ${ }^{6}$

As inevitably occurs in research, I ended up prioritizing some methods over others. Although I believe PV has the potential to transcend the boundaries between western and Indigenous knowledge through the medium of video, I acknowledge that more time would have been needed to build up the capacity of the students to be more critical, and make use of the end product to continue the research with the video-makers and their communities.

\footnotetext{
${ }^{6}$ For readers of this thesis the PV can be viewed at https://youtu.be/Pn-nkQt_38.
} 
One of the biggest challenges I faced was walking the wobbly line between being a researcher investigating sustainability processes, and a person trying to enact a sustainable life. Because I tend to take an activist position in the work I am doing, I needed to be very careful to remain open-minded enough to really listen to those I researched who had different views than I did. This is so easy to say, but so difficult to do in practice. I also had to remember and consider that because research is performative, what and how I research will influence the realities in the making. In other words, which realities did I want to enact, and how might those influence the process and its direction? Asking such questions call for what phenomenologists call 'bracketing' - the becoming aware of your own biases and putting them temporarily aside to minimally distort the process and to be able to see how you own lens might influence what you see (Langeveld, 1983). I also kept in mind that as educated researchers we have a comparatively high awareness about sustainable development and the same time a highly unsustainable lifestyle, which is at odds with global social and intergenerational justice. Paraphrasing the words of environmentalist David Orr, the people with the biggest ecological footprints are not the ones who received no formal education living in poverty but are the ones with PhDs, Masters and Bachelor degrees (Stone and Barlow 2005). I attempted to address this through ethnographic fieldwork where I lived a life of 'voluntary simplicity,' as were the subjects I was researching. The challenges, dilemmas but also the small pleasures of such a lifestyle proved invaluable for my research as well as my personal development.

The last point I want to make is that when one enters the field anything can and does happen. Beyond the incommodities of lice, power shortages, cold showers, and mediocre internet are the changing dynamics of people and communities. I arrived to the community of Atlántida originally intending to investigate a 'successful' ecovillage walking the talk of sustainability. Instead, I arrived to a community whose social fabric was disintegrating and whose dream of the ecovillage was essentially over. This meant I had to change my research questions, which resulted in a different thesis than expected. From a research perspective this proved an enriching experience as I was able to experience firsthand the challenges of these communities and follow the learning processes involved. It also, however, meant emotional upheavals in the encounter with these new contextual realities, and the need to let go of ideals and my nicely planned research schedule in order to be flexible and open up to new opportunities. As they say, 'out of crisis the roads to new opportunities are revealed'; it is however never easy in practice to leave the reality we know for the one we do not. This will become increasingly clear in the next four results chapters. 


\title{
Chapter 4
}

\section{Death and Rebirth of Atlántida: The Role of Social Learning in Bringing about Transformative Sustainability Processes in an Ecovillage}

\author{
Authors: Martha Chaves, Thomas Macintyre, Eliana Riano, Jorge Calero, Arjen Wals \\ Published in Southern African Journal of Environmental Education (SAJEE), Volume 31 (2015)
}

\subsection{Introduction}

"There is an open invitation to live on a piece of land, to build together a community that celebrates the sacredness of life...the earth should not be owned by anybody but used responsibly by all...I want this for my child." (Y Campo, personal communication, February 20, 2014)

This was on Yami Campo's mind when she arrived to Atlántida 12 years ago in 2003, with her partner Jorge and their baby girl Inanna. Their vision was to create an 'ecovillage' in the countryside; an intentional community which would bring together social and ecological values through communal living in close contact with nature. It would be run through horizontal organization, and would serve as a sustainability laboratory and as a source of inspiration for the rest of society. Nine years later, in 2012, the bustling community of Atlántida with 15 permanent members and a strong focus on spiritual and community life, held 'The VI Call of the Mountain,' the annual Colombian ecovillage gathering. With more than 450 participants from 26 countries attending, the event was a success, and Atlántida became at that time the best known ecovillage in Latin America.

It is now September of 2013, almost two years later, and the community is falling apart. The residents of Atlántida are sitting down in a community meeting with less than half the people that used to live in the ecovillage, thinking and reflecting on what happened, what they have learnt throughout the years, and what to do next. This deep and challenging learning journey continues until this day. 
As this paper is going to show, there is a lot to be learnt from people who have experienced living in an ecovillage and have reflected on the deep personal changes and realities of trying to establish sustainability in practice. Far from the abstract world of 'academic' sustainability, or best practices of recycling and buying 'green' products, living in an ecovillage forces an individual to directly face the interconnections of everyday sustainability actions through a communal setting. This includes the dilemmas and consequences of narrowing the knowledgeaction gap and the sharing of agency when putting into practice (or not) visions of sustainability together with other people.

Yet ecovillages, in line with discourses into sustainability, face a profound challenge: putting them into practice is not easy. Taking the definition of an ecovillage (e.g. Litfin 2009:125) as "a planetary knowledge community grounded in a holistic ontology and seeking to construct viable living systems as an alternative to the unsustainable legacy of modernity," one can quickly begin to imagine how difficult this would be to put into practice. In fact, as Christian (2003) argues, only 10 percent of intentional communities succeed in the long-run, thus demonstrating the difficulty in reconciling the intentions and ideals of a community with its day-to-day realities. It is therefore not surprising that measuring sustainability in an ecovillage could be a disappointing experience. Even using a framework such as developed by GAIA education (2015), which is the academic arm of the ecovillage movement and which divides sustainability into the four 'keys' of sustainability - Worldview/Spirituality, Social, Ecological and Economic - a community such as Atlántida would fare poorly.

Yet there is increasing resistance to evaluating sustainability through indicators, with Sterling (2009) arguing that this encourages dis-connective thinking and dis-integrative practices in our education and society. Instead of looking at 'successful' sustainability - of what could or should be - there are increasing calls towards more radical learning-based transformations in individuals and communities so as to transition towards a more reflexive and process-oriented interpretation of sustainability (Wals, 2009). In this sense, it may be more productive to think about the above ecovillage definition as aspirational in nature, and focus more on the processes involved in constructing more viable living systems. For as Wals and Schwarzin (2012) argue, it is one thing to say that we need reflexive communities of learners; becoming one is a whole different matter. Individuals and groups actually need to learn to become reflexive, and this is a challenging venture. Considering the lack of research into defining how to achieve this in a practical sense (Medema, Wals and Adamowski, 2014; Sol, Beers, and Wals, 2013), this paper 
will address this gap by providing a practical example of how a social learning process has unfolded within the community of Atlántida, focussing on the reflexive loops of learning, and the dynamic nature of 'disruptions' within this process which have the potential to promote learning. It finishes with the wider implications this has on society's journey towards a more reflexive world.

\subsection{Methodology}

An important means of gaining access to these social learning processes was obtained through collaboration with research subjects. For this reason this research is action-orientated, which according to Reason and Bradbury (2001) is an interactive inquiry process that balances problem-solving actions implemented in a collaborative context with data-driven collaborative analysis. This was accomplished through 12 months of ethnographic research by two of the researchers, which included semi-structured interviews, and participation in day-to-day communal activities as well as in community reflection meetings.

The reciprocal relationships between researchers and subjects generated during this stage of research resulted in two of the subjects demonstrating an interest to act as co-researchers for this investigation, a characteristic of action research which acknowledges that knowledge is something generated together with other people (Valkenburg et al, 2009). To this end, the first co-researcher Eliana Riano provides an account on the collective reflections made by the community, and what they have learnt about the complexities of putting visions into action. Finally, the co-founder of the ecovillage Atlántida, Jorge Calero, provides an account of his delearning journey of transformative leadership, and the role this has played on himself and the community.

\subsection{From horizontal dreams to circular realities: Atlántida's multi-loop learning journey}

Located in Cauca, a region in southern Colombia, the ecovillage Atlántida has been involved in processes of learning about organizational issues and sustainable living throughout the last 12 years (2003-2015). This learning can be characterised as a type of multi-loop learning, 
signifying that the community has been through deep learning processes promoted by their desire to periodically reflect and use their learning outcomes as a base to improve the collective system.

In a general sense, multi-loop learning involves several layers: single-loop learning generates knowledge from 'doing' and entails corrective actions which do not alter present rules, objectives or mental maps (are we doing things right?); double-loop learning explores the underlying values and assumptions behind our knowledge, and entails reframing (are we doing the right things?); triple-loop learning involves reflexivity on the process by which learning has taken place and developing new processes for re-framing values and mind-sets hence producing deeper changes (how do we decide what is right?) (Romme and Van Witteloostuijn 1999, Medema et al. 2014). This type of learning is increasingly viewed as a crucial element for sustainable decision-making in the field of resource management (Medema et al. 2014).

\subsubsection{The first loop: Are we doing things right?}

One of the primary forces driving early stages of Atlántida twelve years ago was the profound desire for a horizontal organization based on relationships of equality and freedom. Decisionmaking was carried out through consensual processes, where the goal was to take into account all individual opinions and interests, and to make a final decision only if everyone agreed upon the terms. The sense of community was highly promoted and the time spent on communal activities was valued more than that given to individual development. Members were encouraged to contribute to the collective gardens, the communal kitchen, and community chores, thus centralising the energy of the community, rather than dispersing it through individual pursuits such as creating one's own garden or kitchen.

This was due to the desired rupture with the perceived individualistic modern life-style, in favour of serving the collective. At the same time there was hostility towards private ownership, and with the possibility of using existing infrastructure in the community, there was little incentive to construct one's own house. Land tenure was not discussed by members of the community, based on the philosophy that no ecovillager owned the land, not even Jorge Calero, whose father was lending him the land in exchange for administering it. Furthermore, the ecovillage attracted people with few monetary means or needs, enticed by a solidarity economy based on free housing and food subsidies for all residents. This was made possible through a collective 
budget generated by spiritual events held by the ecovillage, such dances for universal peace, in which all residents were meant to participate.

This configuration helped the ecovillage grow in members, and the yearly events led to increased recognition and income for the ecovillage. Nevertheless, over time it also created tensions between residents. Several argued that decision-making was not democratic as the most experienced members and those with the strongest personalities and leadership ended up dominating the decision-making process. On the other hand, the more proactive members complained about tasks not being satisfactorily completed. This led in 2009 to the first thorough collective evaluation and reflection on how they were doing things. The community arrived at the conclusion that there was a need for changing the organizational structure and the decisionmaking methodology so as to be more effective during meetings, and to give a stronger voice to those who were naturally more reserved.

Sociocracy was put forward by one of the community members (who had seen it used in other ecovillages) as a methodology for improving governance and decision-making. These organizational arrangements included horizontal and vertical structures of decision-making to improve effectiveness while maintaining participation. This way of organization recognizes that the best solution will come out of the collective wisdom of those closest to the problem, regardless of their formal position or group membership and that feedback rather than power is the basic organizing principle (Romme and Van Witteloostuijn, 1999)

Within this logic a hierarchy of 'circles' was created. Each circle decided upon issues that were relevant to their work objectives through consent and was represented in the next higher circle by a functional leader and one or more additional representatives also chosen from the circle through consent.

\subsubsection{The second loop: Are we doing the right things?}

Although time spent in meetings was substantially decreased, the expectation of improvement in equality and decision-making through an organizational change was not met. Even though sociocracy supposedly decentralizes leadership and power, many members felt that they were still being inspected and criticized, while leaders on their side were arguing that only their circles 
were the ones working well and meeting expectations. Furthermore, commitment and dedication to the community began to be questioned between members.

During a meeting on conflict resolution a second loop of reflection came forward in the second half of 2010. It was posited that the difference in commitment to the project and inequality in decision-making processes was not being adequately addressed by sociocracy because of the deeper issues of power resulting from the land tenure situation. Commitment to the project and trust between members was believed to be influenced by these power relations, related to the fact that the community did not own the land. The community consequently took the decision of buying part of the property as a communal ownership (seven of the forty-five hectares of the ecovillage) achieved by inviting new members to the community who paid a fee for joining. This action was carried out as a means of assuring ownership of land, so as to promote commitment and equity.

In 2012, the issues of circular organization, the arrangements of new land ownership and the arrival of new members to the community was put aside by the opportunity of hosting the first Ibero-American ecovillage gathering in Latin American - a great honour, but a tremendous challenge for the community. All members of the ecovillage worked together to organize this event; 40 volunteers from around Colombia arrived to help, and people perceived the community as thriving. All members were concentrated on the same goal: hosting volunteers and making the event a success, and tensions were put aside so as not to interrupt this momentous occasion. The event was considered a success by participants, transforming Atlántida into the best known ecovillage in Latin America at that moment.

During interviews, all members pointed out the event as the highest peak in the history of the ecovillage, but the community took a heavy toll. The stress during the event, unresolved issues that had been put aside, and new ones arising through day-to-day communal life began to build up tensions and set the scene for what happened next. A severe emotional conflict between some community members acted as catalyst in which, in the words of Yami, "all the dust previously swept under the rug, began to appear." Facilitators from outside the community were asked to help in the process and several meetings of emotional management and conflict resolution were carried out. During this tumultuous process some of the residents ended up leaving the ecovillage, a few on bad terms, while others did so because they were tired of community life. The golden age of the community was over. 


\subsubsection{The third loop: How do we decide what is right?}

After several months, in September of 2013, a meeting to gather collective learning outcomes from all experiences and realizations was held with those still living in the community. In the following section, Eliana and Jorge will each share some insights into this last loop of reflexion.

\subsubsection{Eliana's attendance at the 'University of Life'}

My name is Eliana, and I was 30 years old when I arrived to Atlántida in 2008 after leaving behind my life as a psychologist, researcher and teacher at several universities in Bogotá. I started living in Atlántida to help co-create an environment which would facilitate human development in all its forms. I now consider that my seven years of experiencing Atlántida has been like attending an intensive course at the 'University of Life.' In the following text I would like to share with you some of the lessons learned.

After the 2012 gathering of the 'The Call of the Mountain' and the unfolding emotional conflict, it took us about three months to gather the energy to come together again to reflect and learn from what had happened. The first fundamental aspect which we had to review was the assumption that we shared common ethics in terms of sexuality and relationships. Although there had been an initial intention in the community to be tolerant to different views on relationships and sexuality, in reality there was great difficulty in accepting, respecting and articulating the different emotional and sexual practices of community members. For example, some advocated free love as a self-development path, while others believed in more traditional family structures. We began to realize that the ethics of community members had changed over time, and was a continuous source of tension which had not been resolved. The collective learning outcome in this respect is the importance of periodically socialising individual ethical codes as these can change over time.

This disarticulation of ethics brought about several emotional conflicts in the everyday life of the community, which were not always well managed. Although different spaces and methodologies for emotional management were put forward, few members attended these meetings. There were several reasons for this. First, there was an environment of mistrust promoted by power dynamics and alliances within the community. This hindered the creation of an atmosphere of trust and neutrality, which resulted in some members feeling uncomfortable in sharing their 
feelings during emotional management sessions. Second, there has always been an underlying feeling of collective saturation in the community through excessive communal activities and responsibilities. Organizational activities were put before emotional ones, in part because the solidarity economy scheme depended on collective earnings during events being used to subsidise the livelihoods of its members. At the end of the day there was a lack of energy for an effective emotional management process.

The above reasons are connected to the realisation that the worldviews of community members had changed over time and were now in tension with one another. Despite the apparent homogenous worldview in the community of living together in harmony, learning from each other, and being connected to nature, deep differences emerged during everyday activities. On the one hand there was the prevailing 'Yang worldview' as I will call it. Great importance is given in this worldview to the achievement of stated goals through action. This demands planning, organisation and strong leadership. Moreover, the mental capacities of problem-solving are highly valued, while emotional and artistic skills are considered more of an added benefit. On the other hand, the 'Ying worldview' gives importance to emotions, and thus to emotional wellbeing. In this worldview, appreciation of creative and artistic skills is highly valued and their development takes a lot of space in day-to-day activities. Moreover, time for contemplation and meditation are crucial, and thus a slower pace in activities is needed. This Ying-Yang dichotomy is obviously an oversimplification, with members often displaying aspects of both, but it serves to demonstrate the opposing tendencies in the community.

A continuous struggle between these worldviews is embedded in Atlántida's story and has manifested itself in many ways. It is connected to a difference of work rhythms, leadership styles, economic schemes, and individual versus communal development. It is therefore no wonder that neither a change of organizational structure (first loop), nor a change to collective land ownership (second loop) adequately addressed power struggles in the community.

A pertinent example is the disagreements over how the economy should be generated and partitioned in the community. While for some it was important to generate resources and investment in infrastructure to improve events, for others, especially members who had families with small children, it was a priority to reinvest in sustaining welfare conditions. Eventually there was a transformation from a clear sense of paternalism - the community taking responsibility for the economic wellbeing of its members - to a realisation of the need for members to resolve 
their own economic circumstances. Subsidies were removed, and members now have to gain at least part of their income outside the community so as to pay for services and food.

To conclude, although there are many other factors and interconnections which we unfortunately do not have space to share, we realised three main things. First, to find a community balance it is imperative to begin by resolving the individual sphere before constructing the collective - as in a collective, unresolved situations are always amplified. Second, a person's agency in a community (the capacity to influence and change activities around oneself) depends to a great degree on the collective. A person can have a great capacity for agency and desire to change the status quo, but if he/she is not supported by other members then change is impossible. Third, difference is always present, thus it is crucial to sincerely acknowledge and accept it so as to co-create sustainability and a learning community.

\subsubsection{Transitioning towards a transformative leadership: Jorge's journey of (de)learning}

The following account details the main processes of (de)learning which I have experienced in what I call 'transformative leadership.' Compared to classical forms of leadership which are based on motivating and encouraging people to take responsibility for their actions, this is an individual process of awakening and evolution towards new levels of understanding.

To contextualize the results of my de-learning processes and reflections, I consider it necessary to begin with a self-portrait. I am 37 years old and father of a ten-year-old daughter. Active since childhood in social and environmental initiatives, I felt from an early age a spiritual call that led me on various roads that currently converge in my practice of Sufism/Dances of Peace and the Native American spiritual path. My strong commitment to making the world a better place is now balanced by the realization that spiritual growth is the spinal cord of any long-term process of social change.

Through my work with grassroots communities, social movements and especially as the cofounder of the ecovillage Atlántida in 2003, the relationship with my peers has been strongly influenced by my performance as a leader. In light of the major conflict mentioned above, the subject of my own leadership in the project has been a major component of the crisis and subsequent reflections. 
I consider that the abuse of rank in leadership is one of my (de)learning points. By rank I mean the natural hierarchy that occurs in every group and system. My level of rank originated in myself being the founder of the project, the land-owner's son, having more experience and capacities in environmental issues, permaculture and ecovillage design than the rest of the group, the ability to organize ideas and express them, and having economic security where some of the other member did not. Totally unaware of this simple fact, I have unconsciously been using my rank in the ecovillage for many years. I am now understanding what Mindell (1995:64) means when he says: "You cannot let go of your rank... the unconscious use of the rank is shown in the tendency to marginalize the problems of others".

The aspect of efficiency serves as a perfect example to characterize this abuse of rank. Personally, I stand on the side of the efficiency 'addicts' who are constantly frustrated when their peers do not adequately fulfill their commitments, which results in the overall system not reaching its projected goals. Specifically I was very determined in promoting shared leadership, as I believed that we are all potential leaders - that we all aspire to leadership consciously or unconsciously - and that all we need are the opportunities and motivation. Yet encouraging leadership in others resulted in tensions, as on the one hand I became intolerant of the efficiency shortages of my peers, marginalizing their personal problems and not being able to see their own limits and real capacities. On the other hand, people felt dissatisfied because they were not reaching their goals and were being criticized and over-supervised. These tensions in the expectations of leadership contributed to the crisis in the community.

During the processes of reflection after the crisis, in which I was forced to stay still for a period of time due to a motorbike accident, I began to relax and decrease my internal rhythm, my constant acceleration, and began to become aware of this simple fact of rank in groups, and the problems of unconsciously using it. It became clear that the problem of inefficiency originated in me and my tendency towards direct and classical leadership, which was to hold a clear vision of the path ahead and motivate others to share responsibility for the actions required to stay on this path. Instead, I am now acknowledging different types of leadership and learning how to use rank beneficially by enacting a new type of leadership. This is based more on mentoring systems in which the most important thing is no longer the result of the action, but the learning process involved. 
The conclusion then is to respect and thank conflict as an alchemical path of transformation. As identified by Mindell (1995), conflict has the potential of being an enlightened sword that cuts the veil of illusion and makes visible what was secretly eating away the foundations of the group. There is conflict in the evolution of any group and the challenge is not to run from it, but rather take advantage of its transformative fire.

\subsection{Conclusion}

I feel Atlántida is in a transitional point in its cycle similar to that found in nature: life, death and rebirth. As an organism Atlántida is dying, and this death is also a part of our learning process... we're all in this transformation towards a re-existence... re-creating from what we have learned without running away from the process. ( $\mathrm{Y}$ Campo, personal communication, February 20, 2014)

We can see in this quote from Yami the long circular journey she and fellow community members have come from their introduction to community life. From the ideals of living a sustainable life together with likeminded people, to the often difficult realities of enacting change together, this paper has attempted to show the complex processes involved in learning to live with one another and walk the talk of living a sustainable life. As Yami and other members have shown, this process is an organic web of life involving 'life, death and rebirth.' This echoes the ideas of Capra (1996) who links society, sustainability and ecosystems within networks of mutual dependencies and diversity.

Another characteristic of ecosystems, which Atlántida also has developed, is the capacity to withstand disruptions and learn from its effects. As Hurst (1995) notes in regards to ecosystems, we can perceive periods of relative stability and calm, which alternate with periods of increased dynamics and greater degrees of insecurity, brought about by disruptions or new challenges. Learning from the case of Atlántida, we can add that in these periods of stability a set of routine activities emerge where people encounter their dilemmas and paradoxes of the discourseaction/vision-reality gap, which can lead to frustration, negativity and a decline of energy. These periods of stability are broken by disruptions that can be in the form of negative forces (such as conflicts regarding land tenure and organisation in Atlántida), or as a positive force (such as the joint mission of Atlántida to hold the ecovillage gathering). The importance of these disruptions 
are that they act, in the words of Jorge, as "transformative fires" which maintain the activities dynamic and evolving.

According to Wals, van der Hoeven, and Blanken (2009), it is specifically in the periods of dynamics and insecurity that one must rely on the learning ability of the system and hence on social learning. The question we are then left with is: What was the learning ability of Atlántida, and what are the greater implications for social learning and sustainability in our society?

Some community members of Atlántida have shown a great deal of reflexivity in the life cycle of the community as is demonstrated by the loops of learning they have gone through. There is also a surprising level of difference between its members highlighting that rather than an ecovillage being "a planetary knowledge community grounded in a holistic ontology..." (Litfin 2009:125), there is ontological heterogeneity which brings diversity and the need for a great level of flexibility. This is shown by their high tolerance for experimentation and failure, and an ability to employ systems thinking, acquired from their triple-loop learning process and their hands-on experience in practicing sustainability. All these features have helped the community to navigate their internal processes. Yet it is interesting that it was a lack of acknowledgment and acceptance of difference which contributed to the big disruption which brought about the third loop of learning. Would they have reached the deepest and most difficult level of reflection if it had not been for the conflict which accelerated the unravelling of the community?

Echoing today's world, the story of Atlántida suggests that disruptions will be important for the transition towards a more sustainable future. Despite the consequences of tough reflexive environments, such as broken relationships and dreams, these types of transformative processes are vital for a society to more realistically address the quagmire in which the discourse on sustainability is currently stagnating. Although we do not all need to live in an ecovillage to accomplish this, it is important that we learn from the experiences of communities such as Atlántida so as to design and facilitate spaces for these 'disruptive' processes to happen in both formal and informal learning environments. This will require further theorisation into the role of disruptions in sustainability contexts, as well as the commitment of people and society to leave the comfort zone of the status quo and embark on deep, and perhaps painful, transformative processes. 


\title{
Chapter 5
}

\section{The Radical Ruralities of Buen Vivir in Practice: Negotiating Territo- realities in a Colombian Network of Sustainability}

\author{
Authors: Martha Chaves, Thomas Macintyre, Gerard Verschoor, Arjen Wals \\ A version of this chapter is under a second review in the Journal of Rural Studies.
}

\subsection{Introduction: The 'good life' of buen vivir}

Living the good life and striving for well-being is an endeavour which appeals to most of us. We want to be healthy and happy, have good relations with our family and friends, and be part of a greater 'something' that gives us meaning in our lives. Yet it is apparent that modern concepts of the good life are placing monumental strains on the environment and society through the idealisation of the consumerist modern lifestyle and domination over nature (Gudynas 2011a). This places a great importance on the need to explore other good life narratives which attempt to reconcile an environmentally and socially responsible life, with the often harsh realities of putting this into practice. To conceptualise the value-action gap between what we will see as territorial visions of a good life, and the realities of putting them into practice in a modern world, we have coined the term territo-realities.

The search for these other 'good lives' led this research to actively follow a Colombian network of sustainability initiatives called C.A.S.A. (The Council of Sustainable Settlements of the Americas). Established in 2012, C.A.S.A. Colombia has the goal of "seeking to coordinate and strengthen efforts of national and regional networks that promote, form, investigate and disseminate sustainable and regenerative lifestyles" (C.A.S.A. 2015). With roots in the Colombian ecovillage network - an association of people and ecological communities dedicated to sustainable living - C.A.S.A. has evolved into a broader network of initiatives, seeking to articulate diverse visions and practices of sustainable living such as those between Indigenous communities, neo-rural settlements and urban initiatives. 
The most established group in the C.A.S.A. network are ecovillages. ${ }^{7}$ These communities are predominantly neo-rural in nature with members seeking a more holistic lifestyle in the countryside, albeit with their own focus on communal living (Aldeafeliz), spirituality (Atlántida/Anthakarana), permaculture (Pachamama), and social justice (Nashira) (See table 1 for an overview of the initiatives). Also describing themselves as an ecovillage is the Hare Krishna community Varsana, whom are a religious movement who adhere to strict hierarchical rules regarding food, clothing and religious rituals and thus contrast with the horizontal relations characteristic of ecovillages. Adding to this diversity are peasant families such as Mamá Lulú with a focus on ecotourism and dignified labor. Another group are urban-based members who participate in events within the network, many of whom represent organizations working for environmental and social justice, and who often spend time visiting and living in different communities. In addition there is a heterogeneous members that come from native afrocommunities or Indigenous peoples from around Colombia. There are the Embera people in the West, Wiwa people of the Sierra Nevada de Santa Marta in the North, the afro-community of Rosario Islands in the Caribbean, the Misak people of the mountains of the South, and from communities of the rainforest of the Putumayo region, to name a few. Finally, there is a group of allied networks, such as Kunagua, which is a network of farms united around the conservation of a river basin in the department of Cundinamarca, and Agenda Caribe in the Caribbean, a network of organizations working on social justice and peace, who have recently become part of C.A.S.A.

Through actively participating in C.A.S.A. network events, ethnographic research in selected communities, and informal and semi-structured interviews with network members, the endogenous concept of buen vivir was repeatedly used by subjects when discussing sustainability visions, and evolved to become a defining concept for the research. Roughly translated as the 'good life,' buen vivir is an emerging concept in Latin America representing a departure from the modern development narrative. Rooted in various Indigenous and nonIndigenous traditions of Latin America, buen vivir is based on a set of shared principles: (1) another ethic to recognize and assign values based on a bio-centric perspective; (2) western dichotomies such as the nature/culture divide are discarded in favour of extended communities of relations where non-human actors are also considered subjects; (3) a critique of the rationality of individualism and commodification of capitalistic logic; and (4) a focus on

\footnotetext{
${ }^{7}$ An ecovillage can be defined as "a planetary knowledge community grounded in a holistic ontology and seeking to construct viable living systems as an alternative to the unsustainable legacy of modernity,"(Litfin 2009:125).
} 
decolonization of knowledge and power by creating spaces of intercultural dialogue, placing importance on sensitivities and spirituality (adapted from Gudynas 2011b, 2014 and Villalba 2013). The above principles emphasize values of reciprocity and community, through a collective means of understanding and of being in the world (Walsh 2012).

From küme mongen (living well in harmony) from the Mapuche in the South, to volver a la maloka (to return to the ceremonial house) of the Indigenous people of the Colombian Amazon in the North, buen vivir can be viewed as a collection of projects: As a social movement, Indigenous populations have mobilised around buen vivir as a means of asserting the importance of their cosmologies in public debates (Huanacuni, 2010; also see Gudynas 2011a for more examples); As political projects, buen vivir has been included in both the Ecuadorian and Bolivian Constitutions, generating considerable political legitimacy for the concept (Walsh 2012); and finally, as an academic project, buen vivir has been put forward as a way of moving beyond the development paradigm to other alternatives (Acosta, 2008; Farah and Vasapollo, 2011; Escobar, 2011a; Rey, 2012; Kauffman and Martin, 2013; Villalba, 2013).

Furthermore, western strains of critical thinking have been linked to buen vivir such as degrowth economics (Thomson, 2011), which questions economic growth as the root of progress; ecofeminism which criticizes patriarchal systems, including current relations between human beings and nature (Maldonado, 2014), and deep ecology (Gudynas, 2011a), which argues for the intrinsic value of nature. Rather than the idea of a universally defined good life, Gudynas (2011a) therefore suggests we refer to 'good lives' in plural to emphasize how different formulations of the good life are adopted for each social context and environment. To avoid confusion in this paper we will use the expression 'good life' when referring to peoples' subjective ideas on living a satisfactory life, while employing the term buen vivir when referring to it conceptually as a social movement based on the five principles above.

Crucial to the understanding of buen vivir as an alternative to modern development is the notion of plurality (Gudynas 2011a; Walsh 2012). In this context, plurality implies the engagement of a common society, which includes a diversity of people (ethnicity, culture, worldviews), different beings (nature, spirits, entities), and diverse knowledges (scientific, local, traditional). Rather than the homogenising tendencies of modern development, buen vivir will therefore be understood and expressed depending on the specific context and situation in which it manifests itself within and between practices. 
With this in mind, it is worth noting that buen vivir not only derives from Indigenous cosmologies, but is also a non-indigenous concept, with contributions from urban, academic and modern mestizos - people of mixed European and American Indian ancestry (Villalba 2013). Yet, the majority of studies conducted so far tend to address only Indigenous forms of buen vivir, and mainly in Bolivia and Ecuador. But what, as Gudynas (2011a) asks, about the good life of rubber tappers in the Amazon, or the residents of a favela in Brazil? Exploring other cultural traditions of buen vivir as well as the pluralities that might be embedded within those traditions, will not only further the dialogue into what the good life really is or could be, but also how people with different backgrounds and skills deal with everyday challenges, and what they can learn from each other.

Buen vivir contexts are also affected by the wider globalizing context in which they exist and are altered. Mega-trends such economic globalization, digitalization, climate change, and biodiversity loss affect the possibilities of creating good lives within a buen vivir framework. Despite the the Ecuadorian Constitution, for example, stating that "nature has rights," the government's approval of a mining law and the proposal of a water law can be interpreted as contradicting the principles of buen vivir by placing economic development over that of the supposed rights of nature (Walsh, 2010). Yet although these debates are important at the political level, and are receiving much attention in the literature, there is a lack of empirical research into buen vivir in practice (Walsh, 2012; Escobar, 2012) and especially into lived experiences (Gudynas, 2011a;).

Investigating the C.A.S.A. network provides the opportunity to explore these lived experiences of buen vivir by looking into how individuals and communities, who are part of a self-financed and self-governed grassroots network, are putting into practice the good life in settings ranging from network gatherings to daily community life. The C.A.S.A. network is especially interesting for two reasons: First, the network is in the process of increasing its diversity of initiatives, having moved beyond its ecovillage base towards a more intercultural network including Indigenous communities and urban initiatives. Such plurality, fundamental to the visions of buen vivir, opens up the opportunity for experiencing a range of visions and practices. Second, the greater context of this study is that of Colombia, a country submerged in internal conflict for the last 60 years, with displacement, poverty and violence affecting large portions of the population. With a peace accord having been signed between the government and the left wing guerrilla group FARC, there is a great need for unifying concepts such as buen vivir to forge more peaceful narratives in a post-conflict country, which can be more widely articulated through 
networks such as C.A.S.A.

The rest of the paper will be structured as follows: section 5.2 will provide a literature review on the key concepts of radical new ruralities and territo-realities; section 5.3 outlines the methodology used with a focus on participatory methods; section 5.4 will present the results; section 5.5 will discuss the findings; and section 5.6 will conclude the paper with a summary and some final insights.

\subsection{A Trial for space: Radical new ruralities and their Territo-realities}

Brought about by the transformative processes in the countryside from the neo-liberal shift and insertion into the global economy, new narratives of rurality have been emerging which branch away from the conventional productivist countryside. Halfacree (2007) categorizes four ideal type narratives to describe these trends: The first is super-productivism which moves beyond productivism by leaving behind the moral dimensions of the countryside in favour of profit maximization, and with nature being seen as an 'accumulation strategy' (Katz 1998). Consuming idylls describes the romance of the agricultural backdrop but based on consumption-oriented uses such as amenity migration whereby properties are bought in the countryside for recreational purposes (McCarthy 2008). There is also the effaced rurality in which the rural, in effect, has been effaced by the geographical development of capitalism, becoming a 'free floating signifier' used whenever a marketable identity is needed (Hopkins 1998).

At the periphery of these new ruralities are the fourth narratives of radical ruralities. These expressions diverge from the inherently capitalistic logic of the other narratives by striving for the production of truly different forms of rural space, which not just extend the scope of rural possibilities but also concern the issues of the ideological underpinnings of the forms of rural space currently debated. Such radical ruralities have three key elements: first, a strong community discourse; second, they promote diverse meanings of land beyond that of simple means of production; and third they give great importance to ecocentric and deep ecological beliefs. While Halfacree (2007) focusses on back-to-the-land movements, community-based ecovillages, and peri-urban cohousing, mainly in the global North, Kay (2008) describes these nuevas ruralidades (new ruralities) as having strong Latin American roots, and uses the term 
communitarian to describe peasant communities which are developing post-capitalist relations. These he relates to the Zapatistas of Mexico and to the Movimento dos Trabalhadores Rurais Sem Terra (MST) in Brazil.

Certain manifestations of buen vivir share these key elements of radical ruralities by striving to create different forms of being in the countryside. Several of these take a stand against what they consider an usurpation of lifestyles and natural resources, and thus attempt to return meaning and control over territories to local populations by redefining relations to place ${ }^{8}$ (Gudynas 2011a, Escobar 2008, Escobar 2001). In this way territory has become essential for articulating a defence of alternative worlds in rural areas by several social movements who use the term to construct an identity of their 'otherness' as a political strategy ${ }^{9}$ (Koop 2014). Within buen vivir the territory integrates the natural and spiritual diversity of all forms of life through their customs, traditions, languages, worldviews, principles and values (Huanacuni, 2010). Furthermore, these expressions of buen vivir promote cultures based on the bond and respect with 'living territories' (Farah and Vasapollo 2011), where a territory is understood as a living dynamic system made up of biotic networks ranging from the cellular world to the ayllu (cosmos in Aymara) (Medina 2011). In this sense, buen vivir prioritizes the rights of the cosmos, which are dependent on human rights, and vice versa, and relate to the land as a 'Mother that one would not hurt,' instead of as a commodity (Puente, 2011).

This integration of human and non-human worlds is an example of the rural increasingly being cast in relational terms (Heley and Jones 2012), and as Woods (2007) notes, concentrating on place allows for a more nuanced understanding on how global processes are remaking rural space through new hybrid forms and relations. Halfacree (2007), however, emphasizes that radical ruralities imagine produced change from actors on the ground, rather than change being induced through external circumstances, with these two competing forces resulting in a trial by space. In this sense, the struggle for building truly different relations to people and territories, and the gravitational pull of conventional habits and structures of modern world realities can be understood as a negotiation process which we call territo-realities.

Following the suggestion of Halfacree (2007), this research into the C.A.S.A. network provides insights into how one of these trials by space is evolving by studying the everyday lives of

\footnotetext{
${ }^{8}$ Here we use Escobar (2001:40) definition of place: as the the experience of a particular location with some measure of groundedness (however, unstable), sense of boundaries (however, permeable), and connection to everyday life, even if its identity is constructed, traversed by power, and never fixed'.

${ }^{9}$ A good example of this is the work carried out by Escobar (1998) who shows the articulation between afro-Colombian social movements and biodiversity-environmentalist discourses.
} 
people and communities in the network of C.A.S.A. through the concept of buen vivir. The specific research questions which we address are: (1) How are C.A.S.A. visions of the good life being put into practice, and how do they relate to the emerging concept of buen vivir? and (2) how are territo-realities being negotiated in C.A.S.A.?

\subsection{Methods}

To address the above questions four methods were employed. The first entailed 12 months of ethnographic research by the first two authors in an ecovillage called Atlántida, located in the southern department of Cauca, Colombia. In this community, the research objective was to understand what the good life means in the context of members' realities by living with them and sharing in their everyday lives. Participant observation allowed first-hand experiences of the dilemmas and paradoxes of enacting a good life in a community of people explicitly trying to do so - all with different backgrounds, ideas, and strategies for the good life. The second method used was participatory photography (PP) among 10 initiatives in the C.A.S.A. network (see Table 1 below), representing a balance between those most engaged in the network (the first four initiatives) and to gain a diversity of initiatives (initiatives 5-10). After visiting each initiative and getting to know its people and environment, interested members were asked to take five photos using a simple digital camera, in which each photo represented an aspect of living a satisfactory good life. Examples of these photos can be seen below (in section 5.4), with the caption below each one stating the good life aspect provided by the respective author. Special attention was placed on the ethics of this method, with Prins (2010) noting on the use of PP in a literacy program in El Salvador, much care must be given to the unintended consequences of this methodology, such as suspicion, timidity and ridicule amongst participants. Gaining trust through participating in day-to-day experiences in the communities, participants opened up to the PP and elicited points of view and issues which could not have been obtained through interviewing alone. 
Table 1. Location and characteristics of communities which participated in the participatory photo methodology.

\begin{tabular}{|c|c|c|c|}
\hline Initiative/ web page & $\begin{array}{l}\text { Location in } \\
\text { Colombia }\end{array}$ & Characteristics & Denoted as: \\
\hline $\begin{array}{l}\text { Aldeafeliz Ecovillage* } \\
\text { www.aldeafeliz.org }\end{array}$ & $\begin{array}{l}\text { San Francisco, } \\
\text { Cundinamarca }\end{array}$ & Intentional community & Aldeafeliz \\
\hline $\begin{array}{l}\text { Anthakarana Ecovillage* } \\
\text { ecoaldeaanthakarana. } \\
\text { blogspot.com/ }\end{array}$ & $\begin{array}{l}\text { Salento, } \\
\text { Quindío }\end{array}$ & Family-based community & Anthakarana \\
\hline $\begin{array}{l}\text { Atlántida Ecovillage* } \\
\text { ecoatlantida.blogspot.com/ }\end{array}$ & Cajibío, Cauca & Intentional community & Atlántida \\
\hline $\begin{array}{l}\text { Varsana Ecovillage } \\
\text { www.varsana.co/ }\end{array}$ & $\begin{array}{l}\text { Granada, } \\
\text { Cundinamarca }\end{array}$ & Hare Krishna community & Varsana \\
\hline $\begin{array}{l}\text { Nashira Ecovillage* }^{*} \\
\text { www.nashira-ecoaldea.org/ }\end{array}$ & $\begin{array}{l}\text { El Bolo, Valle } \\
\text { del Cauca }\end{array}$ & $\begin{array}{l}\text { Low-income, female heads of } \\
\text { households }\end{array}$ & Nashira \\
\hline $\begin{array}{l}\text { El Retoño, Kunagua } \\
\text { http://semilladeroble.blogspot.no } \\
\text { /p/el-retono_20.html }\end{array}$ & $\begin{array}{l}\text { Silvania, } \\
\text { Cundinamarca }\end{array}$ & $\begin{array}{l}\text { Family farm. Is part of a } \\
\text { network of } 25 \text { private farms } \\
\text { partaking in a watershed } \\
\text { conservation effort }\end{array}$ & Kunagua \\
\hline Pachamama Ecovillage* $^{*}$ & $\begin{array}{l}\text { Calarcá, } \\
\text { Quindío }\end{array}$ & Intentional community & Pachamama \\
\hline $\begin{array}{l}\text { La Pequeña Granja de } \\
\text { Mamá Lulú } \\
\text { granjamamalulu.blogspot.com/ }\end{array}$ & $\begin{array}{l}\text { Quimbaya, } \\
\text { Quindío }\end{array}$ & Campesino (peasant) farm & Mamá Lulú \\
\hline $\begin{array}{l}\text { Community of Rosario } \\
\text { Islands* }\end{array}$ & $\begin{array}{l}\text { Caribbean } \\
\text { coast, } \\
\text { Bolívar }\end{array}$ & Afro-Colombian community & $\begin{array}{l}\text { Community of } \\
\text { Rosario } \\
\text { Islands }\end{array}$ \\
\hline Misak University* & $\begin{array}{l}\text { Guambía } \\
\text { Territory, } \\
\text { Cauca }\end{array}$ & Native indigenous university & $\begin{array}{l}\text { Misak } \\
\text { University }\end{array}$ \\
\hline
\end{tabular}

${ }^{*}$ Communities where discussion circles were held.

The emotion some participants demonstrated when presenting their photographs to other group members helped catalyse the discussion circles, which was the third method carried out among seven initiatives (see Table 1). For this, all PP photographs were put together in an itinerant photography exhibition with which visual representations of the good life were used to trigger group discussions about the challenges and rewards of enacting the good life, as well as a means of introducing the conceptual framework of buen vivir.

The fourth method was to actively participate in three consecutive C.A.S.A. gatherings (20132015) called El Llamado de la Montaña (the Call of the Mountain), where around 300 network members meet for five days of communal living, workshops and panel discussions every year. During this annual event, referred to as El Llamado, we conducted semi-structured interviews with members of different organizations and communities from all over Colombia and abroad 
which are interested in sustainable living. To capture diversity in ideas, interviewees differed by age, gender, ethnicity and rural/urban residence. In total we interviewed 65 members of the network about their everyday practices, ideas of the good life, and challenges encountered in putting these into practice. The following section will now describe the findings of this paper.

\subsection{Building territorial relations through envisioning and enacting buen vivir}

There are many common threads which run through the C.A.S.A. network based on establishing or reviving harmonious and peaceful relations between people and nature. An interesting thread which some members used was the term 'territories of peace' which we will use to describe the territorial relations based on peaceful coexistence. These 'territories of peace' take many forms in the network, and are witnessed through a vivid presence of ideas, rituals, symbols, and ways of knowing and living that have permeated the lives of its members.

Despite the diversity of C.A.S.A., the relational connection to territory is fundamental to the different groups. During El Llamado of 2015, called the 'Minga of Territories and Territorialities'10 at the Indigenous Misak University, there were extensive discussions on relationships to territory, including a panel discussion on buen vivir and the construction of peace. A common issue raised was that although Indigenous members have a strong sense of place, with traditions and knowledge to draw upon in negotiating everyday life, this is not so common for neo-rural and urban based peoples. Jorge Calero, a network co-founder, argued that from a mestizo point of view, ${ }^{11}$ territory is directly related to a process of deterritorialization: "We are deterritorialized not only in the relations with the space around us, but also in our lack of historical roots... we do not have such deep and wide roots as the Indigenous peoples. As urban or neo-rural people we have the key task of territorializing ourselves". The desire to form a territorial attachment of this mestizo can be seen in the way many of these members are developing close relationships with native communities as a means for learning how to reconnect to a territory; some have embarked on Indigenous self-development paths such as

\footnotetext{
${ }^{10}$ A minga is a Quechua term referring to a communal work party. It is commonly used to denote people coming together to carry out a collective project, in this case, a project of territorialization.

${ }^{11}$ Although the Spanish word mestizo is generally used in the buen vivir literature to describe European descendants who are predominantly urban, white and educated (see for example, Villalba 2013), the term is often used in the C.A.S.A. network in a broader and more decolonized sense to describe all people of mixed race and heritage.
} 
the camino rojo (red path) and its traditional temascal (sweat lodge) of the North American Indians, or the path of the chicha (fermented maize drink) of the Muiscas of Colombia.

Based on these discussions, along with data from interviews and discussion circles, we have identified a common narrative in C.A.S.A. visions based on the metaphor of weaving territorial relations. ${ }^{12}$ Sandra from the ecovillage Pachamama describes the importance of weaving these relations as this is how "... everything becomes bound in a community; each pulse, each strand has a meaning and manifests its energy through the hands of the other." In these visions there are several territories to relate to, with some C.A.S.A. members describing these relations as being connected in circles, while others as a spiral moving from the central territory to the exterior territory and back. The first territory is described as encompassing relations to oneself; the second as relations to nuclear family and social community; the third as those relations to surrounding environment including non-human entities; while the fourth territory involves network relations.

In the next section we will explore the visions of each territory, complementing each level with the tensions brought about by the territo-realities that surface while enacting these visions in everyday life. We have chosen examples which repeatedly came up in the interviews and through participant observation for each territory, with the idea being that combining the visions and practices will allow us to contextualize the realities of negotiating a good life.

\subsubsection{The first territory: The self}

Maintaining a balanced relationship with oneself means embarking on personal development processes in search of internal peace, and promoting healthy food and living habits. Many respondents, influenced by native traditions, use rituals as a means to spiritually connect themselves to territories, combining different cosmologies, deities and spiritual practices for example (see Figure 4), Tatiana from Aldeafeliz is beating a drum below a dream catcher, both symbols from North American cultures). These rituals may take place on special occasions such as network gatherings, mingas, marriages, and births. They can also take place in day-to-day life while cooking, eating, planting, harvesting, and when a woman menstruates. As one respondent put it, "Life always needs to be mystical, like a ritual, something which motivates you every day and connects you with other people" (Sorya Konda, Varsana).

\footnotetext{
${ }^{12}$ As this is an ongoing grassroots process of assembling diverse visions in the network, it is worth pointing out that these results are representative of the shared visions until 2015.
} 
These mystical relations with the first territory are especially witnessed amongst women groups who organize 'circles of women' gatherings with participants from all over the country. ${ }^{13}$ In these circles, the caring role of women for the earth is promoted, ${ }^{14}$ alongside the reconciliation of sacred femininity, ${ }^{15}$ and their leadership role in society. ${ }^{16}$ This has been well received by the majority of women from the network regardless of their origins (i.e. mestizo, Indigenous and urban), several of whom continuously struggle with these relations in their own contexts.

Although rituals are celebrated by many members, there are those that argue that this ritualism can at times be imposed upon others in the network, and takes away the importance of connecting to the divine through simple day-to-day practices such as planting new seeds. Furthermore, some Indigenous elders expressed, during informal interviews, concerns about the misuse of power plants during rituals, $^{17}$ and the shallowness of following different spiritual paths at the same time, as this hinders the in-depth understanding

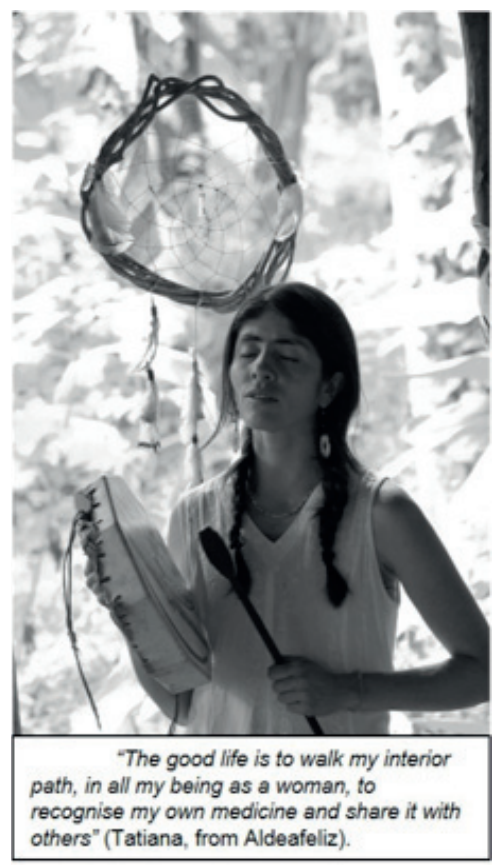

Figure 4. Buen Vivir vision of Tatiana from Aldeafeliz needed to change old habits and establish new relations.

Another well-appreciated strategy for building territorial relations while sustaining a livelihood is to plant and consume from one's owns harvest (See Figure 5). Many projects strive for food sovereignty also as a means of consuming healthier products and several have found

\footnotetext{
${ }^{13}$ For more information about these circles of women, see the webpage www.circulokillawasi.blogspot.com

${ }^{14}$ Through sustainable practices such as using menstruation cups and cloth pads instead of disposable items.

${ }^{15} \mathrm{An}$ example of this are rituals such as 'moon planting' where through the 'planting' of their own menstruation blood in the earth they connect to the natural cycles of being a women.

${ }^{16}$ Through the central role that women play as organizers and speakers in their own communities and during the network gatherings which is not common in some indigenous groups

${ }^{17}$ The term power plants is given to plants used for rituals which have the property to induce other states of consciousness, for example, coca and tobacco. One elder stated that it had taken her 20 years to understand and master the usage of power plants in the rituals she practiced, thus their use should be taken with utmost seriousness and care.
} 
inspiration in the principles of permaculture to achieve this, for example, as a means to integrate food production and community with the natural world. ${ }^{18}$

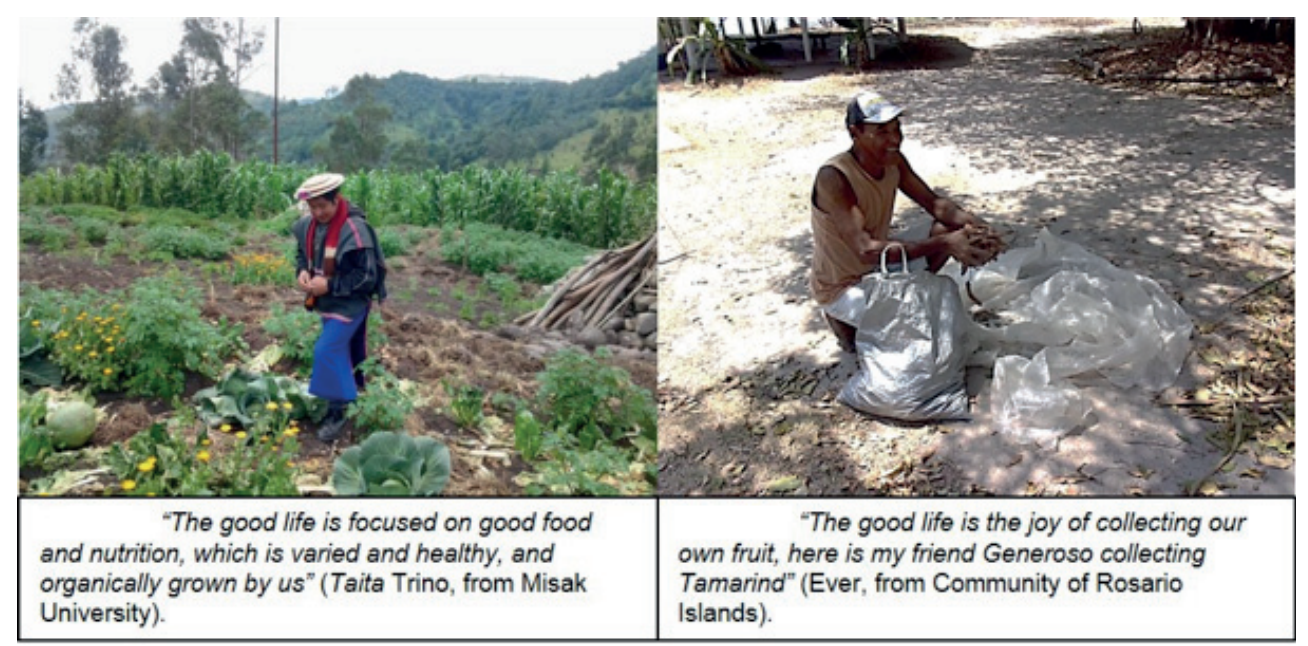

Figure 5. Collage of buen vivir of Taita Trino from Misak University and Ever from Community of Rosario Islands

Yet although growing and eating healthy food is a common thread in the network, food habits differ amongst members. One can find strict vegetarians for ecological reasons (animal production uses a disproportionate amount of natural resources), because of animal welfare (industrial farming involves unhealthy conditions for animals) or for religious reasons (Hare Krishna devotees follow scriptural guidelines of ahimsa principle which does not permit them to eat meat). Yet on the other hand there are those that consider animals and meat an important part of their lives for health reasons (meat is an important source of protein), because it is their traditional food (as argued by an Indigenous Kogi from the Sierra Nevada de Santa Martha), or for economic and ecological reasons as some members they breed their own animals and use the manure to fertilize crops.

Although food production and sovereignty are highly valued aspects of the good life in C.A.S.A., few communities are reaching their goals in terms of production, and those that succeed are

${ }^{18}$ Permaculture can be defined as a method for designing sustainable land-use systems (Mollinson, 1988). 
struggling to make it economically viable. A common story is the initial fever of enthusiasm where members come together to plan and implement productive enterprises. This enthusiasm fizzles out, however, with the realisation of the time, commitment and skills needed for the project to start bearing fruit, and people begin dropping out. Walking around many communities, this is witnessed by abandoned fields, nurseries and fishponds. Mentioning these observations to one neo-rural ecovillager, the reply was enlightening: 'We aren't peasants.' This reflects the fact that although ecovillages and other sustainable initiatives may be hotbeds of alternative living and experimentation into sovereignty, there are territo-realities which are difficult to overcome, such as a person from the city, with visions of living in nature, doing the hard work needed to actually grow his/her own food. To overcome these challenges several members choose to pay labourers instead to work the fields; others establish strategic alliances with neighbouring peasants to provide local food; and some settle with planting token herbs and vegetables in their garden.

Yet even if growing food in a sustainable way is less of a challenge, sustaining the legacies of the modern lifestyles usually is. This is the case of Mamá Lulú, a peasant community situated on one hectare of land. This farm was once a monoculture coffee plantation which has been converted into an agroecological project of permacultural food production, eco-construction and conservation. According to its residents they are easily able to feed themselves from the farm, yet they need to earn extra money to pay for other expenses such as electricity, internet and university education for the children. To negotiate these territo-realities, Mamá Lulú has opened up to tourism and gives courses on sustainable living. However, as a tourist enterprise, the local government has substantially raised their energy costs and taxes, with Mamá Lulú now struggling to reconcile its income with their operational and commodity costs, resulting in more effort and time being taken away from enjoying their farm as they are increasingly forced to rely on tourism to make ends meet. In an informal interview, one member reflected that they had originally searched for food sovereignty so as to free themselves from working as day labourers on other farms. But because of the desire for modern commodities (internet, electricity, university) they now find themselves back to working for others in the form of tourism. 'Was it worth sending my children to the university to learn theory and abstract ideas?' this member asked himself. 'Could they not have learnt more working on the farm?' Such are the dilemmas of this territo-reality. 


\subsubsection{The second territory: family and communal living}

Family relationships and living in a community are a central part of C.A.S.A. member relations. Family is an empowering source of change, and many members started their journey towards unconventional life-styles through the desire to spend more time with their children in a natural environment. In a similar vein, maintaining loving and trusting relations with neighbours and between community members is important, with some describing the community as a container of emotions which keeps members together, providing a sense of belonging and purpose (See Figure 6). As John of Aldeafeliz states: "The [communal] kitchen gives me happiness and generates happiness, it makes me feel useful. We all have a space in the ecovillage according to our tastes and qualities."

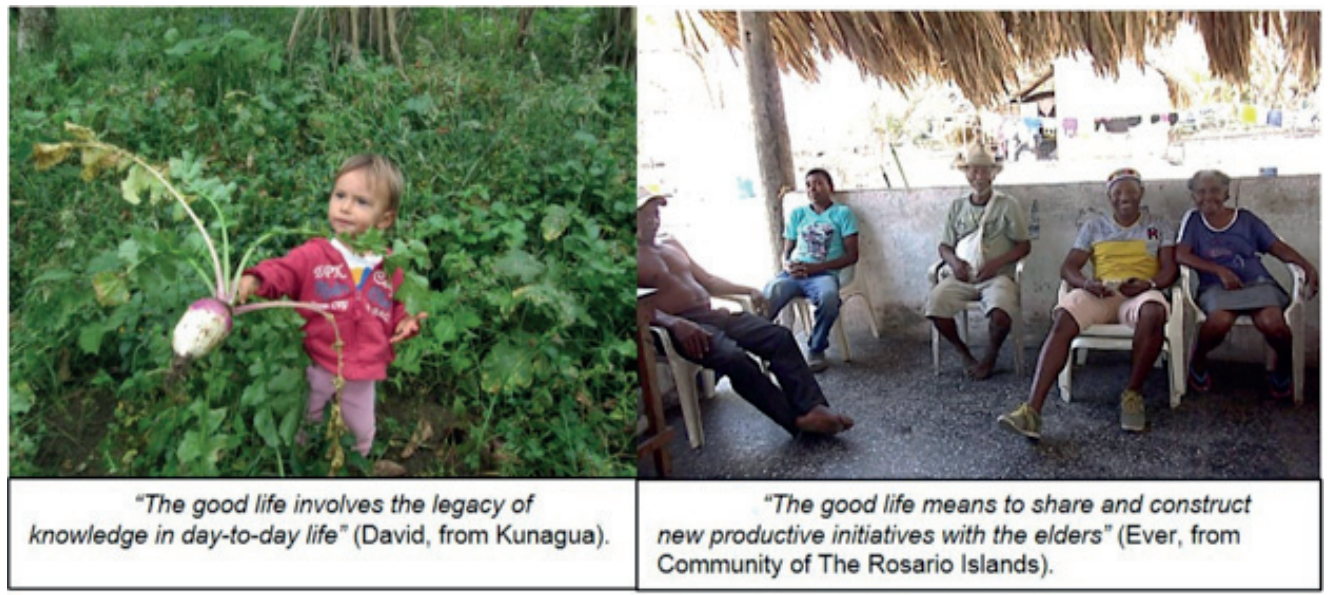

Figure 6. Collage of buen vivir visions of David from Kunagua and Ever from the Community of Rosario Islands

Nevertheless, community is expressed differently within the network. Aldeafeliz ecovillage, for example, has a communal focus where land-rights, food preparation and meals, and community tasks are shared, with a philosophy of human development through close communal living and empathic communication (See Figure 7). This is similar to the Hare Krishna community of Varsana, though the latter places more emphasis on the selfless service to God (Krishna) and to one's fellow man. On the other hand, several C.A.S.A. members stated that they could not bear to live in such tight communal settings, and preferred to pursue community-building goals 
through more individualistic strategies such as promoting networks of like-minded people. Kunagua, for example, is a network of farms where members own their own house and land, and communal activities are based around the territorial protection of the common river basin.

Another well-articulated idea within this second territory was the importance of solidarity economy to promote a good life. The vision of community members helping each other through an ethics based on cooperation and reciprocity is very strong, and is seen as a means of sharing costs and responsibilities to be able to release oneself from the idea that money is the central pillar of life. An example of this is the practice of network members coming together in communal work parties called mingas to build community structures thus saving on costs and building community. Yet losing economic security was the most commented on fear in terms of enacting the good life. In trying to negotiate the territo-

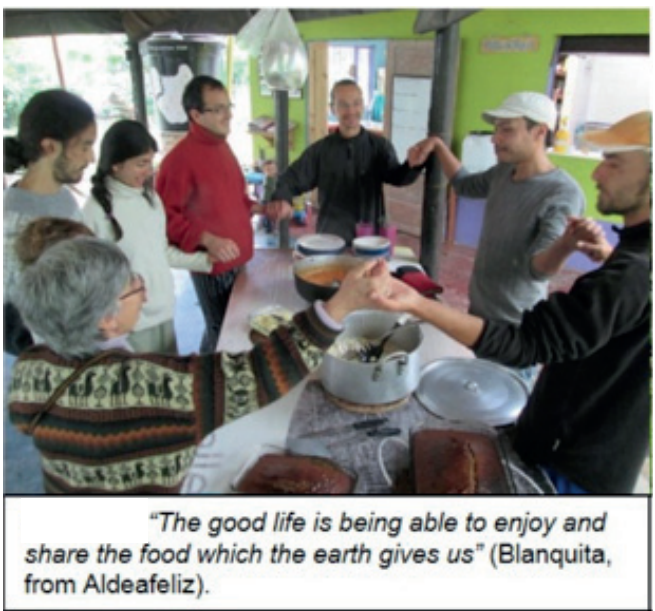

Figure 7. Buen vivir vision of Blanquita from Aldeafeliz reality of the modern nine-to-five workday, many have found themselves in stressful situations and few have been willing to let go of the security of receiving a monthly paycheck. One reason is that it is difficult to establish a reliable source of income from their initiatives which are often deep in the countryside, and so one is obligated to continuously 'leave' the good life for periods of time to generate income - often in the city.

Another important point to make is that although community is placed as a foundation of the good life, a surprisingly common phrase amongst members living in communal settings was that 'Living in a community is tough.' All members have encountered challenges in community relations such as finding the balance between individual and communal interests, the articulation of different working rhythms, and levels of compromise.

An example of these challenges comes from the ecovillage Nashira. As an ecovillage project for low-income single mothers, with backgrounds of poverty and domestic violence, Nashira is very different from other intentional communities (See Figure 8). As became apparent through the photographs taken by members of Nashira, and the accompanying interviews, economic 
security and trust are highly prized aspects of the good life, more so than ecological or healthy food habits. Through collective enterprises Nashira residents are trying to create the opportunities to support themselves economically from where they live. Divided into nuclei, groups of women share enterprises such as quail egg production, compost production, recycling, fish farming and small shops. During our interviews, however, the tensions inherent to the territory-realities of this shared economy quickly came to the fore. The intrigues of people living and working together, and the time that goes towards group activities such as meetings and resolving communal issues takes a lot of their energy. This

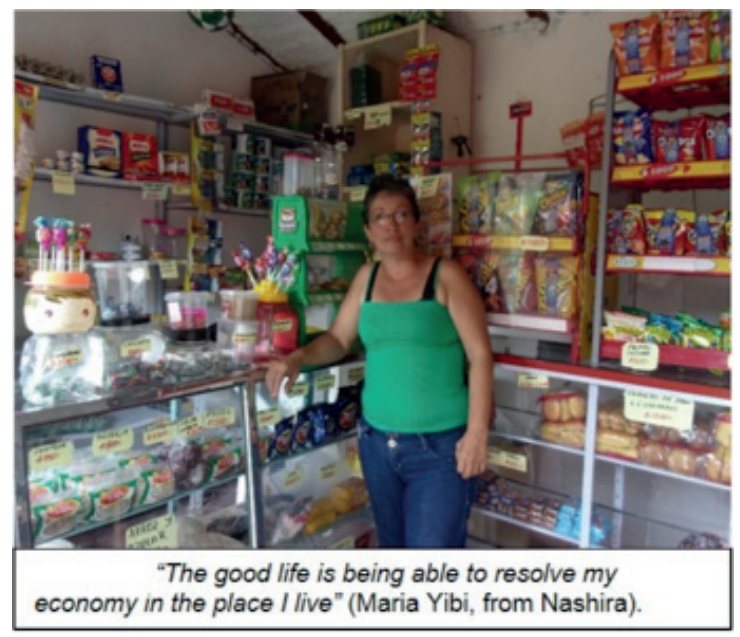

Figure 8. Buen vivir vision of María Yibi from Nashira leaves little space for personal and family time, which to some extent defies the purpose of living in a community to begin with. There are also the power struggles and jealousy between members whose business is going well, versus those whose business is not. Some respondents claimed to be trapped in their shared economy, either by having to subsidize free-riders or by being too dependent on others - thus feeling a loss of liberty. Many enterprises have thus ended in the hands of only one member of the starting group because of internal conflicts where the rest have decided to search for income outside the ecovillage.

Yet even though it is energy-consuming and difficult to achieve, a common reflection was that the solidarity economy has given at least some of these women the opportunity to acquire group-work and conflict resolution skills, and the possibility to work from home and be closer to their children. This would otherwise have been almost impossible to achieve individually without the community. 


\subsubsection{The third territory: connection to nature and the non-human}

The third territory was addressed by C.A.S.A. members through the emphasis on harmonizing one's relation to nature for achieving a good life. In all cases, nature was referred to as subject rather than an object, for example in child development: 'That our children have access to spaces for their development, where they can recognize the sounds of animals and wild fruit' (Eliana, Atlántida); of wisdom: 'The child's faculty of being amazed by the magic of nature, where a kernel of corn is multiplied into a cob of corn' (Anonymous, Pachamama) or as a colleague: 'To have nature as a great companion which makes everything balanced within oneself' (Govinda Jaya Jaya, Varsana). In some cases, the personal connections that members create with nature were blurred with the territory where they live, where non-human 'beings' are related to in a similar way as to another person (See Figure 9). Ana María, from Atlántida, explains it in this way: "The territory is the set of beings that inhabit and coexist in a multidimensional space of a defined piece of land where energy relations are established... its main energy centers are as our heart, liver, kidneys... it is not an isolated organism... it in turn becomes a small organ of the body Colombia, which in turn is like an organ of the planet."

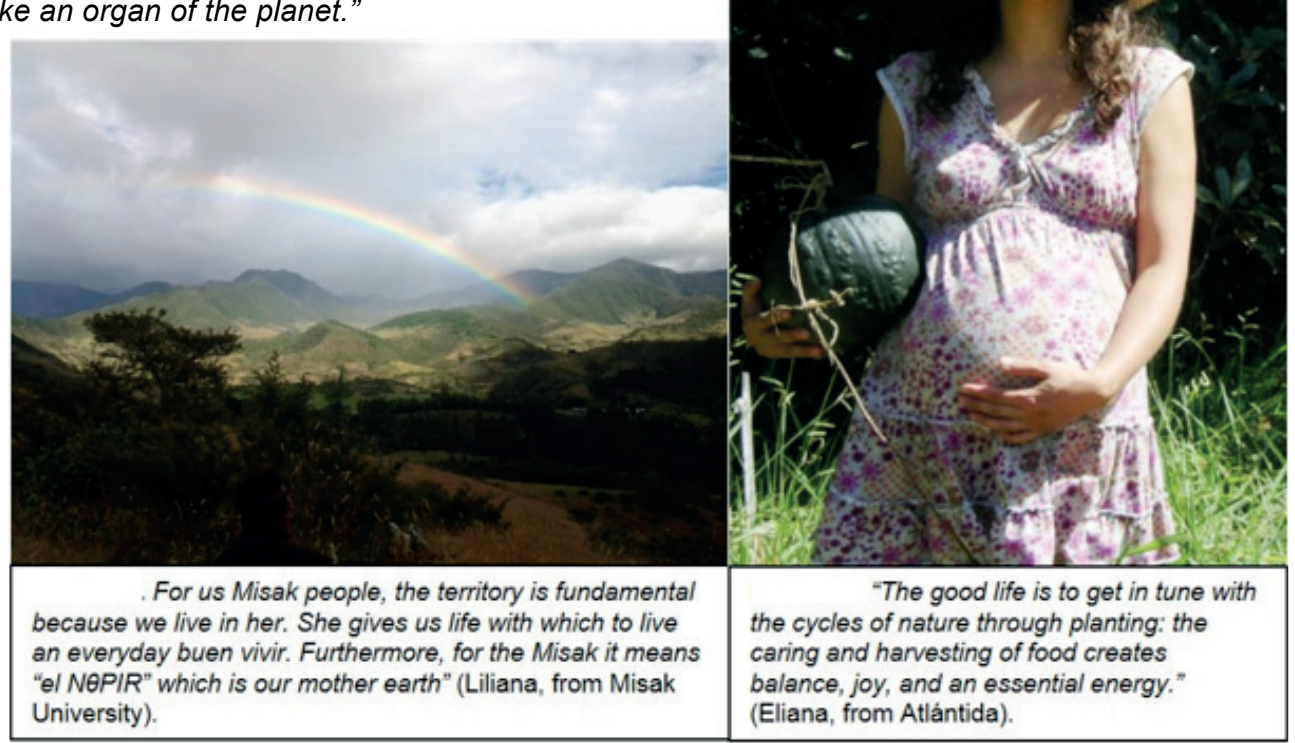

Figure 9. Collage of buen vivir visions of Liliana from Misak University and Eliana from Altántida 
In a similar way, other non-human entities ranging from material objects to words, plants and spirits were attributed agency in their capacities to exert relations of love, power and magic over people in their personal and spiritual journeys. An example of this is the ability of power plants such as tobacco and coca leafs to allow la palabra dulce to flow - talking 'the sweet word' from the heart in a way that every word is meant to do well and not harm anybody. This is common during los círculos de la palabra (circles of word) which are derived from Indigenous traditions. Los círculos de la palabra are a ceremonial conversation held around the abuelo fuego (grandfather fire) who, along with other spirits, is a guest invited to impart his wisdom. La palabra dulce is normally spoken in the traditional ceremonial hut called la Maloca, used by Indigenous tribes of Colombia to acquire wisdom from the universe. Many non-Indigenous initiatives within C.A.S.A. have built their own Malocas, and these have become neutral and central spaces for dialogue between community members and non-human guests (See Figure 10).

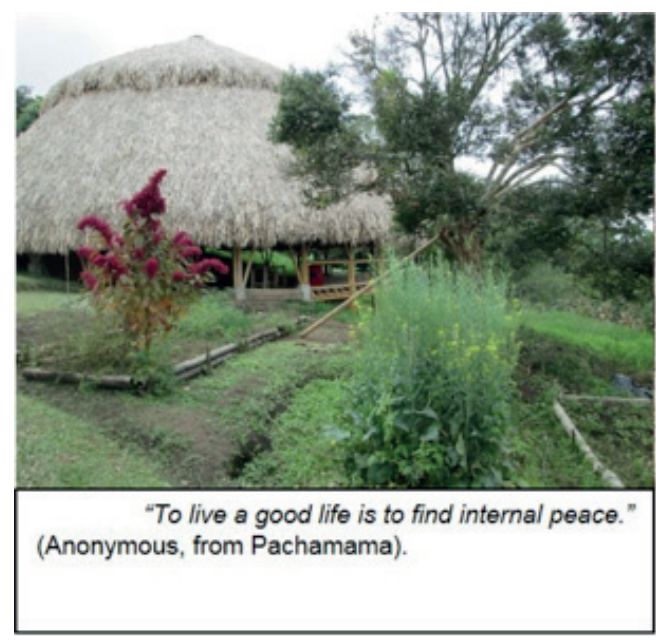

Figure 10. Buen vivir vision of Anonymous from Pachamama

As a means of connecting to nature and the 'divine source,' as well as reducing one's impact on the environment, some members have chosen the path of voluntary simplicity, through lowering material wants and needs. Maha Vakya of Varsana describes this as "the good life is to live a simple life with elevated thoughts." As a Hare Krishna devotee this means living in a group economy where individuals do not earn money, own the bare minimum of possessions, share all 
living spaces including sleeping quarters, and live a strictly vegetarian diet. In contrast there are the individually owned, relatively small and simple houses of many ecovillagers (See Figure 11).

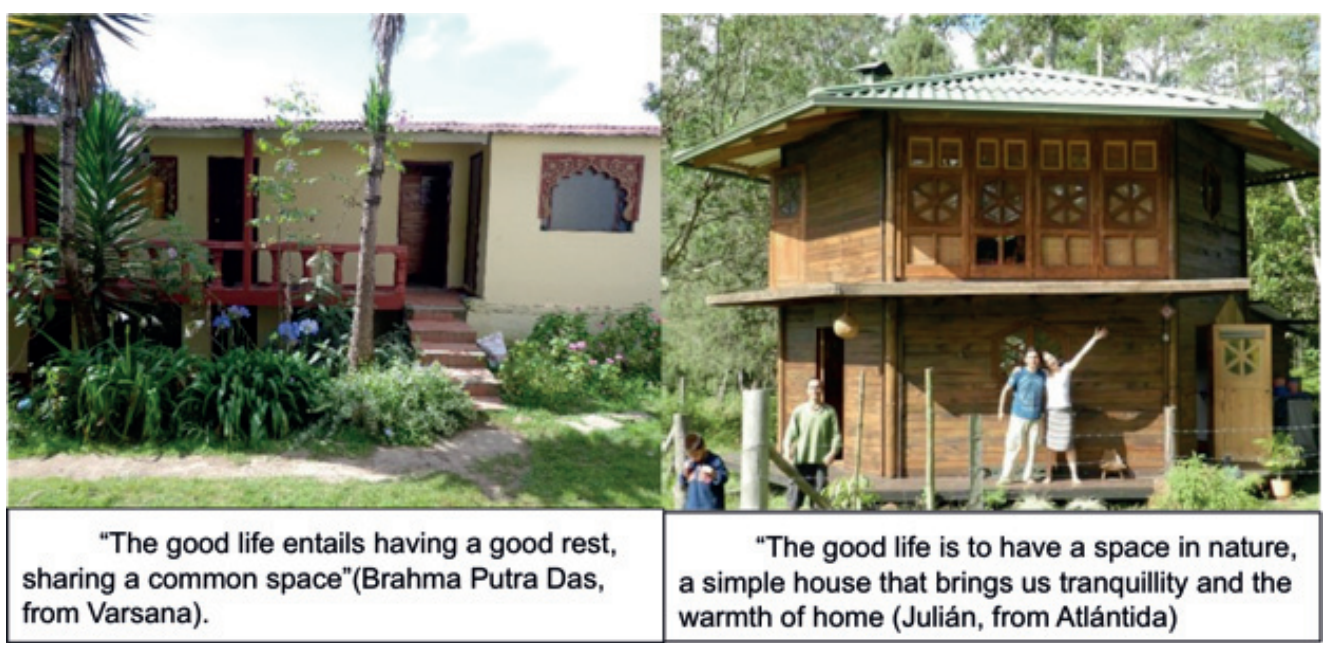

Figure 11. Collage of buen vivir visions of Brahama Putra Das from Varsana and Julián from Atlántida

In practice, many members who are trying to live a simpler life find great satisfaction, for example, in living in small, intimate houses, harvesting rainwater for showering, and taking responsibility for human waste through a compost system. By sharing cooking responsibilities they have been able to lower costs and time spent cooking, and enjoy social meals. Nevertheless, from the mundane impracticalities of waiting for one's turn to use the communal washing machine and only using cloth nappies for babies, to the territo-realities of living in the countryside which includes frequent power-cuts, poor internet connection and outbreaks of lice, the 'simple' life is not particularly simple.

Through one year of participant observation in the ecovillage Atlántida, living in a rustic $12 \mathrm{~m}^{2}$ house, the first two authors of this chapter experienced the tensions involved in communal struggles resulting from the different ideas of what it meant to live a 'simpler' life. Strongly missed was cooking their favourite meals together as a couple which included relatively expensive ingredients which the community usually did not buy communally, and food which was often not local (for example, mushrooms, lasagne, and different type of cheese and chocolate). The authors eventually decided to invest in a small fridge, and a small kitchen in 
their house where food could be stored and cooked away from the communal kitchen. However, they were soon questioned by some of the residents because of their increased energy consumption, and fewer communal meals. The authors negotiated to pay more towards communal energy costs, and the need for more private space in their day-to-day lives was stressed. This type of pressure to be 'ecological' in a certain kind of way was echoed by many C.A.S.A. members who mentioned being questioned not only by other community members, but also being judged by visitors as not living up to the ecovillage label of being self-sufficient and communal.

\subsubsection{The fourth territory: networks}

Although several C.A.S.A. members prefer to concentrate on building relations at the local level within their range of influence, there are also those who live a more migratory lifestyle. Such pilgrims create their relationship with the fourth territory by visiting, for limited periods of time, different initiatives with whom they share ideals. They may visit a place to be part of an event, or volunteer in a community for a period of time to exchange practical skills and experiences, or join a minga (communal work party). By traveling from community to community, these members establish close relationships with residents who some describe as becoming 'like family,' and their territories becoming their 'homes.'

This broader vision of community is seen by several C.A.S.A. members who state the need to create a nuevo pueblo (a new society) or even a 'new humanity' which entails, in the words of Fernando (Fundación Pacha Vida para el Buen Vivir), 'a global community that is fraternal, respectful and understands what it means to complement one another.' In this way, the relations to territory are broadened from communities to networks of people and territories across regions and countries. As Sofía (from the initiative Colectivo Talanquera) puts it: 'the last circle of the good life involves alliances with other territories, with other networks - in order not to be an isolated community, to feel part of not only a bigger territory but to really know myself in a larger territory.' This is enhanced by C.A.S.A. Colombia, which is linked to similar C.A.S.A. networks in other Latin American countries through the C.A.S.A. continental network, ${ }^{19}$ itself a board member of the Global Ecovillage Network (GEN). ${ }^{20}$ Buen Vivir panel during El Llamado de la

\footnotetext{
${ }^{19}$ For more information on C.A.S.A. continental see www.casacontinental.org

${ }^{20} \mathrm{GEN}$ is an umbrella organization for ecovillages, transition town initiatives, intentional communities, and ecologically-minded individuals worldwide. For more information see http://gen.ecovillage.org/
} 
Montaña 2015 (Call of the mountain), the annual network gathering at the Misak University (From C.A.S.A. data base).

Although these non place-based relations are widely exerted by some C.A.S.A. members, a tension exists between those members who consider it important to concentrate on building relations locally to a specific territory, and those who stressed the need to be connected and in tune with a 'global territory.' This tension is especially felt during the auto-organization of El Llamado, where some members wish to focus on building up the network through initiatives that have a place-base relation to community building, while others wish to stress initiatives who do not, for example, eco-caravans, networks, and organizations. Another tension has to do with the self-financed and self-governed nature of C.A.S.A. Although this has been economically challenging, and participatory decision-making is a slow process, it has built up an image of political independence and openness. This stance, however, is countered by a growing number of members who want more engagement with government and institutions to promote a wider platform for change.

Regardless of these tensions a diversity of ideas and practices percolate between people and places - rural and urban, global and local - providing opportunities for inspiration and reflection on good life visions for the construction of 'territories of peace' (See Figure 12). Through enacting communal and sustainable living, and in trying to bring about an intercultural dialogue, several C.A.S.A. members have put forward the realization of gaining experience in healing and restoring social and environmental relations.

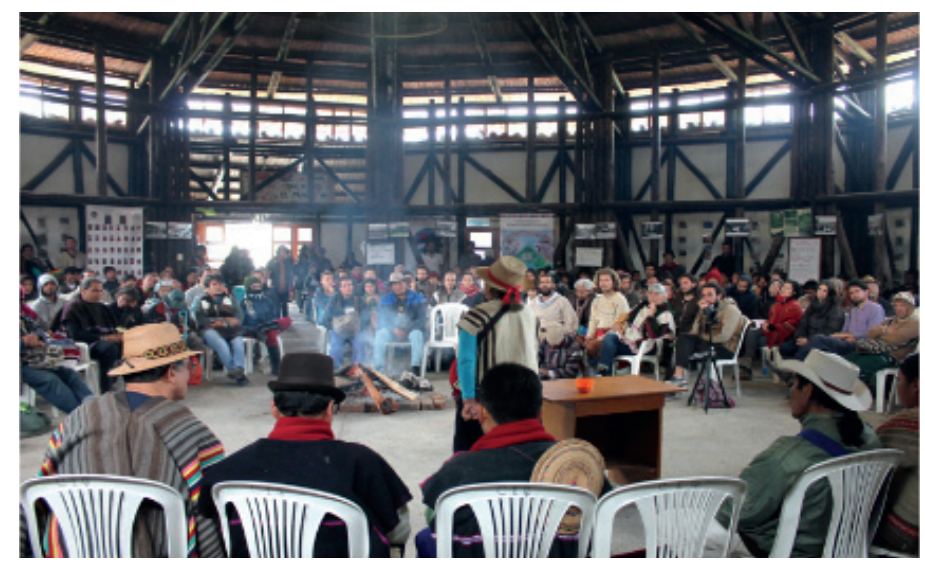

Figure 12. Buen vivir panel during the Call of the Mountain 2015 (from C.A.S.A. data base) 
These, as Gloria Cuartas (a Colombian ex-senator) argued in the network gathering of 2015, are key to promoting peace: "Perhaps the political situation in Colombia... needs the words of these kinds of networks which emerge from another type of life, which know of caring, of respect, of love... They are gas stations of ethical fuel to address the road of reconstruction in this country. Hopefully they will participate in the dialogue by contributing with their ethical points in the peace talks, for this process of peace is incomplete, there is a set of people [pueblo] missing... that pueblo is the people who still have some inner peace. Maybe those of us who have suffered so much pain and rage...need people like you who have taken care of your heart, of your relationships, of your footsteps, of your land, and of your territory. Because Colombia has a pueblo in exile, and I think today the time has come for you to open the doors and welcome, with your words and your body, a country that really needs it."

Yet, enacting an intercultural dialog during five days communal living during El Llamado is not easy. People are removed from the comfort zones of their home environments, and forced to confront what it really means to live in a nuevo pueblo of fraternal and respectful relations. A good example of this was during the 2014 El Llamado de la Montaña held in the Hare Krishna community of Varsana. As followers of Vedic teachings, Krishna devotees use water instead of toilet paper for bathroom purposes because of its healing and cleansing properties. Other C.A.S.A. groups similarly value water, with a common practice being the use of dry toilets. Instead of being flushed down the toilet with water, human manure is collected and composted, whereby it can later be used as a natural fertilizer. The implications of bringing together these standpoints became obvious, however, after the eruption of a toilet paper conflict during the third day of the event. Unaccustomed to having so many non-Krishna visitors, the Krishna hosts kept on forgetting to top-up toilet paper, with more than 300 people being affected. Complaints began to escalate and a moment of tension arose when some participants angrily demanded the Hare Krishna organizers take responsibility for providing the toilet paper. This developed into a heated argument into each other's practices. Beyond the hygienic advantages of water, some Hare Krishna argued that their practices were contributing to the lessening of deforestation through fewer trees being cut down for the manufacture of toilet paper, and thus non-violent actions against trees. This ecological standpoint was contrasted by some opposing C.A.S.A. members who considered their way more sustainable through lower water usage and a practice which does not contaminate the water thus avoiding the chemicals and energy used in treatment plants. There were also voices expressing their repulsion for both forms of 
bathroom practices - (smelly) dry toilets and the thought of using water instead of toilet paper. The situation was resolved when a C.A.S.A. organizer intervened and a more constructive dialogue was established. A solution was reached where each group would take responsibility for their own practices: C.A.S.A. organizer were permitted access to the storage of the toilet paper, while the Hare Krishnas would maintain the supply of fresh water in a bucket next to the toilets for their own use.

Although this tension was quickly defused, and provided a good source of laughter afterwards, it highlights the type of conflicts (and insights) which arise when ideals of the good life play out in practice. Although 300 people can stand united in a circle praying to Pachamama, the way they each enact this respect for Mother Earth will be different depending on who they are and what they believe in.

\subsection{Discussion}

"We are mestizos and this leads us to walk a very interesting path. We have the possibility to untangle the social fabric of two worlds: the thread of the modern world artificial, technological and pragmatic - and the thread of the ancestral world.. we propose to talk about the native-mestizo which suggests the possibility of a synthesis of cultures - a bridge, an agreement to continue in the present by returning to the traditional past.. This implies obeying the natural order of the world...in this way one can develop a capacity to recover... by domesticating modernity and reordering development." (Jate Antonio, Muisca elder)

In the spirit of the above quote by Jate Antonio, we can interpret C.A.S.A. visions and practices as a synthesis of cultures through the configurations of people, communities and ideas coming together to bring about their good lives. If we return to the buen vivir principles stated in the introduction, then we can see that C.A.S.A. members' good lives articulate well with the general concept of buen vivir. To varying degrees, and expressed in different ways, there is a desire amongst members to live a harmonious life, closely related to nature and other beings, based on values of solidarity and personal development, and with a biocentric view of life. Influenced by the strong links to Indigenous wisdom and practices, the relations which are being (re)constructed have a strong territorial emphasis, with the focus on intercultural dialogue being 
witnessed, for example, in the yearly network gathering El Llamado. Yet as emphasised above, the translation of these visions into everyday practices raises many dilemmas and conflicts which question the ability of people, communities and society in general to move towards more socially and environmentally responsible means of living. Below, we delve into these dilemmas and conflicts through a critical exploration of buen vivir as it is being expressed in C.A.S.A., and how these attempts at constructing radical ruralities stand up against the trial by space. We will finish by discussing what the territo-realities of negotiating a good life can tell us about broader processes of social change.

\subsubsection{Plurality, territo-realities, and an intercultural platform of buen vivir}

Individuals in C.A.S.A. display a desire to change their lifestyles towards more responsible ways of 'being,' triggered by a shared feeling that the status quo of the modern world must be proactively changed through connecting to alternative networks of change. This is being portrayed on the one hand by Indigenous, afro-colombian, and peasant members attempting to restore traditional knowledge which is being lost, and on the other hand, by mestizo members connecting with more decolonialised ways of being in the world. This involves a process of territorialisation where many members have turned to philosophies with various historical roots, incorporating new ideas and practices into their good lives through critically choosing what works from their own life experiences. Although in many cases these configurations are complex and at times incoherent as some members have stated, they have led members to finding value in many non-modern sources of knowledge.

According to Gudynas (2014), such decolonization of knowledge is a requisite for a political platform of buen vivir so as to enable different radical positions to converge and learn from each other. These radical alternatives of the buen vivir platform, he argues, must critically sustain the 'rupture' with the mindset of modernity where there is no space for a reformed or adjusted modernity. Instead he asserts this blend to be an alternative project, where the struggle against modernity is what articulates the different expressions of buen vivir in an intercultural platform. ${ }^{21}$ Yet in the C.A.S.A. network, this 'rupture' is not so black and white. While members are trying to distance themselves from the modernity they grew up in, in practice this has evolved into

${ }^{21}$ This echoes the plea of Escobar (2012) for alternatives to modernity rather than alternative modernities. 
moving towards an ecological and social way of living which negotiates all aspects of the modern life.

Consequently the question arises as to the extent to which C.A.S.A. members' good lives are examples of buen vivir? On the one hand, one could argue that C.A.S.A. members in no way achieved a buen vivir as based on the principles introduced in section 1 . This is especially evident in the difficulties of enacting biocentric relations where one has to give up needs and comforts in favour of those of other non-humans. It is easy, for example, to get stuck in acts of ritualism, and forget the more practical actions that can give a place to the 'other' in the current modern world such as fighting to include the rights of nature in the constitution. On the other hand, it is important not to fall into the trap of discussing 'truer' buen vivires (Gudynas 2014). As Gudynas argues, the idea of buen vivir as a platform invites participants to discuss and incorporate its contents, such as nature's rights or intercultural dialogue. It is in these exercises where civil society can appropriate the concept, defend its contents against hegemonic powers and participate in broader political debates. Alongside Gudynas (2014) we consider that participating in these debates and platforms are also in themselves ways of exerting buen vivir. But what does this then say about C.A.S.A. members' imaginaries in terms of reconciling the good life with responsible living and contributing to social change?

\subsubsection{A trial by space and 'territories of peace'}

New imaginaries, such as the ones portrayed by C.A.S.A., are important because as Kay (2008) notes, they have the power to stimulate reflections on current rural transformations. There is a need, however, to move beyond reflection into concrete actions which help bring about changes at all levels of society. With this respect we will now explore how Halfacree's (2007) trial by space is holding up through the territo-realities of the C.A.S.A. network in the Colombian context and the wider societal implications of transition narratives.

The trial by space in this article sees the struggle between attempting to produce difference in the way one puts the good life into practice, and the induced differences brought about through the pull of mainstream habits and structures. By looking at the key elements of the radical ruralities in section 2, we can gain insights into how this process is unfolding. First, a strong community discourse is ubiquitous in C.A.S.A. Still, although gatherings such as the annual El Llamado demonstrate community building at the network level, the ideals of day-to-day 
communal living are hard to reach. We clearly see the individualistic signs of modern life such as private property, information and communication technologies and individual profit competing with, for example, a solidarity economy in the community of Nashira.

Second, the promotion of diverse meanings of land beyond that of simple means of production, is prevalent with initiatives showing the plurality of functions as well as meanings which can be generated in rural spaces. Though prevalent, such multifunctional views of the countryside are problematic. Something as 'radical' as attempting to produce one's own food and living a simple life in the countryside is beyond the reach of most people who lack the skills or financial resources; this in turn leads many C.A.S.A. members to adjust their dream by paying somebody to work in the garden, for example, or returning to the city.

Third, the importance of ecocentric and deep ecological beliefs is a strong cohesive glue in the network in the sense that this biocentrism provides a foundation for the themes of network discussions such as food sovereignty, genetic modification of food, and extractivism. However, unlike Halfacree's rather homogenous model of the radical rural, C.A.S.A. has a strong spiritual focus with people of different worldviews attempting to articulate a good life together. The effects of this in practice can be seen, for example, in what could be described as ontological conflicts in the toilet paper chaos in section 4.3., where what it means to be sustainable goes beyond a simple biocentric worldview to include religious doctrine and competing knowledge systems.

Two areas which Halfacree does not discuss, but which Kay (2008) heavily critiques on communitarian proposals for new ruralities, are economic challenges and the role of the state. With the stand buen vivir takes against modernity and the capitalistic system, and the desire by C.A.S.A. members to live a less conventional life, the fear of living without a monthly pay-check, and the need to pay for basic living costs poses great obstacles to creating the 'rupture' with the logic of modernity as advocated by Gudynas (2011a). This is best illustrated by the example of the peasant family Mamá Lulú, who are self-sufficient in food, but are having to employ an increasing amount of resources in tourism to pay for the amenities of a modern life.

Kay (2008) also holds forth the important role of interacting with the state for economic and political reasons in terms of bringing about radical transformations in the countryside. Although political in the sense of wanting to construct and promote alternative models for society, the C.A.S.A. network does not receive governmental or international aid, and although it promotes itself as a plural platform, there is little dialogue with state institutions. If Kay (2008) is correct, 
then it suggests that if C.A.S.A. members and their initiatives really want to promote sustainable lifestyles at a broader level, then they will need to engage more with actors at the state and institutional level.

Whether or not this happens, a broader platform could potentialise the role of C.A.S.A. in articulating and promoting a peaceful resistance of marginalised groups in Colombia - groups that are increasingly being confronted by modernity inside their territories. This would be based on the desire to promote alternative instead of neoliberal solutions through what C.A.S.A. members refer to as 'territories of peace.' The importance of this cannot be understated in a country like Colombia, in which peace talks among FARC-EP and the government are currently taking place after many years of internal war. If and when peace arrives the country will have to confront the challenging task of reconstructing what war and conflicts have damaged, with a large number of displaced people having to construct a new life. With issues on the peace agenda such as integral land reform, involving the economic and social development of rural areas, C.A.S.A. experiences - both good and bad - of how to re-territorialize relations to the land and themselves will be a great asset for post-conflict reconstruction.

The last point to be made is that the tremendous challenges of negotiating modern legacies in the search for a good life must be seen in light of a greater movement of transition culture. Characterised (in the global North) by its focus on resilience to climate change and lowering the carbon footprint, Neal (2013) argues that transition culture represents a convergence of ruralurban values and practices, linking it to the radical rurals of Halfacree (2007). This blurring of the rural/urban divide can be seen, for example, in the movement of permaculture ideas and conflict resolution methodologies between professionals who take courses organized by the C.A.S.A. network, and who visit urban and rural initiatives to put them into practice. In this way C.A.S.A. members frequently become focal points of social innovation in their social and working environments, acting as bumblebees cross-pollinating society with ideas and best practices, while at the same time going through processes of personal transformation as they are exposed to different ways of seeing the world (see Chaves et al 2015). In this way we can understand C.A.S.A. as a network that links niches of radical ruralities, but also fosters the enactment of 'transgressive' learning processes which disrupt comfort zones of unsustainable living (Lotz-Sisitka et al 2015) whereby 'lived experiences' of the good life can contribute to a broader transition towards more sustainable ways of living with people and planet in mind. 


\subsection{Conclusion: An alternative to modernity, or a modern alternative?}

Put forward as an alternative to modern development by many authors, buen vivir has a lot of expectations resting on its shoulders. Yet although buen vivires of intercultural harmony resonate for many, putting them into practice highlights the contradictions and challenges of transitioning to new ways of living and being. By way of conclusion, we therefore see it as pertinent to reiterate what Gudynas (2011a) stresses about buen vivir: it is a concept in construction. On the one hand this makes it vulnerable to conceptual critique and co-option in practice, as can be argued through extractivist mining in Ecuador. On the other hand, buen vivir has the potential to articulate diverse societal groups through an intercultural platform, contributing to novel ways of building peaceful relations between people and nature, thus helping in the cultural transition towards a more ecological and responsible way of living. The question then arises: Is C.A.S.A.'s buen vivir an alternative to modernity, or a modern alternative?

C.A.S.A. has in no way passed the trial by space, as their grounded territo-realities of buen vivir demonstrate the considerable work that needs to be done in working towards a pluralistic society where radical alternatives are rooted in viable place-based ruralities. In this sense, it is important to view these territo-realities as a continual process of negotiation and sacrifice, where visions - and hence expectations - must be adjusted to the realities on the ground, implying a willingness to change ingrained habits of living. Thus, when addressing the above question we instead ask: Does it really matter? As long as C.A.S.A. members are willing to stay and embrace the negotiation process of their territo-realities there is hope of a transition towards alternatives to modernity through modern alternatives. The danger here is to find modern alternatives too comfortable, and the negotiation process to move beyond them too difficult.

Within this panorama, it is important to find ways for modern alternatives to be striking enough for a wider society to be drawn into and start transitioning, but still uncomfortable enough for people to continue moving beyond. This will not be achieved by only changing practices but also wider narratives of good lives that can promote changes in mindsets. Consequently it is imperative to make visible other voices and practices from those of the mainstream, to encourage reflection and debate within society, and inspire visions and practices that can lead to change. 


\title{
Chapter 6
}

\section{Towards Transgressive Learning through Ontological Politics: Answering the "Call of the Mountain" in a Colombian Network of Sustainability}

\author{
Authors: Martha Chaves, Thomas Macintyre, Gerard Verschoor, Arjen Wals \\ A version of this chapter is under review in the journal Sustainability
}

\subsection{Introduction to other realities}

"We are the new seeds that sprout from the earth. We have been called upon to restore the times of our peoples, and we are going towards the call of the mountain, from whose veins sprout great memories of new dawns in which to live. And we stand up in a silent way, because we recognize the silence of the sun and we know how to listen to the moon. It is the time of the new beings, and the air will give us the strength to carry this great message" (Lorenzo Muelas Tombé $)^{22}$

High up in the Andean mountains of Southern Colombia, in the Indigenous territory of Misak, a sacred walk is taking place. Led by the Misak people, and followed by abuelos (elders), ecovillagers, Hare Krishna, urban intellectuals, and foreigners, this diverse collection of people are walking towards the pueblo of Silvia to "activate and heal the bond with one's own territory $\ldots$ and as a collective prayer for life and for peace" (Ana María, C.A.S.A. network elder). ${ }^{23}$ Everyone is holding a seedling in their hands, and walking to the rhythm of the traditional Misak drums and flutes. Arriving to the pueblo, everyone boards a colourful (if dilapidated) chiva bus,

\footnotetext{
${ }^{22}$ This is the first part of a song written by Lorenzo Tombé, an indigenous Misak youth who made up part of the organization of the 2015 gathering. Lorenzo was inspired by the idea of the gathering and wrote these two verses. The first author of this chapter invited other participants from the gathering to add verses to the song, which resulted in a Hare Krishna devotee, a female ecovillager, and a teacher from another Indigenous community being inspired to add to the lyrics. You will find their contributions in the beginning of the results section.

${ }_{23}$ The sacred walks are an initiative led by the council of women elders of Colombia. For more information see http://consejodeabuelas.wix.com/consejodeabuelas. C.A.S.A. is the Spanish acronym for el Consejo de Asentamientos Sustentables de las Américas (the Council of Human Settlements of Latin America), which is the organiser of the intercultural event El Llamado de la Montaña.
} 
which carries its motley crew to the agricultural development land of the Indigenous Misak University. After being received with the traditional fermented maize drink chicha, the group of over 300 people prepares to sembrar agua (plant water) through the reforestation of 2000 trees in a neighbouring wetland. While the mamitas (women elders) are cooking a traditional soup called sancocho over an open fire (and remarking on the difficulty of making a tasty sancocho without meat as requested by the organizers), an animated group of abuelas, children, Hare Krishnas and ecovillagers are singing and chanting to the soup, while a human chain forms to efficiently move the seedlings to where they are to be planted. Under the animated discussion between Misak youth and permacultural experts about which variety of seedling should be planted where, and accompanied by a steady drizzle of rain, holes are dug, hands reach into the soil, and seedlings are given a new home. When the last seedling is rooted, everyone trudges back to the farmhouse to eat the sancocho, drink an agua panela (sugar cane tea) and celebrate. "Hermanos, thank you for helping us plant our water and for sharing in this collective effort" a Misak organizer cries aloud to everyone, who respond with a cheer. In all this excitement a little girl asks her mom: "why are we planting water? why are we singing to the soup?"

This article is based on the premise that people learn more from each other when they are confronted by different realities - what exists, and our underlying assumptions of what is and what is not. When an urban environmentalist meets an ecovillager and Indigenous person, all three expounding different understandings of what it means to plant a tree - or when a strictly vegetarian Hare Krishna devotee is confronted with an Indigenous Misak or Arhuaco who eats (wild) meat as part of their culture, there is the potential for clashes and conflicts, but also for new insights and understandings in what it means to live an environmentally and socially responsible life together with other people who do not necessarily share that reality. Such ontological encounters have the potential to transform the way we learn from the world around us through challenging deeply held beliefs and habits (Wals, 2011).

The examples above provide a glimpse into the profound but difficult notion of different worlds living side by side in what some authors are calling the pluriverse (Blaser 2010, Martin and Glesne 2002). Such coexistence of multiple worlds denotes a departure from the homogenizing and euphemistic idea of the 'global village' (Martin and Glesne 2002), instead giving status to ontologies which do not lie at the base of the universe. These sub-altern ontologies, it has been argued, can provide a diversity of responses to the global crisis if only one would consider their 
knowledge to be equally valid (Grosfoguel 2011). Such a decolonial attitude fits into the greater sustainability transition discourses which call for radical cultural and institutional transformations to an "altogether different world" (Escobar 2011b, pp:138).

Returning to the opening scene of this article, high up in the Andean mountains, we can see a description taken from El Llamado de la Montaña (The Call of the Mountain). This yearly Colombian gathering brings together a diverse array of people, communities and projects for five days of communal living, in which participants exchange experiences on sustainable living while partaking in working councils, workshops, panel discussions, dances and other artistic pursuits. El Llamado, as the event is affectionately referred to, brings together Indigenous elders and businessmen, urban permaculturalists and peasants, and Hare Krishna devotees and academics, to name just a few. The event is self-financed and self-organised, and has the aim of articulating diverse grassroots movements in Colombia around the theme of caring for the earth and all life within in it, so as to create stronger sustainability coalitions. From this yearly exercise a central challenge has emerged in how to deal with emerging encounters within and between a diversity of peoples, visions and ontologies. It has been recognised by event organizers that such encounters can promote innovation when differences come together in a generative learning environment, yet it is also acknowledged as leading to conflict through misunderstandings, poor communication and other underlying issues.

\subsection{Theory: Transgressive learning and the ontological politics of the pluriverse}

Engaging with the pluriverse means confronting radical otherness in settings which promote the exchange of ideas and experiences between people with different realities. This means we have to engage with the important but confusing concept and practices of ontology, as well as how it relates to issues of power. We can begin by noting that although there may have been an 'ontological turn' in social theory (Escobar 2007), there are various interpretations of what ontology means. As Holbraad, Pedersen and Castro note (2014), we can distinguish between ontology as: 'what there is' (a philosophical notion of what exists as an absolute truth); 'what should be' (a sociological interpretation which critiques such essentialisms for their inherent political nature); and last, 'what could be' (an anthropological view of ontology where a multiplicity of forms of existence are enacted in concrete practices, and where politics brings about the potentials of these forms). This article will be based on this last interpretation of 
ontology, whereby rather than people having different 'socially constructed' viewpoints on the same (natural) world, people are actually living in different worlds manifested through their practices, which together make up a pluriverse made real through their (political) encounters. To give an example: When we look at the title of this paper, we are perhaps struck by the 'call' of the mountain. On one ontological level this can simply be interpreted as the call people feel to connect with mountains and with nature. On another level it can be interpreted as the mountain, personified as a person, calling out to its people, which with a little stretch of the imagination one could even consider as a belief held by some peoples. But how many of us would consider the possibility that the mountain is an actual sentient 'earth-being' (De La Cadena 2010) with the agency to call out to its people? What would our view of this say about the realities we ourselves are living, and how would the relate to those of others?

The importance of this is that if we are not living in a single reality, then there is no one logic that can mediate between the power-saturated realities of different worlds (Law 2011). ${ }^{24}$ The question would then arise as to which logics would be established, and how would the different power relations between them emerge? Accepting ontological politics, as we call these ontological power relations in line with the work of Anne-Marie Mol (2002), is obviously a big leap for those of us whose operating system only knows one template: the one-world world. How many of us are really willing to engage with the complexity of different worlds? And if so, then how are we to navigate sustainability in these murky waters? To start addressing these challenges our social inquiry is inspired by the notion of reality, (but also research), as an 'assemblage' - a notion that has been described as the New Materialist Ontology (NMO) (Fox and Alldred 2015). In this ontology, the relationship that brings together human and non-human actors in specific actions and events are conceptualized as assemblages whose connections (or affections) are dynamic, unpredictable, and always in flux. Breaking several dualisms in social theory such as mind/matter, culture/nature, reason/emotion, human/non-human the NMO changes the anthropocentric focus of social inquiry towards relational networks of animate and inanimate entities. Thus, "the concern is no longer with what bodies of things or social institutions are, but with the capacities for action, interaction, feeling and desire produced in bodies or groups of bodies by affective flows" (Fox and Alldred 2015, p.127). In this sense, agency is defined as the capacity of an actor to affect or be affected by the other entities.

\footnotetext{
${ }^{24}$ Rather than using the term pluriverse, the cited author John Law employs the term 'fractiverse' to describe the idea that reality is a set of contingent, enacted and more or less intersecting worlds in the plural.
} 
Taking these affections and the pluriverse seriously, however, means addressing fundamental issues underlying power relations upheld through practices. Several social movements and theories of decolonialization acknowledge this and have been identified as a stream of emerging 'transgressive' and transformative research and praxis in the sustainability sciences (LotzSisitka et al. 2015). Although the term 'transgressive learning' is still poorly understood as it is a new and emerging concept, we can characterize it is a form of transformative learning which challenges the taken for granted, normalized status quo. It focuses on uprooting structures of privilege and hegemonies of power through innovative strategies which foreground cognitive, epistemic, social and environmental justice, often through activism and normative interventions. This recognizes that socio-technical transitions to sustainability do not come about easily because of lock-in mechanisms which maintain poverty and social injustices. Important, therefore, is the cultivation and utilization of pluralism, which is necessary for transformative disruptions to emerge (Wals 2011). Put simply, people learn more from each other when they are different from each other, as this creates more space for reflection through dissonance (Wals and Heymann 2004). However, it has also been emphasized that the tensions which arise between different ways of thinking are only productive if there is enough social cohesion in the group (Sol et al. 2013). It is therefore important to note that when we talk about a 'transgressive' learning we are walking a fine line between pushing boundaries and overstepping boundaries, which can result in very different outcomes.

In the search for 'worlds and knowledges otherwise' (Escobar 2004), and the potential for transgressive learning which result from the politics of their encounters, this research aims to explore how concrete intercultural practices can lead to insights into how to imagine and practice the pluriverse in the sustainability arena. Considering that the pluriverse can be made visible by examining ontological conflicts (the unequal encounter between worlds) (Escobar 2012), or what has also been referred to as political ontology (Blaser 2010), our research questions are as follows: (1) How might this pluriverse look like in sustainability practices? and (2) To what extent can ontological encounters lead to transgressive learning? 


\subsection{Methodology: Auto-ethnography and a New Materialist Ontology}

In answering the research questions above it is vital to employ a methodology which allows us to enter (to the extent it is possible) the pluriverse, and to critically represent the interactions which take place. Central to this methodology is the acknowledgment that research is never impartial but an assemblage with its own effects on the event researched comprising of researchers, data, methods and contexts (Fox and Alldred 2015). This is in line with the increasing skepticism in the postmodern world regarding the objectivity of the researcher, the generalization of knowledge claims, and the realist agendas where the researcher is put above the subject and the method over the subject matter (Spry 2001). In accordance with NMO ontology we decided to use the analytic auto-ethnography method (Anderson 2010) as a way of acknowledging the role of the researcher and its affection to the research assemblage during fieldwork and in voicing the results. Analytic auto-ethnography involves three aspects which can be seen in our methods:

(1) We are full members of the researched group or setting: Participant observation was carried out by the first two authors who immersed themselves in the network studied (C.A.S.A. Colombia), where the first author gradually became actively involved in the organizing committee of El Llamado. Both authors have participated in several Llamados since 2011 and have carried out informal and semi-structured interviews during El Llamado of 2014 and $2015 .^{25}$

(2) We are visible in the resulting texts: As witnessed by the opening paragraph of this paper, and as will be seen in the first section of the results, a narrative is introduced to communicate findings using the tools of storytelling. This involves employing 'new ethnography' (Goodall 200) techniques to generate "creative narratives shaped out of a writer's personal experiences within a culture and addressed to academic and public audiences." (p.9). Employing personal voice also contributes to the idea that research is performative (Law 2009). ${ }^{26}$

\footnotetext{
${ }^{25}$ The third and fourth co-authors contributed to the research process through research design, visits to the field site, and analysis.

${ }^{26} \mathrm{~A}$ good example of a monologue written in this way can be seen in the work of Mario Blaser who in his book 'Storytelling globalization from the Chaco and beyond' (Blaser 2010) engages in knowledge practice grounded in a relational ontology, advocating a pluriverse where other forms of knowledge and ontologies are accepted.
} 
(3) We are committed to developing theoretical understandings of broader social phenomena: As researchers the focus is on the role of enacting the pluriverse in activating transformative and transgressive learning processes which are been increasingly acknowledged as imperative in sustainability processes for social change.

\subsection{Enacting a learning pluriverse: The collective process of El Llamado}

"We are servants of this humanity, as souls we are all drops of the same sea, love is our nourishment to sprout. To be slighter than the grass and more tolerant than a tree, our heritage is humbleness." (Yayati, Hare Krishna devotee from the community Varsana)

"We are the humanity that is sprouting, cells of the earth remembering, a joyful singing rainbow, to awaken all of mankind" (Tatiana, Ecovillager)

'We are 'taitas', 'mayores' $y$ 'mamitas' -[names given to Indigenous elders, men and women respectively] - we receive the message from the mountain, and together we will construct a new tomorrow" (Camilo from the community Tal, Cundinamarca). ${ }^{27}$

The gathering El Llamado began in 2006 when pioneers in the Colombian ecovillage movement $^{28}$ gathered in the Colombian ecovillage Pachamama to share experiences in a family setting and explore ways to foster a social movement. The gathering remained very much a small ecovillage affair until 2012, when the organizers came together with ecovillagers from different parts of Latin America and Spain to form the Council of Sustainable Settlements of Latin America (C.A.S.A.) with the vision of articulating a broad diversity of initiatives beyond the ecovillage realm around different ways of understanding and practicing sustainability

As of today, C.A.S.A. Colombia has been building up the network with initiatives which exert "views of sustainability different from those of 'mainstream' (including the government) who see

\footnotetext{
${ }^{27}$ These are the last verses of the song written by several participants during El Llamado. The first author invited other participants to add verses to the song - a Hare Krishna devotee, a female ecovillager, and a teacher from another Indigenous community were inspired to add to the lyrics.

${ }^{28}$ An ecovillage can be defined as "a planetary knowledge community grounded in a holistic ontology and seeking to construct viable living systems as an alternative to the unsustainable legacy of modernity" (Litfin 2009:125).
} 
nature as a human resource... but instead consider nature as an entity endowed with spirit, which the human being is caregiver, and with which we want to cultivate a deep spiritual relationship that involves changing our role in the world" (C.A.S.A. institutional documentation). This endeavour has led organizers and participants to immerse themselves in a process of assembling visions and practices of sustainability across many cultures through experiential learning, thus encountering all the challenges of such processes along the way.

In this section we first provide an auto-ethnographic narrative as a way of presenting the transgressive learning experienced by the first author during El Llamado of 2015, in which she was a participant as well as an organizer. In the second part we bring specific examples of ontological politics, which surfaced during the two Llamados of 2014 and 2015, demonstrating further possibilities for transgressive learning through encounters of difference.

\subsubsection{A glimpse into El Llamado de la Montaña, 2015}

"It is the 5th of January, 2015, and I am on the bus entering the Misak territory. Looking out the window I see a beautiful landscape full of rolling hills and mountains. I have seen them several times before, but this time they look different. What I know now about this territory and how it relates to its people has changed my perception of these mountains. They have become alive to me. With a little help from my imagination I see the hills as noses, the mountains as heads, breasts and legs, the small houses as eyes and the clouds as hair or beards, moving in the wind.

After arriving to the pueblo Silvia, it is time to walk up into the mountains along a beautiful river which leads to the Misak University. Curious faces follow me from the houses I pass by, and perhaps this is not strange as before me and behind me there are other 'backpackers' walking the same path as me. This is certainly not so common in what the Colombian government describe as an 'insecure and difficult region.'

As I walk the final steps to the Misak University I reflect on my process of trying to understand the Misak peoples' relations to their territory, and on how these relations influence the way they think and act. How much will participants manage to understand in five days of coexistence? 
Misunderstandings have been common in organizing El Llamado together with the Misak. After each visit I have always carried the feeling of not getting the whole picture of our relationship, and not being able to entirely explain these differences. During the few times I thought 'I got it,' later events proved the contrary. It is not a question of language; it is a question of how our individual and collective worlds work and how we experience them differently. For example, while as an organizer I was more concerned about the logistics of food, accommodation, the scheduling of activities, and special guests, the main concerns of the Misak organizers were the possible harm to the energy of the territory and the fear/excitement of sharing their knowledge with us. They argued, for example, that after their medicine men consulted the territory, it was decided that the temascal (ritual sweat lodges from the Indigenous people of North American which are run by healers in every Llamado) where not possible to carry out during this version of El Llamado: "Our territory is of water and the temascal is a ritual of fire. If we carry it out here we can create an imbalance in nature and even wake up the volcanoes" (Misak organizer). ${ }^{29}$

With all this in mind, I felt the pressure of my anxiety: How will these different worlds meet and connect? How are the relatively reserved Misak people going to face the numerous hugs and other physical contact that are the 'menu of the day' during every Llamado? How are other participants going to deal with all the rules and rituals surrounding the care of the Misak territory?

The first challenge I encountered was during the registration for the event when we had to ask women if they were going to be in their menstrual cycle during El Llamado. This was a shocking question for many, and difficult for me to ask. Even more shocking was the information that if they were in their cycle then they could not help in the kitchen or cross any streams of water, they had to have a special cleansing and harmonization ritual and they could not attend the highly anticipated Minga - the collective work party. The look on the faces of several of these urban-based women was of utter disbelief. Equality? Segregation? Discrimination? I tried to explain the complexity of this 'territorio despierto' (awakened territory) of the Misak people and make them feel positive about their situation. The network of 'women circles' had organized a special event just for the women with 'the moon' (as they call women in their menstrual cycles)

\footnotetext{
${ }^{29}$ Later on an organizer of the Llamado spoke to a well-known Misak elder who did not attend the event who mentioned that temascales are in fact carried out in the Misak territory. This suggests that there are different interpretations of the Misak traditions.
} 
where they could sit with the women elders from the territory to better understand the relation between their 'state' and the territory. Though perhaps not convinced, several of these women accepted the invitation and followed the instructions. It was satisfying when one of these women came to me in the lasts days of El Llamado to tell me that the highlight of her experience had been the circle of women. Through this experience she had been able to connect with her innerself through the stories of other women. She dealt with personal issues and was able to grasp the opportunities and the magic of being a 'woman with the moon.' She also told me of learning practical things about sustainability, such as the option of using cloth pads or women cups instead of disposable pads, and about the importance of bringing feminine qualities (such as caring, emotions, and flexibility) into her job and everyday life.

Late in the afternoon, the cleansing of participants was programed. Participants were asked to sit in a horizontal line behind a group of medicine men who were 'speaking' to the territory. Without an explanation, people accepted the situation and waited for something to happen. After two hours nothing had 'happened'. The medicine men stood gazing out into the mountains, whispering softly to the wind, while participants began to feel cold, tired and bored. Hare Krishna devotees started singing and people quickly joined in - songs about taking care of mother earth - as a means of lightening the mood as well as a means to join in the message of harmony with the territory. Well, the medicine men were not happy about this; they informed me that the noise and energy was making their job more difficult. Yet how could we stop the singing if this was the way people were dealing with such a foreign situation? Eventually a thick mist began descending from the mountains enveloping everyone, further decreasing the temperature and silencing the singing. Many participants, tired and cold, started leaving for their tents. At last, a medicine man explained that the mist was the actual cleansing. He brushed each person front and back with a branch soaked in water infused with medicinal plants. The ritual was over; the remaining people stumbled back to their tents in the dark, some confused, some contented, and most just ready for bed.

The next day, during the programed panel discussion on buen vivir (the good life), in which leaders of several Indigenous communities told their story of struggling to establish their good life against the 'development machine,' I was thinking how far removed my personal story was from those experiences. When it was the turn for the ecovillage representative to speak I felt uneasy. I had lived for a period of time in the ecovillage of this representative, and after listening to all the stories of indigenous repression and resistance I wondered what the ecovillage world 
could contribute? Jorge, the ecovillager speaker, began by explaining the role of the mestizo of urban origin in bringing back sustainability in practice to mainstream society. He talked about our need to learn from native communities how to reconnect with place and nature, but also about day-to-day struggles of dealing with waste management, and the loss of spirituality and hope in youth. This was confirmed by the next speaker, the Colombian ex-senator Gloria Cuartas stating that we (the audience) need it to become 'the geography of hope' to heal this country in conflict, Colombia. I felt inspired again and more secure of what I could offer to others.

Part of my volunteer duties was to help in the kitchen, but when I arrived there was chaos. People were passing through the kitchen on the way to their tents; one group of people were chopping carrots, while others were singing and talking around the fire where the food was being cooked. I felt sorry for the woman in charge of the kitchen who appeared stressed with all the bustle. Together with other C.A.S.A. organizers we tried to organize the flow of people through the kitchen and asked the singers and those just hanging around to leave the kitchen. Suddenly I was stopped by the Misak mamita in charge of the kitchen who asked what I was doing. "I'm helping you organize the kitchen - you looked stressed" I replied. "No, no, no," she told me. "My kitchen is open for everyone, I like having people around; this is the Misak way. Everybody is welcome, all activity and learning starts from the 'fogón' [wood stove] - it is the heart of the community. I'm not stressed because of all the people, but because those who were supposed to come and help prepare the food have not arrived. I'm running late with the lunch!" I felt ashamed to have imposed my perception of a chaotic kitchen by assuming it was the same for everyone. And also frustrated with so much talk about showing love through serving the other, but so few people actually helping in the kitchen. So I stepped out of my organizing role, and joined a gossiping group of Misak women peeling potatoes and good naturedly teasing a Norwegian participant who was helping them and trying out words in their language. I sat down next to Gobinda, a Hare Krishna woman, who shared this reflection with me: "The Misak territory teaches us unity, order, expansion, and brotherhood. Look at the way they organize the kitchen tasks. I generally organize the kitchen of my community by having everything prepared at the same time... five people are in charge of peeling potatoes, while three are in charge of chopping onions, and so on. Here it is different: we all sit and peel all the potatoes, then we all chop the onions...l interpret this as a teaching: is not only about getting the job done efficiently but being together - united in everything we do". 
The day ended with the magical night in which Anthakarana, a family ecovillage of artists, performed what they call the ritual-theater, where they combine sustainability issues with rituals of different origins, which are carried out in interaction with the audience. They asked people to light the candle of the person beside them and to move together as a united group around the fire in the middle of the Misak University hall, calling out visions of how a new humanity could be. Faces of people began to light up with each candle, I saw Indigenous, afro, white, mestizo faces; I saw foreigners, locals, youth, children, elders, women and men. This was a powerful experience with over 300 candle-lit people moving together. At the beginning I felt concern with so many candles around me: my hair! - I thought. I started to think of all the things that could go wrong. But after a while, my mind relaxed and I concentrated in following the movement of people around me. I started to feel trust - 'we are all taking care of each other' I told myself. In that moment I felt like the room became the whole world with all its diversity, I felt that the fire was also dancing amongst us. I started to feel joy in my heart as I was able to feel connected with all forms of beings, all holding one similar wish: to live in a more sustainable and harmonious world. I felt like a large family surrounded me. Perhaps the collective process of acknowledging plurality is the first step in building any long-term sustainability, I thought to myself, and trusting the process the second step. This new insight transformed the way I now see sustainability issues. (Martha Chaves, 2016)

\subsubsection{Ontological hotspots and their dissonance}

As we have seen in the previous section, the diversity of participants and types of activities carried out during El Llamado bring about a number of encounters of difference. What we will look into now are two 'ontological hotspots, ${ }^{30}$ which created a high degree of dissonance between participants, providing the potential for transgressive learning.

\subsubsection{Hare Krishna 'house rules' and the rigidity of ontologies}

El Llamado of 2014 was held in the ecovillage Varsana, Cundinamarca, which is a sacred monastery for Hare Krishnas along the Vrinda line. ${ }^{31}$ Under the hierarchical guidance of their guru Swami B.A. Paramadvaiti, devotees follow the teachings of the sacred Vedic scriptures, in

\footnotetext{
${ }^{30}$ We use the term "hot-spot" to denote a situation or activity which was commonly approached very differently by participants of El Llamado who held different ontologies, and thus were a source of dissonance.

${ }^{31}$ The Vrinda line is one of the forms of Hare Krishna practiced around the world.
} 
which the ultimate goal is the service God. This all-encompassing philosophy of serving God is witnessed through the practices of simple living, serving others and constant prayer through the repetition of the Hare Krishna mantra. The Hare Krishna community has a hierarchical organization, in which the spiritual guide plays a strong role in teaching Vedic scriptures to its followers and in making decisions. Consequently, the 'house rules' of the monastery are well defined and strict: nudity, sexual relations, consumption of meat, the use of any kind of stimulants (including coffee, alcohol and cigarettes) and even campfires are strictly prohibited in the sacred grounds of the monastery. Although nudity and the use of drugs and alcohol are also prohibited by the organization of El Llamado, 'power plants' ${ }^{32}$ such as tobacco and coca leafs are used for rituals, and sexual relations in private places are allowed, as well as consumption of coffee. Furthermore, fire is a strong symbol for several C.A.S.A. members, who consider it a sacred living entity to be invited to impart wisdom during ceremonial conversations such as the mambeo. Elders light a sacred campfire during the opening ceremony of every Llamado, and is kept going during the entire event, day and night. ${ }^{33}$

During the organization of the event it became clear that emphasis would have to be placed on respecting the 'house rules' in Varsana, while negotiating ways for participants to express their own ideas of sacredness. C.A.S.A. organizers made an effort to make the 'house rules' clear to participants during the event and to invite them to following these rules as a means of showing respect to the welcoming host. The Hare Krishna hosts also compromised by allowing the mambeo campfire in the monastery grounds, as they understood it's spiritual purpose, but under the condition that it was only to be lit and maintained by Indigenous elders.

At the early stage of the event participants found ways of negotiating some of these house rules. A group of coffee lovers met every morning outside the property grounds of Varsana to share coffee prepared on a camping stove, while another group hiked to a nearby hill to smoke cigarettes. These early morning activities were for some the means to joyfully bear the rigidity of the house rules and express freedom of choice, as some conversations around the coffee conveyed. Nonetheless, a few participants were not able to follow the restriction on campfires

\footnotetext{
${ }^{32}$ The term "power plants" is given to plants used for rituals which have the property to induce other states of consciousness.

${ }^{33}$ Since the beginning of El Llamado, sacred fires have been lit at each event and are kept going by organizers and participants (often elders) who commit to taking responsibility for the fire. In the closing ceremony the altar candle is given to the next host, as a symbol of empowerment for the next Llamado
} 
and decided to start their own campfire in the middle of social activities to the surprise of devotees and C.A.S.A. organizers. Arguing that the fire was their means of connecting to the earth and of celebrating life, they refused to put it out after a polite request from a Hare Krishna organizer, and it took the heated words of C.A.S.A. organizers and other participants for the fire to be removed.

Further discord grew out of the Hare Krishna philosophy and practices around food and the art of cooking, which is sacred to them. As Nitia from Varsana argues, "Food for us, as we offer it, is more a spiritual food. Of course is also for the body but is more to feed the spirit." The preparation and consumption of food is based on the ahimsa principle, which in Sanskrit denotes non-violence and compassion, and is related to karma. According to scriptural guidelines, if an animal is killed before its time in that particular body, it cannot be promoted upwards to the next species in the spiritual evolutionary scale. Not killing animals is therefore a way of showing compassion and respect.

In accordance with strict vegetarianism, Hare Krishnas have a strict etiquette in the kitchen and for serving food. One needs to be clean, bathed, have good oral hygiene and one cannot taste food or eat anything during cooking or serving (this includes tasting the food before it is served). An important part of El Llamado, however, is the 'loving service' in which participants are asked to volunteer in communal tasks, such as helping in the kitchen. Unlike the Misak who see the kitchen and the fire as a meeting and learning point, the Hare Krishnas found it challenging to have participants not of the faith aid in food preparation and cooking. How could they be sure people were properly bathed and clean? Would they be imparting the right reverence to the food? Problematic situations arose when some participant arrived to the kitchen chewing coca leaves, which was perceived as eating by devotees and hence the participants were initially refused entry. Participants argued, however, that in their ontology chewing coca leaves was sacred and a form of meditation and connecting with the 'great spirit' and were very disappointed at not being allowed to help. In another example, a participant who was a professional chef was most disappointed when his specially brought cooking knives were refused entry to the kitchen as they had previously been in contact with meat, and thus defied the principle of ahimsa. This participant expressed his disappointment, as according to him food 
making was one of the few activities he saw the possibility of sharing and connecting with Hare Krishnas. ${ }^{34}$

Adding to this discomfort of the rules of the kitchen was the actual practice of vegetarianism. The organization of C.A.S.A. programs vegetarian menus for El Llamado as many members are vegetarian and to lower costs of the event, while at the same time providing opportunities for meat-eaters to experience different types of foods. Yet many participants do not consider themselves vegetarian. Several claim that animals are part of the web of life, together with humans and plants, thus respect towards them is shown by the way you breed them and by the compassionate way you kill them, thanking the animals for their sacrifice and ensuring no waste. On the other hand, some strict vegetarians (which were not only devotees) argued that what one eats is directly related to one's level of spirituality, implying that vegetarians have a higher level of conscience than those who consume meat. This ontological difference generated dissonance during El Llamado and got as far as the awkward situation of having some Mamos (highly acclaimed spiritual leaders from Indigenous groups of the region Sierra Nevada of Colombia), excusing themselves for consuming wild meat which they argue is needed to enrich their diets high up in the mountains where they live. Moreover, when writing the final declaration which would represent the voice of all participants of the gathering, the C.A.S.A. organization refused to include vegetarianism in the text as it did not represent all C.A.S.A. members. This created tensions and until today a joint declaration has not been signed.

Unable to resolve these tensions the Hare Krishna organizers became increasingly stressed. Devotees called an urgent meeting with their spiritual leader Swami B.A. Paramadvaiti who arrived during the event, to ask for guidance. A devotee shared the defining outcome of the meeting: "Swami Paramadvaiti told us that the main idea was that people should feel good and accepted in Varsana, for them not to feel in such a strange place that they would not want to get involved. He told us to be flexible if other's intentions were good and were done in a loving manner." This message relaxed devotees who became more flexible and tolerant to the transgressions of participants. Since the 2014 Llamado, the involvement of the Hare Krishnas has grown. In 2015 there were Hare Krishna facilitators and participants in the Misak University,

\footnotetext{
${ }^{34}$ In a later conversation with a Hare Krishna devotee it was remarked that there are in fact cleansing ceremonies which can be undertaken to cleanse utensils which have been in contact with meat. For whatever reason such a ceremony was not suggested or carried out at the time.
} 
but although they helped in the kitchen and joined all activities, they also quietly prepared their own food in their tents when conditions in the kitchen did not meet their requirements.

\subsubsection{Learning about power relations through ontological encounters}

El Llamado of 2015 was held at the Misak University in the territory of Guambía. As an informal university, its purpose is to prepare young leaders to work in their territory in accordance to their ancient wisdom and customs. According to the Misak cosmology, their territory is alive and it is important to exert close relationships to it through their customs. For example, as the Misak people originated from the highland lagoons of their territory, they consider these areas sacred and it is where their ancestors guard the 'wisdom of all times.' Consequently, they devote up to $70 \%$ of their territory to preserve the lagoons and paramos (cloud forests) in which the water of their territory is born (the other $30 \%$ they inhabit).

As a knowledge community attempting to bring back traditional knowledge and practices which are being lost due to a history of colonisation and now modernity, the Misak University saw the possibility of forging an alliance with C.A.S.A. as a means of promoting territorial discussions, albeit within a context of deep suspicion by several students and teachers towards foreigners. ${ }^{35}$ Miscommunication caused a major rift already before El Llamado began. Unlike the hierarchical decision making process of the Hare Krishna community Varsana, the Misak university has a more horizontal (though multilevel) platform. The director of the University is the governor of the Indigenous territory Guambía, and decisions are made together with academic directors, coordinators, and to a degree, students. The C.A.S.A. organization committee followed protocols by asking permission to carry out El Llamado from the governor and the university coordinators. However, this permission was given before students were informed. This caused discontent among some students who stood up against El Llamado arguing that it represented an outsider agenda to 'steal' their knowledge and impose western ways. C.A.S.A. organizers attempted to mend the situation by explaining the philosophy of El Llamado directly to students, emphasising that all activities would be respectful to their territory and traditions, and that they were invited to share as much as they felt comfortable with.

\footnotetext{
${ }^{35}$ Based on a history of colonialism, marginalisation through government policies, academics writing about their traditions without their approval, and economic challenges of globalisation, many Misak see the possibility of having their knowledge and resources exploited by outsiders who visit their territory.
} 
Although some students decided not to attend, others embraced the event, eager to exert their knowledge by ensuring that the meaningful practices and rituals of the Misak people were carried out in the proper way. Protecting these relations, the desire of students to take charge and 'protect' their territory led to several incidents. One of the students (a skeptical opponent to the event taking place) took the opportunity to practice his studies into Misak medicine and rituals, and letting people believe he was an expert, conducted a cleansing ritual to harmonize the energy of the C.A.S.A. organizers with that of the territory. Afterwards, organizers were told that because the ritual was carried out during the day (and not the night) it did not count, and that a Misak elder with more expertise would have to repeat it (this was the cleansing ritual described in the previous section).

Another important point within the Misak ontology is the relationship with el abuelo fuego (grandfather fire). It is around el fogón (the hearth fire) that from an early age knowledge is imparted by family and elders. In keeping with this tradition, a central hearth fire is continuously burning in the main University hall, around which many discussions are held. During the event, Misak organizers decided to appoint one of their teachers to maintain the central fire, which involved nurturing it by placing the logs in a special way, and periodically feeding the fire with tobacco and coca leafs. ${ }^{36}$

It is not clear why the Misak organizers chose this person to take care of such important Misak tradition, as he himself was not a Misak person born in the territory but of urban origin. Nevertheless, he was a knowledgeable academic, who knew not only about the Misak traditions but also had contact with other Indigenous groups of Colombia. This task gave great authority to this person who meticulously controlled the fire and those helping him. However, as the days passed by, the situation became an increasing source of tension as the teacher became rude and impatient with those around him, reprimanding those who were not 'following' the Misak ways. On the energetic level, non-Misak elders began talking of a strong negative energy pervading the event, and hence the need for neutralizing the situation at the energetic level. C.A.S.A. organizers and participants tried to remain open minded and respectful of the teacher's appointed role, but tensions became unbearable when his actions increasingly became

\footnotetext{
${ }^{36}$ This role of maintaining the fire involved a lot more than this, but this was what we were able to capture through participant observation, as the Misak were not willing to share details about this responsibility.
} 
offensive and divisive. Misak organizers were informed of the situation and all parties agreed to talk around another fire to understand what was happening. After a long session where the teacher kept verbally attacking the event and its participants, one of the highest ranked Misak organizers stood up and stamping the floor with his staff, stated: "I am Misak, I am my territory, and I only accept the positive. What I have seen here [in this event] are only positive things for my territory." Everyone stood up in support of this statement, and although asked to stay, the teacher left the event. With this episode, the role of elders as keepers of harmony at the energetic and spiritual levels was better understood by C.A.S.A. organizers, who were unaware of the struggles at this invisible level. Furthermore, organizers began to understand the extent to which roles and positions appointed during El Llamado give power to people, thus they must be well understood and only given if strictly necessary, as power struggles can cause a disharmonized environment not conducive for learning and for social cohesion.

\subsection{Discussion}

"One feels that nobody is right here, I mean, nobody owns the truth...each person is a link within the chain we are all part of." (Anonymous Participant of El Llamado de la Montaña, 2014).

The above results sections have attempted to show what it would mean to experience an intercultural gathering from the perspective of a pluriverse. By bringing the reader through a day in El Llamado, and highlighting two ontological 'hotspots' of potential transgressive learning, we have witnessed something which at least hints at the encounters between different worlds. What we want to bring to the discussion table now is the extent to which we can talk about a pluriverse in practice, and how engaging with these worlds can lead to transgressive learning towards more sustainable living.

Reading through the results section it becomes clear that our modern day anthropocentric distinctions between humans and nature do not articulate well with what takes place in intercultural events such as El Llamado. Non-human actors such el abuelo fuego (grandfather fire) and the territory as a sentient being square better with a relational ontology which attempts to break down the divisions between nature and culture, us and them, and individual and community. Yet no matter how we talk about wanting to be open minded and inclusive to other ontologies, engaging with them in practice can be extremely difficult. Although a 'cleansing' for 
the territory may be necessary for harmonizing energy between people and place, a four-hour long ritual with no information outside in the cold is a difficult task. Similar would be not to be able to participate in most community activities because one has 'the moon', or not being able to cook with knives brought from home because they have been in contact with meat.

Yet we can argue that from the examples above, to some extent, transgressive learning has taken place. Having managed to transgress her moral boundaries on equality and male/female relations, the participant on 'her moon' managed to engage and reflect on her own femininity not only in the context of the event, but also in her own day-to-day life. This was made possible through a woman's circle where these issues were discussed and rituals took place. The situation with the teacher also brought up learning points on the power of traditions and unseen forces, and the necessity of valuing energetic levels in resolving these tensions. Compare these examples to the situation of the participant whose knives were denied access in what we can see as an 'ontological impasse' where little positive learning has taken place. As one Hare Krishna devotee noted in retrospect (see footnote 33), a ritual cleansing of the knives and a reflexive talk around the principles of ahimsa could have been carried out, and if this had occurred together with the participant then a two way conversation could have taken place in which the two parties came to some form of understanding, and perhaps even a compromise. On a more collective scale, the ritualistic cleansing would have been an opportune time for the Misak to bring the participants into their world, explaining about the harmonization of energetic levels, and really creating an 'experience' which would cross boundaries of reason and meaning. Instead, at best, the cleansing maintained the mystical quality of people with a very different ontology, and, at worst, maintained a disconnection and a barrier to entering the world of the Misak.

The role and power of those that mediate between different worlds brings us to the second point. As noted about the pluriverse in section two, there is no one logic that can mediate between the power-saturated realities of different worlds (Law 2011). This means that issues of power arise when negotiating these different worlds as there is no one person who is 'right.' Yet each respective ontology has representatives of power. In the hierarchical ontology of the Hare Krishna, the guru holds ultimate power through the interpretation of the ancient Vedic scripts, and it was to him devotees came with their concerns over the transgressions of non-Hare Krishna participants. It was a positive sign to the devotees, participants in El Llamado, and possibilities for greater sustainability processes that a leader of such a religious community had 
the capacity to be flexible in the rules of the community and was able to grasp the type of inclusive social tissue being created beyond a single 'truth.' In the community of the Misak University, however, power is held by University directors and students, and wielded through the elders and medicine men who are knowledgeable of the customs and traditions of the community and have the power to communicate with the territory. It is ultimately they who can communicate with other entities through rituals such as the mambeo and the cleansing, and decide what is allowed and what is not.

Consequently, when we talk about a decolonization of knowledge where equal importance is given to different ways of knowing and being, we must be prepared for a strong degree of inflexibility in ontologies, and ever present power negotiations between those who represent each ontology. As the example of the teacher demonstrated, the capacity to understand (or at least represent) an ontology can give tremendous power, and his inflexibility and aggressive stance in upholding what were for him Misak traditions created tensions and disrupted relations between the organizers and participants. It is then interesting that unlike the top-down conflict resolution of the Hare Krishna community (without dialogue between the parties) Misak and C.A.S.A. organizers were able to sit down around the fire to discuss the conflict with the teacher. For one of the Taitas to stand up against the 'negative energy' of the teacher demonstrates a negotiation of power between representatives, though unfortunately after this negotiation the teacher left and there was no opportunity to continue a reflection on the situation which could have resulted in deeper learning for all parties. Nevertheless, for C.A.S.A. organizers this became a source of learning in understanding the invisible power struggles that emerge when enacting the pluriverse.

So what does engaging with the pluriverse tell us about facing the sustainability challenges of our time? Well clearly a 'world in which many worlds fit' is an exciting but rather utopian idea, at least at this point in time. Accustomed as most of us are to our own ways of thinking and being, accepting different realities and what they imply, as this paper has shown, is a long and complicated process. Although there may well have been transgressive 'moments' for participants and organizers, for it to be called learning implies a long-term process in which structures are not just broken, but also to an extent surpassed. It is perhaps better to think of a transition towards more inclusive understandings of other worlds and their sustainability practices. This does not necessarily mean a harmony between different ways of being sustainable, but at least a conversation as equal partners. El Llamado represents an attempt at 
such a transition through a tangible engagement with the pluriverse whereby, for example, participating in a cleansing, a sacred march and in a collective effort to 'plant water' participants have the potential to gain insights into different enacted realities where harmonizing foreign energy and planting trees increases the territory's satisfaction and thus creates water in the mountain's lagoons through which the ancestors guard the territory's wisdom. At the same time, however, the initial inflexibility of the Hare Krishna community clearly created a lot stress for the devotees and divides between participants and the host community, as well as the divide, in the Misak case, between those who can communicate with 'earth beings' and hence represent and control that ontology in its relation to others.

It is therefore worth ending this discussion with what we can view as both an inspirational as well as perhaps naive message from the Hare Krishna guru and the Misak Taita: only the positive is welcome - if things are done out of love and good intentions then we should be flexible enough to allow for their manifestations and embrace the challenge that they bring to us as stimulants to improve our own ways. Although this philosophy contributed to the reduction of tensions during both events, crossing boundaries in both ontologies and leading to a learning about overcoming set norms and power relations, it also raises the issue of the extent to which we should compromise what we believe in in the name of a tolerant and inclusive social tissue, especially if we should consider other ontologies inherently unsustainable and unfair. Vegetarianism is an example of an issue in which no compromise could be made at the level of writing a common manifesto. With the complexities of different ontologies, it could be useful to keep in mind the idea that our understandings with other ontologies will only ever be 'partial connections' (Strathern 1991) in which different ontologies are entangled with one another, and which we will never really 'get.' Hence, a question which is left for further research is how can we make a better use of these 'partial connections' to engage the pluriverse in transitions towards a more sustainable and inclusive future?

\subsection{Conclusion}

To sum up this chapter, the main findings are that engaging with the pluriverse forces us to encounter differences in other people and in ourselves, which has the potential to make us reflect on our own norms and habits. This means leaving our comfort zones and experiencing other worlds where territories are literally alive, where food being prepared cannot be tasted out 
of respect for serving God, or where women 'on their moon' have such strong and sacred energy that they cannot participate in communal activities. In a context of entrenched unsustainable practices which most of us partake in, such experiential learning can be transgressive to the extent that we really manage to cross the boundary of our own personal bubbles and embrace not just the idea that we are different, but also what this means in practice.

It is important to note, however, that this is no easy process. As our example of El Llamado de la Montaña has hopefully demonstrated, organizing, facilitating and participating in intercultural settings, which are generative to transgressive learning, is a challenging endeavour. Diversity in itself is no panacea and often leads to misunderstanding and even conflicts, which must be addressed if learning tolerance, reflexivity and new ways of living through difference and conviviality are to take place. Ontologies are not just very complicated; they may be more or less rigid and saturated with power, and negotiating them in the name of crossing boundaries towards different worlds will require new types of knowledge, skills and methodologies for the future.

Lastly, not all people are willing to engage and experience the pluriverse as it means leaving the safety of a single 'truth' and predictability of one's own comfort zone. This is a challenge for the pluriverse which implies participation by many actors. During El Llamado there is a pronounced absence of mainstream politicians, government officials and businessmen which gives the event a feeling of alternativeness, and hence marginalization. The extent to which processes in intercultural events such as El Llamado can be scaled up and appeal to a wider audience may perhaps depend upon how much individuals and the collective are willing to compromise in what they believe in for a greater common good. This remains a great challenge for El Llamado, as well as society at large as the mainstream is also part of the pluriverse, and articulation with these groups is essential for transitioning towards truly deep changes in society. 


\title{
Chapter 7
}

\section{The Nature of Transformative Learning for Socio-ecological Sustainability}

\begin{abstract}
Authors: Martha Chaves, Arjen E.J. Wals
Accepted for publication with minor changes as: Chaves, M. and Wals, A.E.J. (2017) The nature of transformative learning for socio-ecological sustainability. In: Krasny, M. (Ed.) Grassroots to global: Scaling up community environmental stewardship. Ithaca, NY: Cornell University Press.
\end{abstract}

\subsection{Introduction}

'Learning' seems to be the talk of the town nowadays. Once the exclusive domain of the educational sciences and learning psychology, and often restricted to the formal education of the young and old (adult education), learning has become a key mechanism for realizing things like change, adaptation, innovation and transitions in the context of meeting the grand sustainability challenges of our time. In this chapter we understand sustainability as an emergent property of complex relations, which bring about the well-being of planet Earth, including all forms of life, now and in the future. Such well-being necessitates the processes of living within the constraints of a dynamic equilibrium between continuity and discontinuity, growth and decay, uncertainty and clarity, chaos and coherence, and adaptation and disruption. In this context, the challenges of our time include the rapid loss of biodiversity, disaster management, food and nutrition security, rising inequality, and runaway climate change, to name just a few.

Dealing with such 'wicked' and inevitably interrelated challenges, above all, calls for learning individuals, learning organizations, learning networks, learning communities and even learning societies. This, however, does not imply just any kind of learning; the learning required for breaking with dominant and resilient unsustainable routines and systems is learning which makes explicit and questions our assumptions, values and the ways of seeing different worlds (Wals 2015). This is learning that invites us to continuously reflect on the tensions and contradictions between the above aspects, and which reveals the powers and inequities that tend to keep things the way they are or forces us in directions we may not want to go. In other words, learning that questions what is taken for granted, the normalized, the hegemonic and the 
routine. Furthermore, it is learning that enables us to make changes and to transform others and ourselves, while learning from the process.

To complicate things further, all this needs to happen in a world that is in constant flux - a world where what we thought to be true yesterday turns out to be quite different today. This is a world where what we think works well in the Bronx in New York, may not work very well in de Bijlmer in Amsterdam, and not at all in Temeke in Dar-es-Salaam, or in an ecovillage in Colombia. We might call all this reflective learning or even reflexive learning when such learning has a critical and even disruptive quality in the sense of transforming and transgressing stubbornly resilient patterns and systems that in their essence - at the level of the foundations and values on which they are based - are deemed undesirable.

Being or becoming reflective - let alone being or becoming reflexive - is not something that comes easily or naturally. In fact, people have a tendency to avoid the deeper questions and to steer away from the feeling of unease that is caused by friction, disruptions or dissonance (Barker 2003). Yet it is these tensions and (inner) conflicts that create the kind of energy and questioning that is needed to actually learn in term of re-thinking the way we think, and when the conditions are right, co-create new ways of thinking, seeing and doing. It is assumed that this requires going a little deeper to interrogate the foundations of our practices and to enable participants in multi-stakeholder settings to re-design and co-create new practices that, at least for the time being, are more sustainable than the ones they seek to replace. This connects well with Argyris and Schön's (1974) notions of double and triple loop learning (Figure 13). 
Triple loop learning involves principles. The learning goes beyond insights and patterns and creates a shift in understanding the context or our point of view.

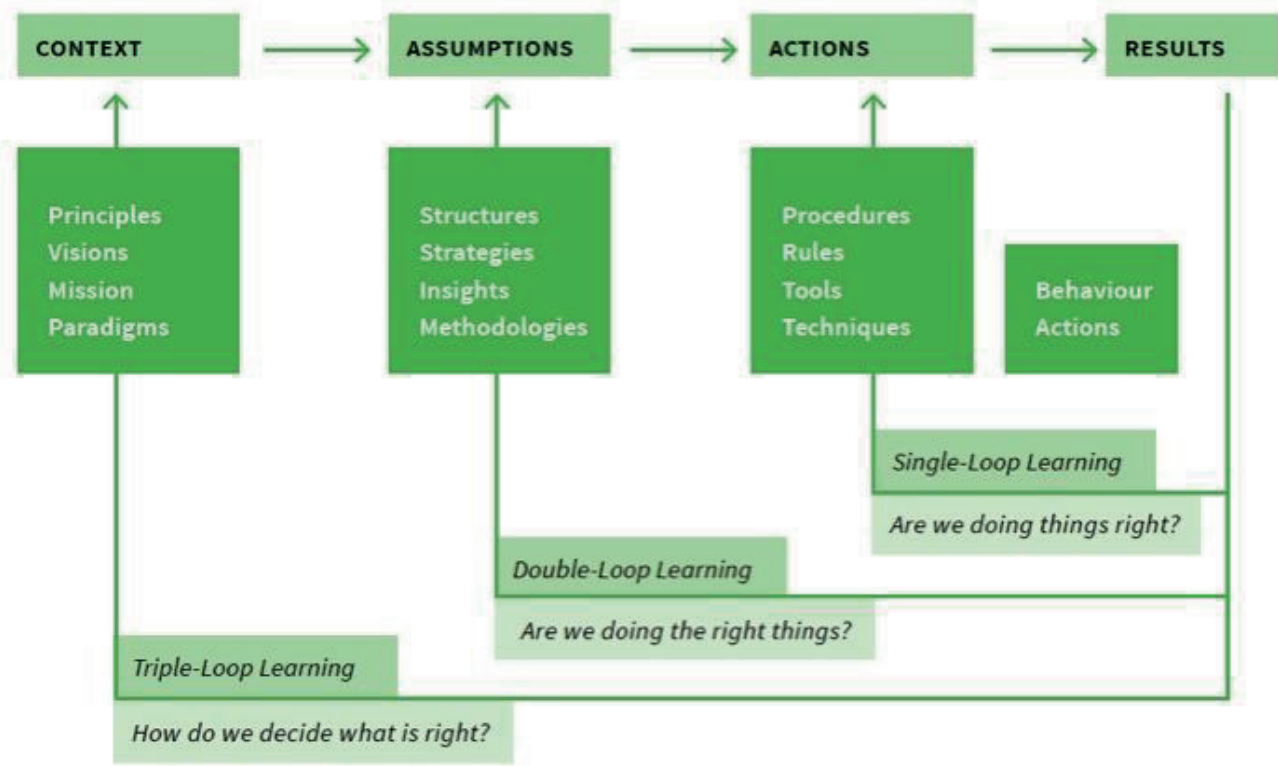

Figure 13. Diagram of triple loop learning based on Argyris and Schon (1974)

Often it is so-called 'boundary crossing' that enables this type of deeper learning - where people, ideas and practices transgress traditional boundaries - to come together to make a change (Akkerman and Bakker 2011a; 2011b). Civic-ecology represents such a space for deeper learning. From a village grove restoration project in South Korea (Krasny et al. 2015), to Community-led reforestation and recovery in post-Katrina New Orleans (Tidball 2014), to reconnecting people to sacred sites and ancestral practices in Bogota (this volume) civic ecology describes everyday people in their home communities setting out to discover, understand and solve local problems through trial and error at the grassroots level, in collaboration with (or sometimes instead of) local, regional or national governments.

It appears, however, that we know very little about both the nature of learning in socioecological and civic ecology practices and the outcomes of such learning. Does the engagement of citizens in boundary-crossing and multi-stakeholder environments make it 
possible to transform and transgress resilient patterns and systems that contribute to 'glocal' systemic dis-functionality? What might be some levers and barriers for such learning and the possibilities for designing spaces - physical and social - that facilitate boundary crossing?

To address these questions we will explore some design principles of boundary crossing in civic ecology, which contribute to more transformative learning. As we have found in the field, these principles are expressed in diverse spaces that emerge differently depending on the context of each case. We will therefore begin by outlining in general the five design principles in section 2 , while in section 3 we will contextualise them in specific undocumented Civic Ecology Practices (CEPs). Furthermore, we will explore the potential of upscaling transformative CEPs through promoting the design principles in a bioregional network, as well as outscaling through national network gatherings based on methodologies that invite communal reflection, diverse ways of learning and the co-creation of shared visions and practices.

\subsection{Design principles for transformative learning}

The first thing that comes into one's mind when thinking about boundary-crossing conditions is transforming our 'wicked' habits through engagement. People are accustomed to being in their social, existential, and physical comfort zones, where they feel safe and in control. People will normally not leave this security unless they have a strong desire to experience something different, or if circumstances force them to. This desire can be compared to being a 'tourist,' travelling to an exotic place, experiencing what it has to offer, but in the full knowledge that they can return to their home environment - their comfort zone. This could be like visiting the family cabin in the mountains without electric or running water, or watching a documentary about shamans in the Amazonian jungle who believe in spirits and the power of dreams. Although these experiences may provoke reflection, it does not necessarily empower individuals to change their frames of reference or question their worldviews, which is arguably the ultimate goal of transformative learning (Moore 2005). The question therefore is how to engage people in an on-going transformative and cross-boundary experience in which people can leave their comfort zone in a reflexive manner, and confront the sustainability issues which affect us all.

Mainly based on transformative civic ecology practices we as authors have been involved in over the years (Chaves et al. 2015; Wals et al. 2009; Wals and van der Waal, 2014), we have found that there are certain principles that resonate in terms of designing transformative spaces. 
These are the following: experiencing a good story; collaborative leadership: embracing organic processes, employing passions and emotions; and promoting plurality for change. In the spirit of collaboration, as well as a means of validation, these principles were shared with the participants of the SESYNC workshop on "Civic Ecology for creating environmental stewardship and socio-ecological well-being" held in Annapolis, USA, in early 2015. The workshop brought together 25 ethnically-diverse community leaders engaged in civic ecology practices and academics, activists and policy-makers from universities, NGOs and governments. Sixteen of the participants, all contributors to this volume, were able to take the time and respond to these proposed principles through an online survey. They were asked to rate the extent to which the principles resonated with their own experiences in their respective fields, as well as to provide feedback and critique through comments. With $38 \%$ of respondents situating themselves as practitioners, $38 \%$ as academics, and the remaining $25 \%$ as somewhere in between (or who did not associate themselves with either label), the feedback is evenly balanced between academics and practitioners. As Figure 14 demonstrates below, all principles either resonated highly, or resonated somewhat. There was also no apparent difference in answers depending on the background of respondents. Next we will describe the design principles, weaving in the anonymously provided comments and feedback from the respondents.

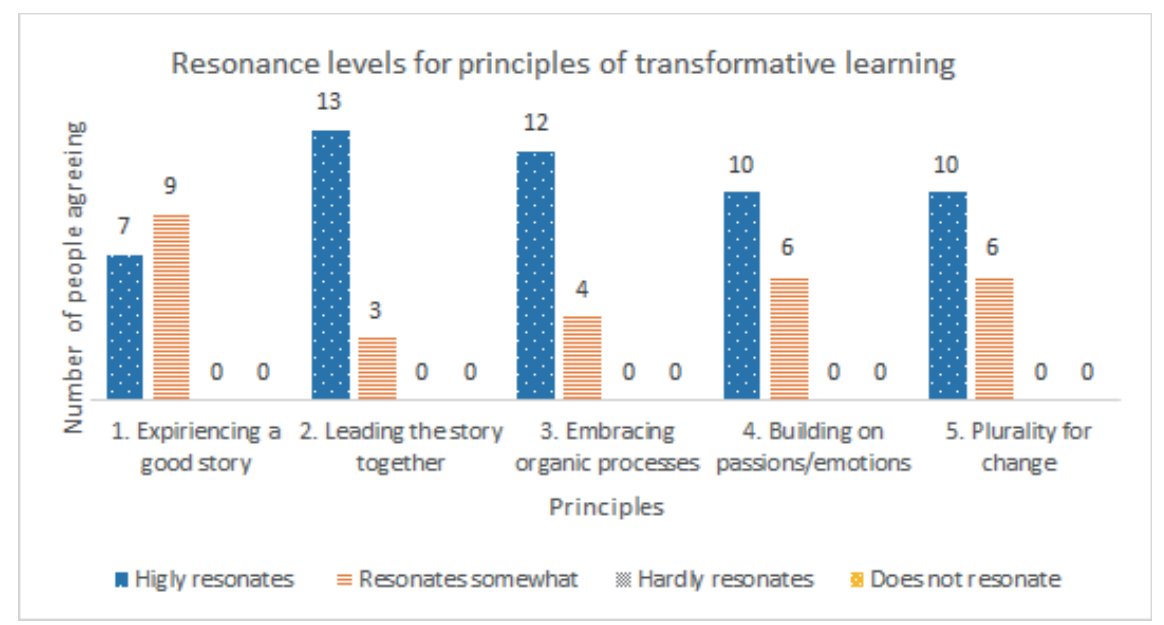

Figure 14. Resonance levels for the principles of transformative learning according to the responses of the survey participants 


\subsubsection{Principle 1: Experiencing a good story}

People are more willing to leave their comfort zone if they are engaging in a cause for which they believe in. Throughout history, there are numerous examples of everyday people and communities, across ethnic and cultural boundaries, which have come together to fight against social injustice and ecological degradation. From the fight against apartheid in South Africa, to the deforestation of the Amazonian rainforest, such battles are generally based on a 'story'; a fundamental way in which humans organize, store and make meaning of information. These stories have converged in recent times into the grand narrative of 'sustainability', in which society is coming to grips with the realization that we humans are to a large extent responsible for the social and ecological damage taking place on this earth, and things will only get worse if we do come up with new ways of living within the limits of the planet.

In this way, it can be argued that the human imposed phase of planetary evolution, referred to as the anthropocene (Steffen et al 2011) has created 'tipping points' in which Krasny and Tidball (2012) argue that coalitions of interests - increasingly including those of civic society - are coming together to confront or propose new ways of addressing pressing socio-ecological concerns. These narratives come in many forms, from the global environmental and social justice movement described by Paul Hawken in Blessed Unrest (2007), to community action groups addressing local issues such food production in community gardens (Krasny and Tidball 2012), and the more extreme eco-militant views of those who want to dismantle the industrial basis of society in order to save nature (McBay et al 2011).

What is interesting is that beyond stories of injustice creating 'bad guy' antagonists with which to take a stand against (albeit the plastic bag or the western model of development), there are other unifying sources promoting new stories of 're-existence' and ways of being in the world. Respondents to the survey mentioned 'finding a voice', and 'uncovering those stories of past success that lead to present possibilities/opportunities'. As one of the survey respondents puts it: "I also believe the energy in what mobilizes and unifies stories comes from places of empathy first, before the commonality of the "bad guy." When the unifying story finds the commonality of self motivation for change the antagonist takes a seat and what unifies them becomes the power they share collectively, not the threat they each are under."

The last point to make in this principle is that the story needs to be experienced to create a change. As one respondent wrote, "I think what gives people the courage to step out is 
"touching the fire", when people live it directly or see the impact of it on someone they love it is more real to them." With narratives such as sustainability and climate change taking on such a global significance, it can feel overwhelming to think about what can be done in one's own sphere of influence. For this reason, practical projects such as community gardens provide excellent arenas for bringing people together to closely interact and respond to a shared narrative, creating spaces for hope and transformation.

\subsubsection{Principle 2: Leadership and power}

Although a good story is important for motivating people into leaving their comfort zone, it is dependent on leaders who are willing to envision a different world, break boundaries, and take action. Their role is to set the scene for new structures to evolve through encountering the chaos and uncertainty of putting forward new ideas, thereby inspiring others who are not ready to leave their comfort zones. Yet this places a great importance on leaders for the success of new projects. As one respondent notes, "the problem of leadership burnout, and/or rigid control, or failure to delegate out of impatience with others, leaves an organization highly vulnerable, and ultimately, fails."

Another respondent therefore notes that beyond motivating and inspiring others into action, good leaders also "...recognize their obligation to build leadership in others and thus, make room at the table for those beginning their journey." This is, however, a challenge, which many projects face, sometimes referred to as the founder's-syndrome, where one or more of an organization's founders maintain disproportionate power and influence (often unintentionally), even after 'stepping down' to let others lead (Christian 2003; Block and Rosenberg 2002). Such power can be operated through rank, which describes how influential someone is in the hierarchy of a group (Brouwer et al 2015). This influence is often established by differences in experience and knowledge. As we have demonstrated through an ecovillage case-study in Colombia (Chaves et al, 2015), the act of a leader coming to terms with his/her inherent rank, and how this effects the project and the people around him/her can be a transformative process of realizing who one really is, and one's purpose in life.

Another path to take is that from the outset the leadership is collaboratively distributed within a group in the first place, and expands and contracts as other join and leave the group. In this way, people can "lead the story together" as one respondent wrote, and "the leadership can come from a community organizing process that itself is cultivating leadership." This type of 
evolving collaborative leadership implies a high degree of commitment and self-discipline to the cause, but rather than one dominant leader giving directions or making space for others, evolving collaborative leadership is about creating conditions where actors across different domains, with different leadership styles, working rhythms and levels of commitment can be empowered to assemble and take responsibility, work together and tackle 'wicked' issues from different angles.

\subsubsection{Principle 3: Embracing uncertainty and organic processes}

We live in an accelerating world where change and uncertainty are constant factors. Through trying to control this uncertainty, we have a tendency to put what we know into neat little boxes, and turn away from the greater complexity of socio-ecological systems which all seems just a little too 'messy'. Yet the deepening global crisis shows that we must begin to acknowledge the embeddedness of all relations and see the bigger picture of how everything is connected, crossing boundaries of knowledge and certainty. It also means recognizing that systems are dynamic, and do not always work as we want them to Brouwer et al (2015). This implies learning to be more flexible and adaptive, comprising of evolving systems and processes.

One way of addressing this uncertainty is through promoting organic processes of change. This involves high levels of self-organization and continuously embarking in cycles of planning, action, evaluation and reflection. This allows spaces for personal and community monitoring of projects and hence their adaptation (Krasny and Tidball 2012; Krasny et al 2014), and reflection and learning loops (Chaves et al 2015; Capra 2009). Important for these feedback loops is a high tolerance for 'failure,' for as Brouwer et al note, "in the evolution of complex systems, there is much failure and just a few big successes that change the system" (2015:62). The important thing is to have the courage to experiment with something new, and use 'failure' as an opportunity to learn.

In our experience and that of several other authors of this book, organic processes boost crossboundary and transformational learning. However, it is not an easy task as one respondent commented, "we are individually and collectively starved for synthesis and discussion time; we don't know how to be nimble problem-solvers or we don't let ourselves; we prefer the ladder (one step at a time) to the web (throw it all out there and find your way)." Another barrier in these types of processes is that in many cases they produce very slow change and because of their complexity they are challenging to upscale. As one respondent notes, "answers evolve 
from observations and we have to be willing to learn, yet there is a mismatch of how quickly those observations will evolve into useable answers to benefit society". Although this may be true, we consider that such smaller and slower processes may act to balance other 'failures' to maintain enthusiasm and a feeling of moving forward.

\subsubsection{Principle 4: Using passions and emotions}

Passions and emotions are what drive people towards taking action, pushing them out of their cognitive comfort zone, and into what might sometimes seem like irrational situations. As one respondent wrote, "Our humanity, our neurobiology, seeks connection and belonging. We are at our strongest when we support this basic human need.' By balancing our very much 'head' based understanding of the world around us, with that of our 'heart' - the way we feel about what is happening - we have a better chance of connecting with the world around us by breaking down traditional barriers such as the human/nature divide, age and gender differences and rational versus intuitive understandings. This is greatly reinforced through opening oneself up to experiencing these emotions: "People are drawn to passionate people who deliver stories and messages that resonate intellectually and emotionally. The ability to get fired up is alive but dormant in too many of us" (Survey respondent).

Moreover, an important aspect of emotions and passions in the civic ecology literature is that of psychological well-being when working with nature (Krasny \& Tidball 2012). With more people living in cities, and being removed from food production and the cycles of nature, it is increasingly important to generate closer relationships between people and nature. What we are looking for is what Capra (2009) conveys as an emotional and passionate climate, conducive to emergence of new structures, which promote mutual support, trust and celebration and a type of learning 'from the heart'.

Nevertheless, as some respondents noted, "emotions and passions can also have the opposite effect causing people to resist innovation and to fall back on fear of change." There is also the danger that emotions may be directed at groups and are seen as the cause of the problem, resulting in an 'us-them' mentality. This can limit our capacities to build alliances through alienating groups of people, and our abilities to compromise in finding workable solutions. This means being careful not to place too much focus on fear-inducing passion for gaining public engagement, which Sterling (2009) argues has been used by some members of the environmental movement, or using emotions as powerful advertising tools when attached to 
products and lifestyles to convince consumers (McGregor 2009). To counter this, one respondent wrote, "We use intensive community engagement to entice people to feel more a part of the community first and then introduce innovative ideas into an atmosphere that already feels safer and more supportive." Through building these affective relations, people can experience a sense of family from the outset, feel supported, and in turn support others: a fellow volunteer becomes a friend, a place becomes a home, and the network becomes a family.

\subsubsection{Principle 5: Plurality as a driver for change}

"Expanding the boundaries of our own understanding is a critical step in changing the status quo". In light of this assertion, given by one of the respondents, we consider that creating and facilitating plural environments plays an important role in pushing people to the edge of their reflexive boundaries. The importance of 'difference' and diversity for energizing people, pushing reflexivity and unleashing creativity, is also exerted by other authors in the social learning arena (Sterling 2009; Sol et al 2012, among others) and the arena of Multi-Stakeholder Perspective (Brouwer et al 2015). What we want to emphasize here, however, is that beyond diversity, plurality implies the engagement of a common society, which includes a diversity of people (ethnicity, culture, worldviews), different beings (nature, spirits, entities), different knowledges (scientific, local, traditional), and ways of learning (classroom, around the fire, artistic).

Plurality is an important concept to address because it encourages us to move away from the idea that we live in a universe - where there reigns one truth, and a 'most' sustainable way of living - towards a pluriverse where many different worlds coexist. Escobar describes this as a

world "ceaselessly in movement, an ever changing web of interrelations involving humans and non-humans" (2012:17). Put in simpler terms, one respondent note that, "This broader definition of diversity is what we used to call open-mindedness. Our tendency to build and live in silos has shut this down considerably. We need to celebrate a convincible mind, so that information and emotion can indeed be transformative."

Yet we must be careful not to over-romanticize plurality. It is more aspirational than fact, and promoting and operationalizing it in practice can be challenging in terms of encountering misunderstandings and disagreements. How many of us, for example, would be comfortable having a conversation around a fire where spirits are invited guests? How seriously would we take what they have to 'say'? Important for negotiating these tensions are what Wals (2011) 
describes as the 'optimal dissonance,' whereby a learner is far enough away from his or her comfort zone to be challenged, but not too far away as to be alienated.

Based on their practical experiences, respondents to the survey wrote suggestions to operationalize plurality in practice by "addressing the need for currently dominant groups (industrialized, western, white, male, etc.), to undertake practices (reading? meditation? listening?), to support a shift in their perspectives to make room for the subjectivity of oppressed and marginalized perspectives," and including financial support in organizational budgets to promote "diversity and inclusion of new voices, ideas, and surroundings to the table." One respondent also made the point that although a culture may appear very western and homogenous at the macro level - say the city culture - at the micro level we are all different. This suggests that in any case - heterogeneous or not - it is of great importance to acknowledge and embrace differences amongst people and with the other non-human voices to achieve optimal dissonance for transboundary learning. As a practitioner puts it, "I have to do this [dealing with plurality] everyday and I'm a better, wiser person for it. Not always the easiest when you think you know all that you need to know about an issue/situation. However, when I'm humbled enough to open myself to the "other, " new ways of thinking and being come into play."

\subsection{Designing and expanding transboundary spaces for CEP}

The principles above are meant to be used as guiding lights in designing transboundary spaces in civic ecology where transformative learning can take place. We will now illustrate some undocumented examples of CEPs connected and inspired through bioregional and national networks in Colombia. These are promoting transboundary spaces for the development of novel relations between people and nature to emerge at the civil society level. By demonstrating the possibilities of uniting diverse people and institutions in spaces for dialogue, capacity building and action, we will illustrate the potential strategies for up-scaling and out-scaling CEPs for transformative learning.

\subsubsection{A city in transformation - the emergence of civic society in Bogota, Colombia}

Described in the early 90 s as one of the worst cities in the world, Bogota, the capital of Colombia with over 10 million people, has gone through a dramatic transformation. 
Campaigning against violence, corruption and nepotism, three contiguous mayoral administrations starting in the mid-90s set about transforming civic norms and habits towards a culture of citizenship through introducing bike lanes, an effective public transport, and city parks. Though still a metropolis with grave problems of inequality and congestion, Bogota is a story put forward of how it is possible to give a city back to its people, creating public spaces and civic pride. (Berney 2010)

Alongside these top-down measures are bottom-up civic ecology practices contributing to this new story of Bogota, many of which are connected to the processes taking place in El Llamado de la Montaña. The examples which we want to share are based on reconnecting an urbanized Bogotano people to their ancestral history, as well as to promote caring for oneself and the local community and encouraging nature conservation through the connection to sacred natural sites in the city. The Eco Sembrando Barrio (Eco-planting neighborhood) initiative is a good example of this where urban activities such as vertical and horizontal urban gardens are constructed together with citizens using recycled material (Eco Sembrando Barrio, 2016). Taking place in neighborhoods of different socio-economic strata, the goal is to foster values of caring and peace. Edible, medicinal, and native plants are cultivated as a form of retrieving what Krasny and Tidball (2012) call 'social-ecological memories' of ancestral knowledge and practices. Photographs of the person who sowed the plant are placed in the pots as a metaphor for planting and caring of one's own 'being' (See Figure 15).

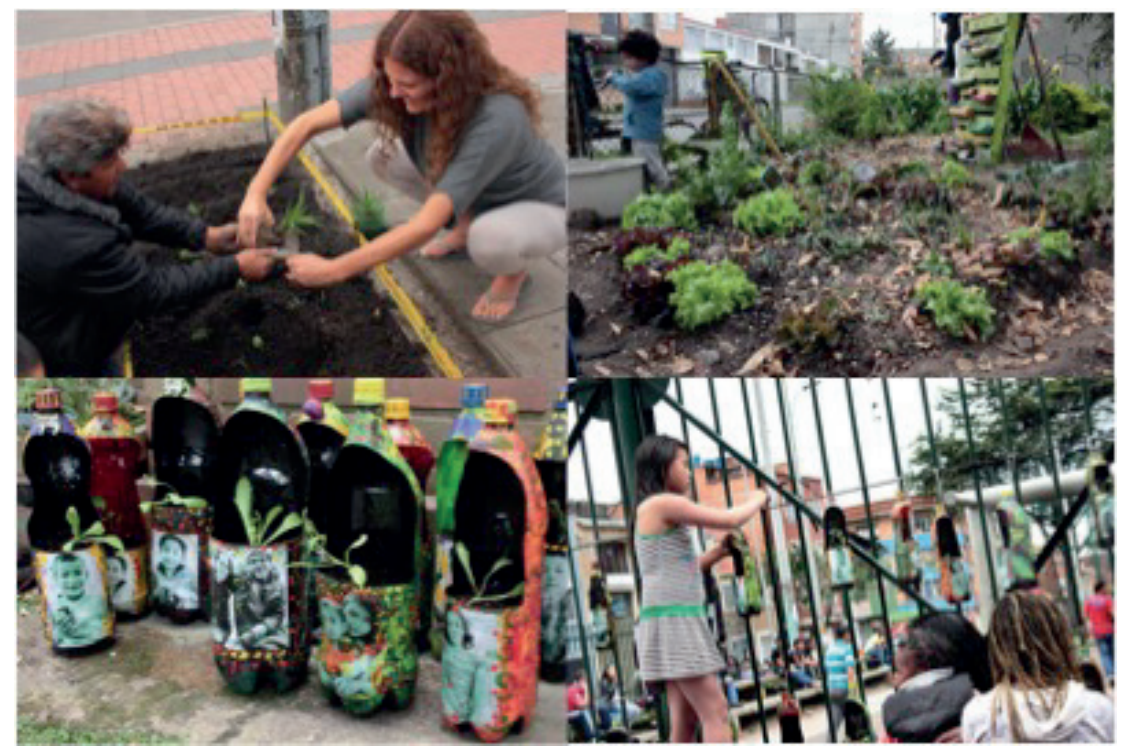

Figure 15. Collage of photographs from Eco Sembrando Barrio experiences 
Other examples are the Carnival of Maize, and Native Quinoa which are initiatives which address the loss of biodiversity of native seeds (Carnaval de maiz colombia 2016; Quinua Nativa 2016). These initiatives consider native seeds not only an important natural resource to protect and restore, but also an essential cultural resource expressed in the traditional Andean diet which has been deteriorating over the last 50 years because of the agroindustrial model. Through festivals and artistic activism, and community cooking rituals with the abuelas (women elders), these initiatives promote activities involving the entire food cycle: the planting of native seeds, local markets, seed exchange, rituals and circulos de la palabra (discussion circles) around the fire with elders to strengthen traditional knowledge and traditional/modern recipes (See Figure 16).

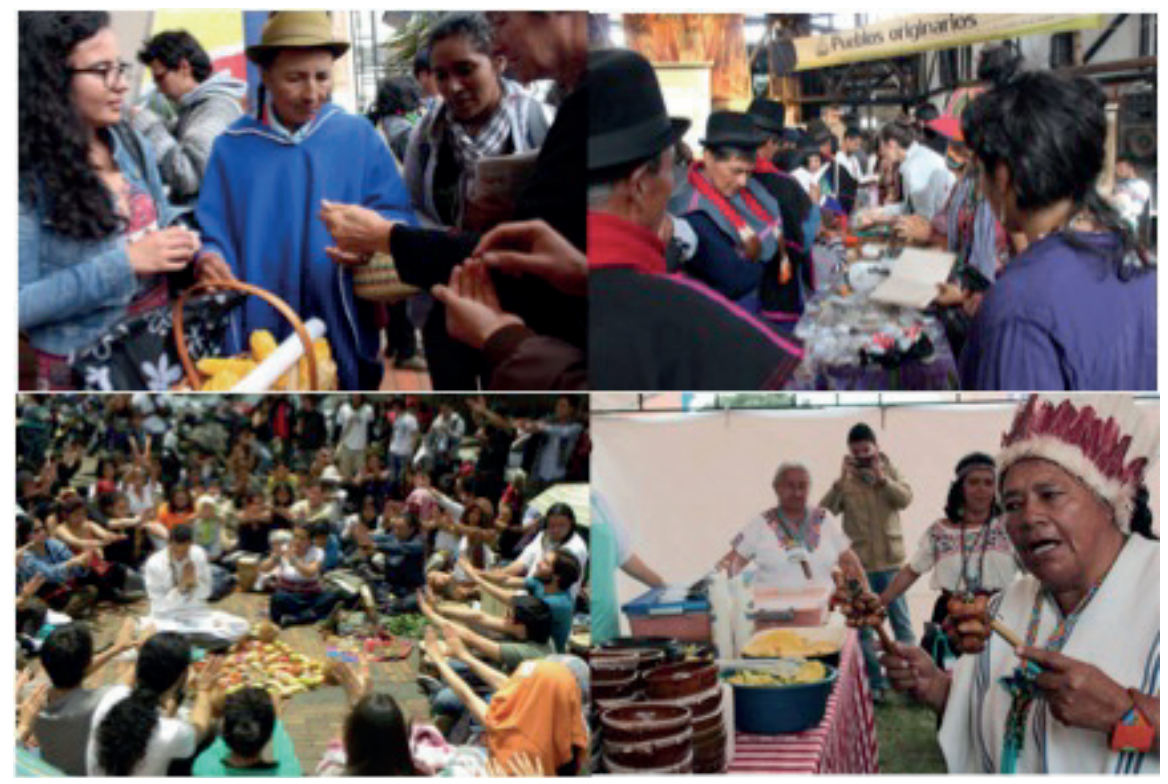

Figure 16. Collage of photographs from Carnival of Maize and Native Quinoa experiences

The last example is that of the Foundation Naturaleza y Patrimonio whom together with local communities has led an initiative to promote the connection between residents and nature through natural tourism in Bogotá (Naturaleza y Patrimonio 2016a). They have identified at least 34 nature sites in the city which are in danger of disappearing due to infrastructure development in the city. In order to regenerate these sites, and to be appropriated by local citizens, this foundation together with local authorities and the local community have developed a bike tour 
where tourists are brought to two sites important for their natural and cultural characteristics. The ravine Las Delicias was a sacred site for the original Indigenous Muisca people, and wetland Santa María del Lago is one of the last remnants of an extended wetland which was Bogotá (See Figure 17). Together with the initiative Cantoalagua (sing-to-the-water) they are also promoting conventional cleanup of the sites, as well as non-conventional cleansing activities through encouraging people to go beyond the rational boundaries of nature as an external entity, and instead promoting nature as a living being which receives positive energy when people sing mantras to it (Cantoalagua 2016).

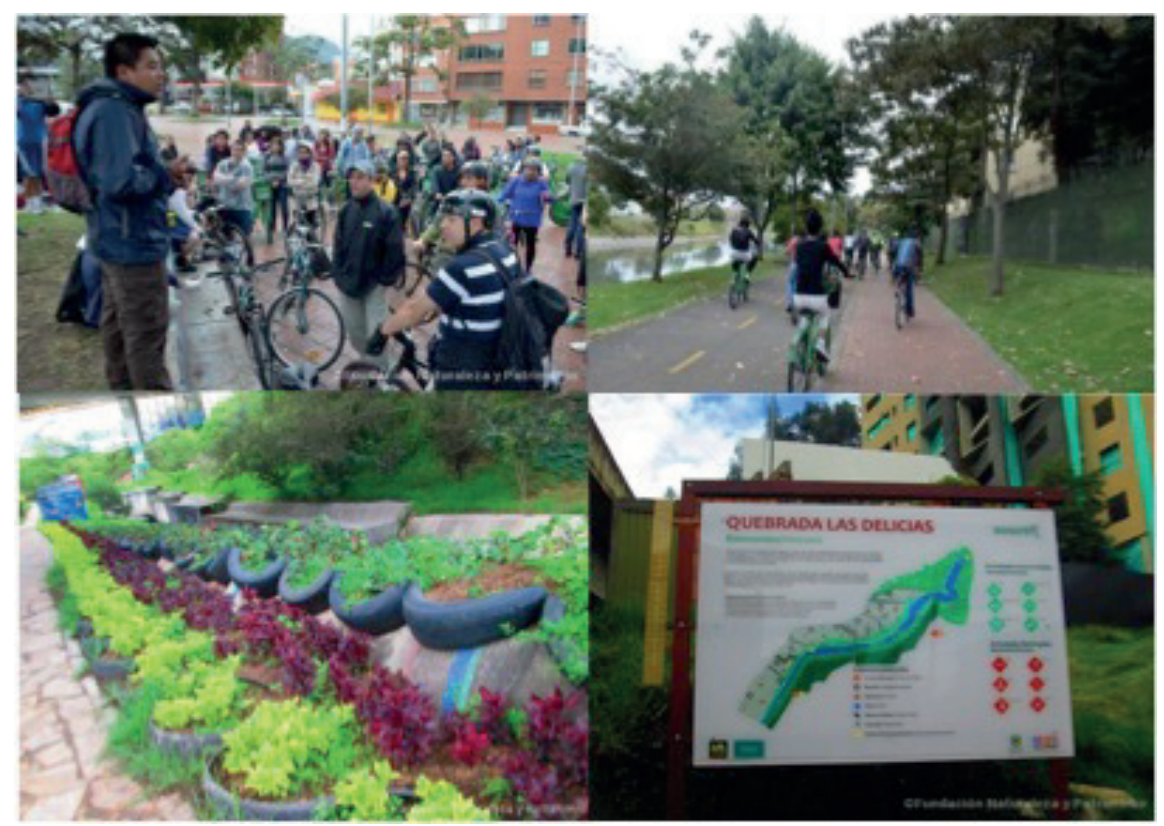

Figure 17. Collage of photographs from Foundation Naturaleza y Patrimonio experiences

From these CEPs in Bogotá we can begin to elucidate some of the principles discussed in section 7.1. We can see the importance of plural knowledge from elders and Indigenous peoples of the region, and experiencing a good story by using passions and emotions exerted in the artistic and spiritual activities of re-connection with ancestral ways and sacred sites. We will expand more in how these and the other principles are expressed in practice in the following section. 


\subsubsection{Up-scaling transformational CEPs through bioregional networks}

Urban gardening in eco-neighbourhoods; the protection and propagation of ancestral seed varieties; and the restoration and defense of natural sites in the city: Where do all these initiatives meet? Apart from being CEPs where local residents, activists, and institutions come together to protect local resources and promote community, these examples are connected by their shared participation in the Aulas Vivas Comunitarias Itinerantes de Bakatá - Itinerant Living Community Classrooms of Bakatá. These Aulas Vivas (living classrooms) are self-organized intercultural spaces for citizens of Bakatá (the ancestral name of Bogotá) where local residents, project leaders and sometimes local authorities meet to network, share learning experiences from their respective projects, as well as carry out communal activities (Naturaleza Patrimonio 2016b).

Taking place in various places around Bogota, these Aula vivas are based on participatory methodologies such as 'circulos de la palabra' (discussion circles) whereby the ancestral knowledge of the "lost" Indigenous people of Bogotá - the Muiscas - is being recognised and revived. The Muisca population considered themselves to be 'people of the water' - the territory originally having been a wetland - and ceremonies are carried out during gatherings where the sacred nature of Mother Earth are expounded, as well as the importance of traditional crops such as Maize and Quinua. Communal activities such as generating an olla communal (communal pot) of shared food cooked together promotes community amongst often diverse participants, as well as artistic activities such as dancing and singing to celebrate being together. There is also a concerted effort to influence local politics whereby these gatherings set out to manifest proposals around water conservation, seeds and diversity, and the formulation of guidelines for public policies such as allocating $0.01 \%$ of local budgets, and $0.1 \%$ of national budgets to strengthening of cultural, artistic, self-sustaining, permaculture, digital community processes in the city. These proposals have been promoted in strategic places such as the Climate Change Conference in the City Hall of Bogotá in 2015, as well as public spaces such as libraries.

With the recognition that each initiative by itself only has a limited possibility of making change, the strength of working as a network is that they have been able to construct a stronger, more passionate and articulated story of the need for reconnecting people to the ecological and cultural memory of ancestral Bakatá (principle 1 and 4). Through new realizations of the lost 
ecological wetland that was their city, and the revival of the ancestral knowledge of the Muiscas and their territory, many participants of the Aula Viva have found transformative insights towards a shared collective identity as descendants of the 'water people' of Bakatá. This has involved organizing themselves as a bioregional and intercultural network including participants of different ages, ethnicities, social strata and belief systems (principle 2 and 5), while allowing the process of the network's development to evolve in its own time and in its own directions (principle 3), while at the same time achieving recognition by local authorities as a legitimate entity. On April 7, 2015, in conjunction with the Ministry of Culture, Recreation and Sport and the District Board, the network carried out an Aula Viva whose advocacy topic was "walking towards peace - live community culture" within the framework of the World Summit on Arts and Culture for Peace in Colombia. As the bioregional network continues growing and consolidating, the hope is to increase its influence in proposing new public policies and raising awareness of environmental and social towards their ecological and cultural memory.

\subsubsection{National networks which promote out-scaling of CEPs}

The above example of the Aulas Vivas de Bakata demonstrate the possibilities of up-scaling transformational CEP through a bioregional network of initiatives which together collaborate, share and learn from each other with the goal of creating social and political change. Equally important are means of out-scaling such activities across Colombia. With respect to this, the yearly intercultural gathering El Llamado de la Montaña (The Call of the Mountain) plays an important role for Aulas Vivas de Bakata and other bioregional networks in forging national alliances among diverse actors, capacity building in terms of leadership and methodological tools, and putting into practice skills and knowledge through workshops and collective activities. Organised by the network C.A.S.A. Colombia (Council of Sustainable Settlements of America) El Llamado de la Montaña is a five day 'course' of co-sustainable living whereby peoples and initiatives from all over Colombia and beyond meet in in a host community and participate in an ongoing social learning processes on how to assemble sustainability visions in a plurality and co-create collective actions, that in many cases result in CEPs. Participants range from Hare Krishna devotees, neo-rural ecovillagers, local residents, urban professionals, and indigenous shamans. Through opening up spaces for shared living, preparing food together, and engaging in intercultural discussions on shared concerns such as deforestation, food sovereignty, and mega-mining, transboundary as well as transformative learning is promoted. 
Beyond acting as a social laboratory for sustainable living, El Llamado de la Montaña has developed during its 10-year history a collective toolbox of methodologies for generating concrete sustainability actions and strengthening relations between participants, organizations and territories. The logic of the methodology is create and facilitate diverse learning spaces where different types of reflexive learning are promoted within the day-to-day experiences of five days of co-living. There are spaces which promote a more 'head' based cognitive learning such as conferences and panel discussions, as well as three-day 'vision council' workshops around themes such as ecology, education and ancestral knowledge. Especially important for these vision councils are the organic manner in which they develop, with participants collectively deciding on the agenda and carrying out collective reflections on the process of the workshop hopes, expectations and realities. This is a reflection of principle 3 in which importance is placed on acquiring multiple and critical perspectives in addressing complex and ever-changing 'wicked' problems.

The second category of spaces promoted are those of the 'heart' which encourage weaving social relations through experiencing the passion of a good story (principle 1). This is based on the emotive and empathic understanding of living in a plural society in which we celebrate our differences in a unity of spirit in connection with Mother Earth (principle 4). To activate the heart, and balance the oftentimes head based focus on sustainability issues, El Llamado de la Montaña creates spaces such as 'dances of universal peace' which are multi-cultural circle dances that use sacred phrases, music and movements from many spiritual traditions of the earth create a sense of unity. Another space is that of the mambeo, which is a ceremonial conversation around a fire in which indigenous elders speak 'from the heart' inviting spirits to impart knowledge and wisdom. Both examples highlight spaces which transcend the modern logic of individuality and rationality, challenging participants to leave their comfort zones and confront (if not embrace) other ways of thinking and being.

The last category are 'hands' spaces in which participants actively engage with the concepts learnt during the event. This can take the form of workshops which build skills in areas like bioconstruction and art. Another area is the day-to-day chores which participants are expected to complete in order for a self-financed and self-organised gathering to take place. Participants must help prepare food, wash their own dishes, clean toilets and help keep clean the host community. Beyond simply using ones 'hands', these activities also bring out the 'head' skills 
needed for self-organizing these activities, as well as the 'heart' of the feelings and emotions of contributing to a collective task for the good of the community.

This generation of community is exemplified by the minga space held every year during El Llamado de la Montaña. The Quechua word for a collective work-party, minga is a foundational methodology in which the community come together to carry out a specific task without monetary incentive. At one level this could be to leave behind small concrete improvements in the host community such as a playground for the children, or to prepare a plot of land for planting. On a bigger scale, the minga can take on the characteristics of a CEP when a local ecological issue is addressed. In El Llamado de la Montaña of 2015, participants of the event, the local authorities, local residents and the host community came together to replant a wetland which had been deforested due to cattle grazing. In the spirit of plurality as a driver for change (Principle 5) this CEP was especially powerful because of the importance placed on connecting the action to the cosmology of the host community - the Indigenous University of the Misak people. The Misak cosmology describe the territory as a living organism made up by the relationships between people, animals, plants and spirits. Several participants noted that the activity of planting trees, within the context of the Misak cosmology, gave them an appreciation of the importance of one's territory and the necessity of local stewardship.

Beyond being a transformative space for individuals, the potential of El Llamado de la Montaña lies in its ability to inspire and empower individuals to start CEP projects in their own communities around Colombia, especially in the cities in which almost $75 \%$ of participants come from. In this sense, the design principle 2 of leadership and power are vital. The organisation of the event is based on the collaborative leadership model of sociocracy, which is a consensual form of decision making and distributed organisational structure. This model places emphasis on developing horizontal leadership capacities in those that co-organise and facilitate the event. Being part of an emotive story of co-creating a more sustainable and intercultural world, leaders emerge from El Llamado de la Montana to pollinate processes in their respective spheres of influence as can be seen in the Aulas Vivas de Bakatá where many of its members are actively involved in El Llamado de la Montana. 


\subsection{Reflections for designing and expanding transformative learning and CEPs}

One of the emerging areas of transformative actions are those taking place at the community level between people and their local environment. Such 'civic ecology' actions can be a source of socio-ecological transformation when participants learn through small-scale experimentation and observation, and collaborate with other sectors of society such as universities and NGOs, in adapting the co-management of local resources. We argue that one way of achieving this is through stepping out of one's comfort zone into situations which demand deep reflection of one's own way of being. As the principles at the start of this chapter state, this can be promoted through engaging in a meaningful story which is led by visionary people who have the selfinsight to step aside and allow for a collaborative and organic process to happen. Important for this process are the roles of plurality and affective relations as drivers in bringing about these deeper reflections and possibilities for a deeper learning.

Beyond such general guidelines it is important to note that CEPs reflect the local history, cultures and aspects of the built and natural environment (Krasny and Tidball 2012). Our example of Aulas Vivas en Bakata has shown a contextual example of how a network has gone about articulating through its members a shared vision of reconnecting people to places through the recognition and revival of the ancestral territory of the Muiscas. With initiatives working in their own spheres of influence, they share a common purpose through the network, as well as spaces for sharing and celebrating their visions and experiences. When we think about levers for transformative learning we can see the advantages of creating bio-regional networks who can work together to articulate territory-based civic environmental movements in which CEPs can be inspired and potentialized. However, as one respondent noted in section 2.3, allowing for the organic development of collective processes means being patient, and being open for failure which is difficult for many more action-minded people to accept. Although Aulas Vivas opens up opportunities for upscaling activities through increasing its critical mass, and diversity of perspectives, a potential barrier to greater processes of transformative learning is the slower pace of change taking place due to the negotiation needed between its members.

At the level of outscaling, intercultural events such as El Llamado de la Montaña have the potential for transformative learning to take place through creating transboundary spaces where participants are exposed to novel ways of thinking, feeling and acting. Such a forum of social learning encourages the weaving of community fabric, promotes more biocentric thinking in 
terms of the importance of nature, as well as promoting a more relational way of being and understanding the world. As a lever for expanding transformative learning, intercultural gatherings such as El Llamado de la Montaña play an important role in creating alliances and coalitions between individuals and organisations which cross cultural and institutional boundaries. The gathering also has the goal of building leadership capacities and improving methodologies for social cohesion which has led to many transformative CEPs, network building and related projects being initiated by participants in their own communities. Yet although the 'dissonance' created through the interaction of such diversity can have positive outcomes, it also risks alienating those who go too far out of their comfort zones without a safety net. Although a methodological emphasis is placed in balancing the domains of head-heart-hands, a participant for example in a mambeo may simply not be able to connect to a night of elders speaking of and to 'spirits' and 'energies'. Likewise, those connected at the spiritual level may not connect to the cognitive domain of critical thinking and planning and organizing. And for all participants, the transformative potential of these gatherings are the abilities of participants to put them into practice during and, importantly, after the event. For this to happen, all the guiding principles will have to be incorporated within a holistic framework in which a shared vision and desire for action can lead to change. 


\section{Chapter 8}

\section{General Discussion and Conclusion}

"One feels that nobody is right here, I mean, nobody owns the truth...each person is a link within the chain we are all part of." (Anonymous Participant of El Llamado de la Montaña, 2014).

This thesis has set out to defend the idea that endogenous concepts such as buen vivir provide a platform for not just envisioning alternative paradigms of good living, but for promoting learning-based change of a transformative and even transgressive nature. From triple-loop learning in an intentional community setting, to transgressive learning during ontological encounters, experiencing different ways of thinking and being has the power to change points of reference in our worldviews. C.A.S.A. Colombia (and the new social movements it is part of) then provides a means of articulating and forging alliances between diverse people and communities attempting to live more responsibly within the limits of the earth. However, such learning processes are incredibly complex, and the value-action gap remains substantial in many cases. It is one thing to talk about wanting to live in harmonious relations with people, nature and Mother Earth, but quite another to put this into practice; for example, by living in an intentional community, growing your own food, and inviting non-human actors such as spirits into one's life. What this thesis has shown, however, is that by putting into practice principles of buen vivir such as reconnecting to ancestral wisdom, questioning values of competition and individuality, and forming new relations to place and territory, one begins to question one's own set of norms, and those of society. In what we conceptualize as 'territo-realities,' the process of reconnecting ourselves to a place or a territory involves difficult negotiations with modern legacies such as the idea of there only being one truth, but by being critical to such ideas we can open ourselves up to the possibilities of new ways of being in the world.

To expand on these conclusions we will next revisit the respective research questions 1 and 2, and summarize the answers through addressing the concepts outlined in the introduction (8.1. and 8.2). We will then provide a section on the theoretical contributions this thesis has made (8.3), concluding with research implications and new directions for research (8.4). This thesis will finish with some final remarks (8.5). 


\subsection{New social movements as sources for alternative paradigms}

Research question 1: How are new social movements such as the C.A.S.A. network selforganizing and articulating visions and practices on alternative paradigms of socio-ecological, responsible good lives?

c. What are the everyday sustainability challenges of individuals and communities who make up the C.A.S.A. network?

d. How are notions of plurality dealt with in the network?

The C.A.S.A. network emerged in 2012, out of a previous network of ecovillages in Colombia called RENACE, to include a broader range of initiatives also striving for more socio-ecological responsible good lives. A strong focus of C.A.S.A. is on increasing diversity of ethnicities, cultures, customs, social strata and gender, regardless of differences in religious affiliations or sexual orientations. To varying degrees, and expressed in different ways, there is a shared desire amongst members to live a harmonious life, closely related to nature and other beings, based on values of solidarity and personal development, and with a biocentric view of life. In this endeavour C.A.S.A. has initiated what I describe as a 'social laboratory' to experiment with how to integrate new members with different visions and practices on the good life, and also on how to self-organize and self-finance their collective actions. C.A.S.A. has found, in the organization of the yearly network gathering, the space to not only experiment with participatory governance and decision-making systems, but to also weave a plural social fabric through visions, emotions, passions and collective actions. During El Llamado de la Montaña, a methodology of 'vision councils' are used, where several working groups discuss and articulate visions and actions on a topic considered important for sustainability and buen vivir. Vision councils are organic, dynamic and an ever changing collective construction; at the moment of writing this final chapter, the council themes are: Culture, Art \& Ancestry, Sustainable Settlements \& Ecovillages, Social Movements, Economic Solidarity, Education, Children, Youth, and Ecology \& Permaculture. Each council has a group of facilitators called dinamizadores, who come together before, during and after El Llamado de la Montaña to organise, facilitate and provide feedback and evaluate the respective vision council, thus providing learning loops to improve the agenda and the organization. Through the decision-making tools of sociocracy (also used within several initiatives of the network such as Atlántida and Aldeafeliz) the network has found a more participatory means of self-organizing and decision-making. Several 'cells' work 
independently, making the decisions needed to carry out their objectives, while a core group made up of representatives of each cell jointly make more general decisions. The same structure is used for the organization of the network, with an annual general assembly of representatives of all C.A.S.A. members with the aim to discuss the direction of the movement, yearly activities, and to choose through sociocratic decision making, the representatives of the cells and the cocina (the kitchen, as the core group is called).

In the enactment of various C.A.S.A. member practices there is a prominent influence of Indigenous wisdom and practices, to which many have turned to for inspiration in (re)constructing territorial relations. This is mirrored in the literature in which we see, for example, the increasing use of traditional ecological knowledge in areas such as adaptive management (Berkes et al. 2000), as well as the increasing importance given to intercultural education (Coulby 2006). Such processes of territorialisation involve members turning to philosophies with different historical roots, such as deep ecology or sufism, incorporating new ideas and practices into their good lives through critically choosing what works from their own life experiences. In these processes, the buen vivir concept has emerged as a platform for more radical alternatives to modernity and mainstream development, as proposed by Gudynas (2011). Nevertheless, while C.A.S.A. members are trying to distance themselves from a modernity they perceive as negative, in practice this has evolved into a difficult process of negotiation between wanting to live a more socio-ecological good life (buen vivir) and the modern legacies which pervade society. We have called this negotiation between wanting to establish new territorial relations and modern habits as territo-realities.

An illustrative example of these territo-realities entail the difficulties of enacting biocentric relations where one has to reconcile the needs and comforts of a modern life often removed from nature, with a philosophy which in practice requires giving space and rights to non-human actors in everyday life. Although there is increasing attention given to the notion that love for nature is something innate (see the concept of biophilia, Wilson 1984) and that time in nature is beneficial to health and wellbeing (Brymer et al. 2010), taking this to the next level of doing something as 'radical' as growing your own food is beyond the capability of most people in the C.A.S.A. network. Other examples are the negotiations between wanting to live in a solidarity economy, but not wanting to give up private property, or the dilemma for many of wanting to live a simple life in the countryside, but not being able to live without a monthly pay-check from the city. These territo-realities have led many C.A.S.A. members to adjust their buen vivir visions to 
accommodate the realities of living in a modern world. In this sense there is the very real possibility of buen vivir being 'hijacked' by neoliberal paradigms, as Parr (2012) argues has happened to sustainability.

Yet what I argue in this thesis is that it is the way C.A.S.A. understands and promotes plurality which gives it the potential to promote more sustainable paradigms of socio-ecologically responsible good lives. From a perspective of decolonization, the aim is to open up to novel ways of relating to one another and nature, building on intercultural knowledge exchange, with an emphasis on putting this into practice in everyday life. Beyond the power of such narratives to stimulate reflections on current rural transformations and the status quo of mainstream society (Kay 2008), the C.A.S.A. network provides a lived example of how such different paradigms can be put into practice. These efforts may often appear contradictory, with members giving the impression of being 'a bunch of pampered elitists,' as one journal reviewer noted, but walking the talk provides important insights for the rest of us into what to do - and not to do - in envisioning and putting into practice good lives together with other actors.

That said, the C.A.S.A. network has a lot of work ahead of it in terms of becoming more plural and articulating all the difference within its network. The network does not receive governmental or international aid, and there is little dialogue with state institutions beyond that of innovative local municipalities. In this sense, although C.A.S.A. promotes itself as a plural platform, there remains a lot of work in articulating other groups from broader society. As I argued in chapter 6 , the inclusion and articulation with diverse actors can activate the use of dissonance through the politics of ontological encounters so as to promote exchange between competing knowledge systems, as well as a means of up-scaling de-colonisation processes of knowledge production. Nevertheless, when we talk about a decolonization of knowledge where equal importance is given to different ways of knowing and being, we must be prepared for a strong degree of inflexibility in ontologies, and ever-present power negotiations between those who represent each ontology. No matter how much we talk about wanting to be open-minded and inclusive to other ontologies, engaging with them in practice can be extremely difficult. Part of the reason for this, as this research shows, is that there is no one logic that can mediate between the powersaturated realities of different worlds. Furthermore, the capacity to understand (or at least represent) an ontology can give tremendous power, thus the role and power of those that mediate between different worlds is very important in these settings. 


\subsection{Social learning for addressing 'wicked' problems}

Research question 2: To what extent does the enactment of socio-ecological, responsible good lives within the C.A.S.A. network lead to 'glocal' social learning processes?

e. Are social learning processes being promoted within and between initiatives in the C.A.S.A. network? If so, what types of learning processes are being promoted and how are they expressed?

f. To what extent are these processes confronting wicked socio-ecological problems?

This research was initiated in an intentional ecological community called Atlántida, exploring sustainability practices through ethnographic methods. Although the original focus was on evaluating these practices within a framework of sustainability indicators, the context of the community showed that it was more important to analyze the learning processes which individuals and the community were going through in terms of 'attempting' to live sustainable lives. Great disruptions had occurred in the community, and the social fabric holding it together was unraveling. In this difficult environment members were attempting to understand what was taking place through reflective community sessions. By living in the community and actively participating in these sessions (as researcher and resident) I was able to conceptualise this process through triple-loop learning (see chapter 4).

By following these reflective loops I was able to show that social learning was taking place in the community, characterised by deep reflection and emotions. On the one hand, it was realised that differences in worldviews, ethics and leadership among members had contributed to the 'death' of the community. On the other hand, it was acknowledged that these differences had contributed to a third loop - a reframing of values and mindsets - which had activated a process of transformative 'rebirth' within what was left of the community. I argue that although reaching this ultimate reflexive loop was only possible due to a major disruption in the community, this disruption acted like the proverbial final straw in dissolving the dream of what the community once was, leading many residents to leave the community. If we use this as an analogy for wider socio-ecological problems, then it suggests that we as mankind will need further and more fundamental disruptions (the end of oil or cheap food, for example) to catalyze a process of 
transformative learning which will change our unsustainable behaviour. However, like the Atlántida case demonstrates, this will be extremely tough on society.

The insights from this initial stage of research were important for my research as they helped shape my understanding of the need for creating 'spaces' for building critical perspectives and capacities so as to aid in boundary crossing (Akkerman and Bakker 2011a; 2011b). Individuals are accustomed to being in their social, existential, and physical comfort zones, characterized by safety and control. Individuals normally do not leave this security unless they have a strong desire to experience something different (or if circumstances force them to, such as the case with Atlántida above). What is needed are experiences which not only provoke reflection, but empower individuals to change their frames of reference or question their worldviews. This is what Moore (2005) argues is the ultimate goal of transformative learning. The following are five principles, developed in chapter 7 , which seem critical for engaging individuals in an on-going transformative and cross-boundary experience in which they can leave their comfort zone in a reflexive manner while confronting sustainability issues through active engagement.

1. Experiencing a good story: People are more willing to leave their comfort zone if they are engaging in a cause they believe in. From the fight against Apartheid in South Africa, to the deforestation of the Amazonian rainforest, such battles are generally based on a 'story' - a fundamental way in which humans organize, store and make meaning of information.

2. Leadership and power: Change is dependent on leaders who are willing to envision a different world, break boundaries, and take action. Their role is to set the scene for new structures to evolve through encountering the chaos and uncertainty of putting forward new ideas, thereby inspiring others who are not ready to leave their comfort zones.

3. Embracing uncertainty and organic processes: We live in an accelerating world where change and uncertainty are constant factors. We must begin to acknowledge the embeddedness of all relations and see the bigger picture of how everything is connected, crossing boundaries of knowledge and certainty.

4. Using passions and emotions: Passions and emotions are what drive people towards taking action, pushing them out of their cognitive comfort zone, and into what might sometimes seem like irrational situations. 
5. Plurality as a driver for change: Creating and facilitating plural environments plays an important role in pushing people to the edge of their reflexive boundaries through generating dissonance through encounters with difference.

The next step was to explore what these principles look like in practical spaces, and how they facilitate boundary crossing and transformative learning. This was addressed by exploring intercultural encounters during the annual C.A.S.A. network gathering El Llamado de La Montaña. By actively participating in these intercultural gatherings, which include Hare Krishna, Indigenous peoples, ecovillagers, and urban dwellers, I demonstrated how encounters between different ontologies can result in transformative and potentially transgressive learning in terms of disrupting stubborn routines, norms and values which tend to accelerate unsustainablity. Spaces such as el mambeo - a ceremonial conversation around a fire - expose different worlds to participants where non-human entities such as el abuelo fuego (grandfather fire) are given agency in discussions. However, the politics of these ontological encounters also bring forth conflicts through inflexible ontological stands and the inherent power relations within and between ontologies.

So to what extent does engaging with social learning help us address wicked socio-ecological problems? By defining wicked problems as complex, uncertain, constantly changing, and requiring many different perspectives, it is clear that the means of addressing them require a perspective in which there is no 'one right answer' and which builds the reflexive and critical capacities of people to develop their own ways of dealing with sustainability challenges. Yet, accustomed as most of us are to our own ways of thinking and being, accepting different perspectives and even realities is a long and complicated process. Although there may well have been transgressive 'moments' for participants and organizers through tangible encounters with the pluriverse, for it to be called 'learning' implies a long-term process in which structures are not just broken, but also to an extent surpassed.

Social learning, however, helps us to understand that learning is a process that we undertake together with others - both human and non-human - and thus it is perhaps better to think of a transition towards more sustainable futures where it is the learning we undergo in facing wicked problems which is most important than specific outcomes. Even in the case of Atlántida, members who left the community have gone on to start other projects in their new spheres of interests which they report are inspired by their experiences living in a community. As Eliana 
states, her seven years of experiencing Atlántida has been like attending an intensive course at the 'University of Life' (Chapter 4).

\subsection{Theoretical contributions}

Next I summarize the main theoretical debates engaged with, and my contribution to these academic fields.

\subsubsection{Political strategies of C.A.S.A. as a New Social Movement}

I want to contribute to the secessionist/confrontationist debate by problematising the secessionist strategy as normally being portrayed as apolitical, and suggesting that there is more movement along the secessionist/confrontationist line than is usually considered. At a first glance, C.A.S.A. appears to be following a predominantly secessionist strategy characterized by self-organization and participatory decision-making. Rather than directly engaging with formal governance institutions and structures, this activism is enacted through lifestyles on the borders of mainstream society: attempts to live a good life (buen vivir) characterized by community living, limited integration in the economic system, and more holistic worldviews. Yet as Barnes (2016) notes in his criticism into studies of other transition initiatives, the picture is not so black and white. Rather than being 'post-political', 'depoliticized', and 'unpolitical,' Barnes (ibid) argues that transition initiatives are more diverse and confrontational than the literature usually acknowledges. My research backs up these assertions, showing how interaction between network members can have very real political outcomes in terms of bringing forth (confrontational) power relations between different ways of knowing and being (see the ontological politics of chapter 6). This is within settings which are promoting seemingly secessionist strategies of collectivism and horizontal organisation styles of change (chapters 4 and 5). Yet although Neal describes such consensual and inclusive relations as 'post-political' due to their desire "to work through negotiated, consensual parameters and without antagonism and difference as their key dynamic" (2013: 68), I argue that such strategies are political by nature by attempting to live by different social norms which necessarily antagonize society. As Melucci (1996, in Buechler 2016:153) states, "The very ability to envision and symbolically enact new and different ways of organizing social relationships can itself be a potent challenge to 
dominant social arrangements." It is important not to ignore these cultural forms of power as an important form of resistance (Buechler 2016).

Furthermore, C.A.S.A. is not a uniform set of initiatives promoting the same goals and strategies. Through the C.A.S.A. goal of increasing its diversity of members, and hence its socio-political impact, the network is actively trying to make alliances with more confrontational initiatives, such as the afro-Colombian community of Las Islas del Rosario and the Indigenous Misak University. With long histories of political and social marginalization, these groups have developed strong resistance movements which have directly challenged the state. Due to the political situation of Colombia, however, these resistance movements risk violence and persecution of movement leaders. The issue of engaging in more confrontational politics within the C.A.S.A. network is therefore delicate. C.A.S.A. has been attempting to build a movement without a clear hierarchy (and hence no leader), while assembling different political strategies which are non-violent and which focus on consolidating the network and the social movement.

However as Barnes (2016) notes, there are trade-offs between secessionist and confrontational approaches at the local level, where the former strategy can even be regressive in nature when it fails to make an impact in pressing local concern. Although I argue that this is not the case in C.A.S.A. at this point in time, there are increasing tensions in the network with those who feel that although the micro-politics of C.A.S.A. is generating deep transformations among its members and their respective spheres of influence (chapter 7 ), the process of translating this into wider processes of change is too slow. There are proposals to aid in this process, for example, by financially supporting collective projects which are actively confronting government structures.

My own thoughts are that in light of the importance of social learning in generating critical reflection and developing innovative ideas, an effort must be made to continue diversifying the actors involved in the process, which includes government authorities and institutions. Without including these partners, the movement in the long run risks becoming homogenized (and perhaps even regressive), lacking the potentially 'dissonant' voices that can generate critical discussions. Although this supports the view of Barnes (2016) that the best political strategies for generating change combine secessionist and confrontationalist strategies, emphasizing theories of plurality and equal distribution of power, I argue that this must be a careful and 
critical process whereby acknowledging and potentially embracing institutional governance and administrative frameworks must happen on equal terms.

\subsubsection{Buen vivir and the good life}

The dangers of grassroots movements being co-opted by formal institutions is linked to the debate as to whether the emerging buen vivir concept really represents an alternative paradigm to development: Is buen vivir a modern alternative or an alternative to modernity? My contribution to this debate has been to show that at the level of visions, buen vivir strongly articulates a diversity of peoples and cultures connected by a desire to live harmoniously in the wider web of life. Rather than the concept of sustainability - which some subjects in this research perceived as a capitalistic concept - buen vivir is an endogenous Latin American concept with which many people and communities connect with. This was manifested by visions of territorialization, whereby subjects were engaging in processes of (re)connecting to their respective territories through revitalising indigenous rituals and practices, self-reflection, and building up of regional and national alliances. These visions, I argue, clearly demonstrated a rupture with the modern development paradigm.

However, at the level of lived-experiences, buen vivir as an alternative paradigm is much more blurred. Much like at the state-level politics of buen vivir, the legacies of modernity are strongly ingrained in people and institutions, and enacting new ways of living is profoundly difficult in practice. Examples of this are the economic logic of needing a monthly paycheck to pay for food and services; difficulties of living the talk of more communal relations; and perhaps most difficult, giving the non-human a real voice in negotiating new ways of living. Together with coauthors in chapter 5, I developed the term 'territo-realities' to conceptualise this value-action gap in terms of enacting a buen vivir.

As Villalba (2013:17) ultimately notes, although buen vivir at the state level involves many ambiguities in its implementation, it nonetheless has great transformative potential in creating 'chains of meaning' which will be difficult for the capitalist system to appropriate. In the same way, at the experiential level, the process of transitioning towards new ways of living and being can be transformative when it generates critical reflection and action-based change. In response to the opening question I therefore reiterate the conclusion of chapter 5 : does it really matter? As long as C.A.S.A. members are willing to stay and embrace the negotiation process of their 
'territo-realities' then there is hope of a transition towards alternatives to modernity through modern alternatives.

\subsubsection{The ontological turn and its politics}

Important for the above transition is the ontological 'turn' in which an increasing focus is being placed on our need as a civilisation to transform towards more plural ways of being (Escobar 2007). The contribution of this thesis to the debate on plural ontologies versus radical constructivism, is to further demonstrate the importance power relations play in bringing about, but also shutting down, the encounters between different 'worlds.' The debate as to whether different worlds 'exist' or not is one which will probably never be answered, but this thesis has shown that opening up the 'possibility' of a pluriverse through face-to-face intercultural encounters provide the potential for subjects to explore novel ways of seeing the world, and potentially questioning their own cultural points of reference. This involves, for example, bringing to the table non-human actors, or 'earth-beings' as de la Cadena (2010) calls them, who are given agency in more relational ontologies, as well as community ethics of living which are often at odds with the individualistic rationalism of many in the modern world. This supports the idea that ontological encounters have the potential to transform the way we learn from the world around us by challenging deeply held beliefs and habits (Wals 2011).

However, engaging in the politics of these encounters brings to light the complicated power relations which these encounters elicit through hierarchy and representation. Ontologies, like habits, are notoriously rigid, and through their encounters my research has shown the importance of generating an environment in which conversations - and importantly actions - can take place between different ontologies. If the environment is conducive to dialogue, and participants have the capacity to be reflective and flexible (which is always tough) then deep learning processes can be activated. This is, however, by no means certain, and despite the romantic sounding notion of a pluriverse, ontological encounters can generate substantial misunderstandings and conflict. I therefore find resonance in the ideas of Strathern (1991) who states that ontologies will only ever be 'partial connections' in which different ontologies are entangled with one another, and which we will never really 'get.' 


\subsubsection{Social learning, dissonance and plurality}

I have contributed to the debate about the merits and forms of an emancipatory social learning by showing in practice some of the characteristics needed in learning environments for dissonance to lead to transformative learning, while demonstrating the considerations such an approach demands. In the community of Atlántida (chapter 4), triple-loop learning demonstrated how community members underwent personal as well as collective loops of learning brought about by disruptions in the community. Results showed that despite the seemingly homogenous setting of the community (neo-rural middle class residents) significant differences in values evolved over time, creating dissonance in the community. For this dissonance to be generative, however, significant self-reflection and acceptance of difference had to take place. Some members were able to get through this tough reflexive environment, while others left the community.

As mentioned earlier, these insights are important because they reveal the characteristics of learning which will play important roles in confronting upcoming disruptions to our planet, for example through climate change. These are critical reflections, which play a vital role in transformative learning (Mezirow 1990), as well as acceptance of difference, which is a cornerstone of buen vivir (Gudynas 2011).

The second theoretical contribution builds on the above notion of 'disruptions' through theorizing how dissonance - through ontological politics - has the potential to generate transformative and even transgressive learning processes (chapter 6) through the boundary crossing concept of Akkerman and Bakker (2011a). In the intercultural setting of El Llamado de la Montaña, there was a high degree of heterogeneity of people and ontologies, which generated substantial dissonance amongst participants and organizers. I argue that these 'confrontations' were brought about by organizers and participants leaving their comfort zones (intentionally or not) through a mixture of the principles outlined in section 7.2. By being on the 'boundary' between different domains of knowledge and even ontologies, opportunities arose to 'transgress' these boundaries and to experience something entirely 'other.' As I argue in chapter 6, some individuals managed this, such as the woman participating in the 'circle of women' who embraced her 'sacred' role of a woman, as well as the organizers who realized (through discussions with Indigenous elders) the importance of harmonizing good 'energy' during the event. On the other hand, rigidity of ontological standpoints and hierarchies of power acted as 
barriers to transgressing these boundaries, such as the divisive role of the Hare Krishna kitchen rules, and the lack of communication between the Misak medicine men and participants in the cleansing ritual. Only in situations where individuals had the capacity for deep self-reflection and flexibility did we glimpse transgressive learning moments. The conclusion of both examples in terms of adding to the debate is that although dissonance is a strong driver for creating conditions for deep learning through boundary crossing, there needs to be the capacity and willingness to be open, reflexive and flexible for such learning to actually take place.

The last point I want to make here is the importance of taking into consideration the human toll of these transformations. Although it may be that the extent to which people can adapt to changing contexts will depend on 'emancipatory' capacities of critical-reflection and flexibility, it is worth keeping in mind the price that such 'capacity building' entails. In the first case, this was the breakup of the Atlántida community, and in the second case, broken relationships, such as the Misak teacher who left the gathering. Besides more research into situated and personal 'optimal dissonance,' it will be important to develop ethical frameworks which address the moral implications of promoting learning of a more 'transgressive' nature.

\subsection{Research Implications and new directions}

As this thesis has shown, a strong case can be made for the importance of social learning processes in sustainability networks, such as C.A.S.A. Colombia. Such networks offer a plurality of perspectives on addressing 'wicked' challenges and, importantly, are comprised of people and initiatives focusing on practice-based change. Yet although some questions have been answered in this research, new questions have arisen. The following are four areas which would provide fruitful avenues for further investigation:

Further research in urban areas: This research has predominantly taken place in rural settings because of the original emphasis on ecological, Indigenous and peasant communities which are normally located in the countryside. The research trajectory, however, has shown that there are numerous links between rural and urban spaces. Over half the participants of El Llamado are based in cities, and many residents, especially in ecological communities, either come from the city and/or have close relations through family and work. Although we explore the urban/rural connection in chapter 5 , and explore some urban networks of ecological stewardship through 
civic ecology in chapter 7 , more in depth research is needed into urban initiatives that are proposing new ways of relating to people and the environment, especially considering the continued urbanisation of countries such as Colombia.

Deeper engagement with native communities: The focus on interculturality has been witnessed by participants and host communities during the network event El Llamado de la Montaña and the way it articulated with the afro-Colombian community Las Islas del Rosario, the Indigenous community of Misak, and the peasant community Mamalulu (as seen in participatory photography exhibition in chapter 5). Yet apart from the Hare Krishna community and individual Indigenous elders who are now well integrated within the C.A.S.A. network, it has been difficult to engage with longer-term processes with native communities. One reason may be that although values align through frameworks such as buen vivir, everyday realities and short-term interests do not. This highlights the need for further research into participatory methodologies which can engage a diversity of people and communities in a collaborative path, perhaps through more action-based projects.

The role of government in scaling up activities: The orientation that C.A.S.A. has so far taken has been limited in terms of its engagement with the state apparatus. Nevertheless, although this research has demonstrated the importance of secessionist strategies for enacting change, it has also shown the limitations that such a strategy can accomplish in terms of scaling up actionbase change in its context. There is a desire within some C.A.S.A. members to move from proposals towards concrete scaling up actions that can promote changes at all levels of society. To achieve this, the organizing committee is starting to generate strategies and invite actors at an institutional level. However, as this is a new venture it is was beyond the scope of this thesis. It would be useful to explore the strategies and hence possibilities of C.A.S.A. to engage with political groups and/or resources as a means to expand their platform, while being mindful of the risks of co-option by the 'sustainability' or 'buen vivir' discourse. There is also the possibility that such a move towards confrontational strategies could result in a Janus-faced effect, whereby some members may feel alienated by engaging with government structures whom they have little faith in (Barnes 2016). A recommendation of special importance for this process is to reaffirm with all C.A.S.A. members the collective identity that they have been constructing over the years of operation, so as to have a clear position when engaging with formal institutions and government agencies. 
The role of transgressive learning in disrupting hegemonic power structures: As a form of learning-centered transformations which cross and break boundaries, this thesis has argued that transgressive learning has the potential to take place in intercultural environments such as El Llamado (a niche germ cell). When people leave their comfort zones they are better able to reflect on their own assumptions and the (un)sustainable habits of their ontologies. The setting for such learning, much like wicked problems, are uncertain, complex, changing, and organic, and training people to become open and reflexive vis-à-vis such open processes helps people to address wicked problems in their own communities. However, although I attempted to track the impact of El Llamado de la Montaña on participants and their communities - Misak youth during the event, and two community members of las Islas del Rosario - I only found specific impacts on individuals and to a limited effect, their communities. Further research is needed into the causal links between transformative and transgressive learning in specific intercultural spaces like El Llamado de la Montaña and potential upscaling through changes at multiple levels, including at the political level.

\subsection{Final remarks}

On June 23, 2016, the Colombian government and the Revolutionary Armed Forces of Colombia (FARC-EP) signed a ceasefire, effectively ending more than 50 years of internal conflict. With more than 220,000 people killed, and over 5 million people displaced from their homes, the world's longest running civil war has come closer to an end (Brodzinsky and Watts, 2016). Despite this historic moment, immense challenges face Colombia in terms of postconflict reconciliation and reconstruction. The country carries deep wounds, and although the post-conflict era represents a new chapter in Colombia's history, it is uncertain where this chapter is leading to. What we can see is that the narrative of neoliberal development is as strong as ever, and that the 'wicked' sustainability problems lurk around every corner. Within this context, a broader platform for C.A.S.A. Colombia could actualize its role in articulating and promoting a peaceful resistance of marginalised groups in Colombia - groups that are increasingly being confronted by modernity inside their territories. This could be based on the desire to promote alternative lifestyles based on what C.A.S.A. members refer to as 'territories of peace.' With issues on the peace agenda such as integral land reform, involving the economic and social development of rural areas, C.A.S.A. experiences - both good and bad - of how to re-territorialize relations to the land and themselves will be a great asset for post-conflict 
reconstruction. As a recommendation, C.A.S.A. should keep in mind, in its efforts to articulate difference within the network, the extent to which it should compromise its visions and goals in the generating a tolerant and inclusive social tissue. This is especially important should other ontologies appear inherently unsustainable and unfair. To end this thesis I would like to reiterate the words of the Colombian ex-senator Gloria Cuartas who spoke at El Llamado de la Montaña of 2015 on the role of C.A.S.A. in promoting peace:

"Perhaps the political situation in Colombia... needs the words of these kinds of networks which emerge from another type of life, which know of caring, of respect, of love... They are gas stations of ethical fuel to address the road of reconstruction in this country. Hopefully they will participate in the dialogue by contributing with their ethical points in the peace talks, for this process of peace is incomplete, there is a set of people [pueblo] missing... that pueblo is the people who still have some inner peace. Maybe those of us who have suffered so much pain and rage...need people like you who have taken care of your heart, of your relationships, of your footsteps, of your land, and of your territory. Because Colombia has a pueblo in exile, and I think today the time has come for you to open the doors and welcome, with your words and your body, a country that really needs it." 


\section{References}

Acosta, A. (2008). El Buen vivir, una oportunidad por construir. Revista Ecuador Debate, 75, 33-48.

Akkerman, S. F., and Bakker, A. (2011a). Boundary crossing and boundary objects. Review of Educational Research, 81(2), 132-169.

Akkerman, S. F., and Bakker, A. (2011b). Learning at the boundary: An introduction. International Journal of Educational Research, 50(1), 1-5.

Anderson, L. (2006). Analytic Autoethnography. Journal of Contemporary Ethnography, 35(4), 373-395. doi:10.1177/0891241605280449

Ateljevic, I. (2013). Visions of Transmodernity: "A new renaissance” of our human history? Integral Review, 9(2), 200-219.

Australian Public Service Commission. (2007). Tackling wicked problems: A public policy perspective. Canberra, Australia: Australian Government. doi: $10.4324 / 9781849776530$

Barker, P. (2003). Cognitive Dissonance. In: Guy Burgess and Heidi Burgess (Eds.) Beyond Intractability. Conflict Information Consortium, University of Colorado, Boulder. Accessible at: www.beyondintractability.org/essay/cognitive-dissonance, last accessed December 19th, 2015.

Barnes, P. (2016). Transition Initiatives and Confrontational Politics: Guidelines, Opportunities, and Practices. Western Political Science Association 2016 Annual Meeting, 0-29.

Berkes, F., Colding, J., and Folke, C. (2000). Rediscovery of traditional ecological knowledge as adaptive management. Ecological applications, 10(5), 1251-1262.

Berney, R. (2010). Learning from Bogotá: how municipal experts transformed public space. Journal of Urban Design, 15(4), 539-558.

Beukema, L. (2009). Unity in diversity: Many forms of action research. In: Almekinders, C., Beukema, L. M., and Tromp, C. (Eds.) Research in Action: Theories and Practices for Innovation and Social Change, Volume 6, (pp. 207-220). Wageningen: Wageningen Academic Publishers.

Blaser, M. (2010). Storytelling globalization from the Chaco and beyond. Durham and London: Duke University Press. 
Block, S. R., and Rosenberg, S. (2002). Toward an understanding of Founder's Syndrome: An assessment of power and privilege among founders of nonprofit organizations. Nonprofit Management \& Leadership, 12(4), 353-368.

Bookchin, M., (1982). The ecology of freedom: the emergence and dissolution of hierarchy. Palo Alto, CA: Cheshire Books.

Brodzinsky, S., and Watts, J. (2016). Colombia and Farc rebels sign historic ceasefire deal to end 50-year conflict. The Guardian. Retrieved June 25, from https://www.theguardian.com/world/2016/jun/23/colombia-farc-rebel-ceasefireagreement-havana.

Brouwer, H., Woodhill, J., Hemmati, M., Verhoosel, K. and van Vugt, S. (2015). The MSP Guide: How to design and facilitate Multi-stakeholder partnerships. Wageningen: Centre for Development and Innovation, University of Wageningen.

Buechler, S. M. (2016). Understanding social movements: Theories from the classical era to the present. London and New York: Routledge.

Bullard, R.D. and Johnson, G.S., (2000). Environmentalism and public policy: environmental justice: grassroots activism and its impact on public policy decision making. Journal of Social Issues, 56 (3), 555-578. doi:10.1111/0022-4537.00184.

Brymer, E., Cuddihy, T. F., and Sharma-Brymer, V. (2010). The role of nature-based experiences in the development and maintenance of wellness. Asia-Pacific Journal of Health, Sport and Physical Education, 1(2), 21-27.

Cantoalagua (2016). Retrieved July 24, 2016, from http://www.cantoalagua.com/.

Capra, F. (1996). The web of life: A new scientific understanding of living systems. New York, NY: Anchor Books.

Capra, F. (2009). Foreword. In: Wals, A. E. (Ed.) Social learning towards a sustainable world: Principles, perspectives, and praxis. Wageningen: Wageningen Academic Pub.

C.A.S.A., (2015). www.casacontinental.org. Retrieved 15 January, 2015.

Carnaval de maiz colombia (2016). Retrieved July 24, 2016, from http://carnavaldelmaizcolombia.org.

Castells, M. (2012). Networks of outrage and hope: Social movements in the internet age. Cambridge, UK: Polity Press.

Chaves, M., Macintyre, T., Riano, E., Calero, J., and Wals, A. (2015) Death and rebirth of Atlántida: The role of social learning in bringing about transformative sustainability 
processes in an ecovillage. Southern African Journal of Environmental Education, 31, 22-32.

Christakis N. A. and J.H. Fowler (2009). Connected: the surprising power of our social networks and how they shape our lives. New York, NY: Little, Brown and Co.

Christian, D.L. (2003). Creating a Life Together: Practical tools to grow ecovillages and intentional communities. Gabriola Island, BC, Canada: New Society Publishers.

Coulby, D. (2006). Intercultural education: theory and practice. Intercultural education, 17(3), 245-257.

De La Cadena, M. (2010). Indigenous cosmopolitics in the andes: Conceptual reflections beyond "politics." Cultural Anthropology, 25(2), 334-370. doi:10.1111/j.15481360.2010.01061.x

Deleuze, G., and Guattari, F. (1988). A thousand plateaus. London: Athlone.

Eco Sembrando Barrio (2016). Retrieved July 24, 2016, from https://sembrandobarrio.wordpress.com/

Escobar, A. (1998). Whose knowledge, whose nature? Biodiversity, Conservation, and the Political Ecology of Social Movements. Journal of Political Ecology, 5(1), 53-82.

Escobar, A. (2001). Culture sits in places: reflections on globalism and subaltern strategies of localization. Political geography, 20(2), 139-174.

Escobar, A. (2004). Beyond the Third World: imperial globality, global coloniality and antiglobalisation social movements. Third World Quarterly, 25(1), 207-230. doi:10.1080/0143659042000185417

Escobar, A. (2007). The 'ontological turn' in social theory. A commentary on 'Human geography without scale', by Sallie Marston, John Paul Jones II and Keith Woodward. Transactions of the Institute of British Geographers, 32(1), 106-111. doi:10.1111/j.1475-5661.2007.00243.x

Escobar, A. (2008). Territories of difference: place, movements, life, redes. Durham and London: Duke University Press.

Escobar, Arturo (2010): Latin America at a Crossroads, Cultural Studies, 34(1), 1-65.

Escobar, A. (2011a). Una minga para el postdesarrollo. Signo y Pensamiento, 30(58), 306312.

Escobar, A. (2011b). Sustainability: Design for the pluriverse. Development, 54(2), 137-140.

Escobar, A. (2012). Encountering development: The making and unmaking of the Third World (2nd ed.). New Jersey, NJ: Princeton University Press. 
Escobar, A. (2012). Más allá del desarrollo: postdesarrollo y transiciones hacia el pluriverso. Revista de Antropologia Social, 21, 23-62.

Fals Borda, O. (2006). Participatory (action) research in social theory: Origins and challenges. In: P. Reason \& H. Bradbury (Eds.) Handbook of action research (pp. 27-37). London: SAGE.

Farah, I. and Vasapollo, L. (2011). ¿Vivir bien: Paradigma no Capitalista? Bolivia: CIDESUMSA.

Fotopoulos, T., (1997). Towards an inclusive democracy: the crisis of the growth economy and the need for a new liberatory project. London: Cassell.

Fox, N. J., and Alldred, P. (2015). New materialist social inquiry: designs, methods and the research-assemblage. International Journal of Social Research Methodology, 18(4), 399-414. doi:10.1080/13645579.2014.921458

Romme, A. G. L., and Van Witteloostuijn, A. (1999). Circular organizing and triple loop learning. Journal of Organizational Change Management, 12(5), 439-453.

Ghisi, L. M. (2008). The knowledge society: A breakthrough towards genuine sustainability. Cochin: Arunachala Press.

Gilman, R. (1991). The Ecovillage Challenge, In Context, 29, 10-14.

Glasser, H. 2007. Minding the gap: The role of social learning in linking our stated desire for a more sustainable world to our everyday actions and policies. In: Wals, A.E.J. (Ed.), Social learning towards a sustainable world (pp 35-62). Wageningen: Wageningen Academic Publishers.

Goodall, H. L. (2000). Writing the New Ethnography. Walnut Creek, CA: AltaMira Press.

Graeber, D. (2015). Radical alterity is just another way of saying" reality": A reply to Eduardo Viveiros de Castro. HAU: Journal of Ethnographic Theory, 5(2), 1-41.

Grosfoguel, R. (2011). Decolonizing Post-Colonial Studies and Paradigms of Political Economy: Transmodernity, Decolonial Thinking, and Global Coloniality. Transmodernity Journal of Perispheral Cultural Production of the Luso-Hispanic World, 1(1), 1-36.

Gudynas, E. (2011a). Buen Vivir: Germinando alternativas al desarrollo. América Latina en Movimiento, 462, 1-20.

Gudynas, E. (2011b). Buen vivir: today's tomorrow. Development, 54(4), 441-447.

Gudynas, E. (2014). Buen vivir: Sobre Secuestros, Domesticaciones, Rescates y Alternativas. In: Oviedo, A. (ed) Bifurcación del Buen Vivir y el Sumak Kawsay (pp 23-45), Quito, Ecuador: Ediciones Yachay. 
Gutiérrez, F. (2012). Del discurso del desarrollo a la visión territorial sostenible: From the speech of development to the sustainable spatial vision. Perspectiva Geográfica, 17, 233-258.

Halfacree, K. (2007). Trial by space for a 'radical rural': Introducing alternative localities, representations and lives. Journal of Rural Studies, 23(2), 125-141.

Hardt, M. \& Negri, A. (2004). Multitude: War and democracy in the age of empire. New York, NY: Penguin Group.

Hawken, P., (2007). Blessed Unrest: How the Largest Movement in the World Came into Being and No One Saw It Coming. New York, NY: Viking Press.

Heley, J., and Jones, L. (2012). Relational rurals: some thoughts on relating things and theory in rural studies. Journal of Rural Studies, 28(3), 208-217.

Holbraad, M., Pedersen, M., and Castro, E. de. (2014). The politics of ontology: Anthropological positions. Cultural Anthropology Online. Retrieved May 18, 2016, from https://culanth.org/fieldsights/462-the-politics-of-ontology-anthropologicalpositions

Hopkins, J. (1998). Signs of the post-rural: Marketing myths of a symbolic countryside. Geografiska Annaler: Series B, Human Geography, 80(2), 65-81.

Huanacuni, F. (2010). Buen Vivir / Vivir Bien: Filosofía, políticas, estrategias y experiencias regionales andinas. Lima, Perú: Coordinadora Andina De Organizaciones Indígenas.

Ivanova, M. (2011). Global Governance in the 21st Century: Rethinking the environmental pillar. Conflict resolution, human security and global governance faculty publication series. Paper1. http:/scholarworks.umb.edu/crhsgg_faculty_pubs/1

Kates, R.W, Parris, T.M., and Leiserwitz, A. A. (2005). What is sustainable development? Goals, indicators, values and practice. Environment: Science and Policy for Sustainable Development, 47 (3), 8-21.

Katz, C. (1998). Whose nature, whose culture?: Private productions of space and the 'preservation' of nature. In: Braun, B., Castree, N. (Eds.), Remaking Reality. Nature at the Millennium (pp. 46-63). London: Routledge.

Kauffman, C. M. and Martin, P. L. (2013). Scaling up Buen Vivir: Globalizing Local Environmental Governance from Ecuador. Global Environmental Politics, 14(1), 4058.

Kay, C. (2008). Reflections on Latin American rural studies in the neoliberal globalization period: a new rurality? Development and Change, 39(6), 915-943. 
Kindon, S. L., Pain, R., and Kesby, M. (2007). Participatory action research approaches and methods: connecting people, participation and place. London: Routledge.

Koop, K. (2014). Conventional or alternative development? Various meanings and purposes of territorial rural development as a strategy for the Global South. Geographica Helvetica. 69, 271-280.

Krasny, M. (2013). Introduction: Tales of a Transdisciplinary Scholar. In: Krasny, M. E., and Dillon, J. (Eds.), Trading Zones in Environmental Education: Creating Transdisciplinary dialogue (pp. $\mathrm{x}-\mathrm{xxi}$ ). New York: Peter Lang.

Krasny, M. E., Russ, A., Tidball, K. G., and Elmqvist, T. (2014). Civic ecology practices: Participatory approaches to generating and measuring ecosystem services in cities. Ecosystem services, 7, 177-186.

Krasny, M. E., Silva, P., Barr, C., Golshani, Z., Lee, E., Ligas, R., Mosher, E. and Reynosa, A., (2015). Civic ecology practices: insights from practice theory. Ecology and Society, 20(2), 12.

Krasny, M. E., and Tidball, K. G. (2012). Civic ecology: a pathway for Earth Stewardship in cities. Frontiers in Ecology and the Environment, 10(5), 267-273.

Lange, E. A. (2004). Transformative and restorative learning: A vital dialectic for sustainable societies. Adult education quarterly, 54(2), 121-139.

Langeveld, M. (1983) Reflections on phenomenology and pedagogy. Phenomenology \& Pedagogy, 1(1), 1-7.

Law, J. (2009). Seeing like a survey. Cultural Sociology, 3(2), 239-256. doi:10.1177/1749975509105533

Law, J., \& Urry, J. (2004). Enacting the social. Economy and society, 33(3), 390-410.

Law, J. (2011). What's Wrong with a One-World World. Retrieved April 10, 2016, from http://www.heterogeneities.net/publications/Law2011WhatsWrongWithAOneWorldW orld.pdf

Litfin, K. (2009). Reinventing the future: The global ecovillage movement as a holistic knowledge community. In: G. Kütting \& R. D. Lipschutz (Eds.), Environmental governance: power and knowledge in a local-global world. Cambridge: The MIT Press.

Lotz-Sisitka, H., Wals, A. E., Kronlid, D., and McGarry, D. (2015). Transformative, transgressive social learning: rethinking higher education pedagogy in times of systemic global dysfunction. Current Opinion in Environmental Sustainability, 16, 7380. doi:10.1016/j.cosust.2015.07.018 
Lunch N. \& Lunch C. (2006). Insights into participatory video: A handbook for the field. London: Insightshare.

Markard, J., Raven, R., \& Truffer, B. (2012). Sustainability transitions: An emerging field of research and its prospects. Research Policy, 41(6), 955-967.

Martin, P. M., and Glesne, C. (2002). From the Global Village to the Pluriverse? "Other" Ethics for Cross-Cultural Qualitative Research. Ethics, Place \& Environment, 5(3), 205-221. doi:10.1080/1366879022000041597

McBay, A., Keith, L., and Jensen, D. (2011) Deep Green Resistance. New York, NY: Seven Stories Press.

McCarthy, J. (2008). Rural geography: Globalizing the countryside. Progress in Human Geography, 32(1), 129-137.

McGregor, S. (2009) Sustainability through vicarious learning: Reframing consumer education. In: Wals, A. E. (Ed.) Social learning towards a sustainable world: Principles, perspectives, and praxis. Wageningen: Wageningen Academic Pub.

Medina, J. (2011). Acerca del Suma Qamaña. In: Farah, I. and Vasapollo, L. (eds). ¿Vivir bien: Paradigma no Capitalista? (pp 39-65). Bolivia: CIDES-UMSA.

Melucci, A. (1996). Challenging codes: Collective action in the information age. Cambridge: Cambridge University Press.

Meyer, D.S., (2014). The politics of protest: social movements in America. (2nd ed). New York, NY: Oxford University Press.

Mezirow, J. (1990), How critical reflection triggers transformative learning. In: Fostering Critical Reflection in Adulthood: A Guide to Transformative and Emancipatory Learning. (Mezirow, J. and Associates, eds.). San Francisco, SF: Jossey-Bass.

Mol, A. (2002). The body multiple: Ontology in medical practice. Durham, NC, and London: Duke University Press.

Mollinson, W. (1988). Permaculture: A Designer's Manual, NSW, Australia: Tagari Institute.

Moore, J. (2005). Is higher education ready for transformative learning? A question explored in the study of sustainability. Journal of transformative education, 3(1), 76-91.

Naturaleza y Patrimonio (2016a). Retrieved July 24, 2016, from http://naturalezaypatrimonio.com/category/proyectos/

Naturaleza y Patrimonio (2016b). Cultura viva comunitaria red Bakatá Colombia. Retrieved July 24, 2016, from https://www.youtube.com/watch?v=_TTWKs0GLY\&feature=youtu.be. 
Neal, S. (2013). Transition culture: Politics, localities and ruralities. Journal of Rural Studies, 32, 60-69.

Paehlke, R. and Torgerson, D., eds., (2005). Managing leviathan: environmental politics and the administrative state (2nd ed). Toronto: Broadview Press.

Parr, A. (2012). Hijacking sustainability. Cambridge: Mit Press.

Prins, E. (2010) Participatory photography: A tool for empowerment or surveillance? Action Research, 8(4), 426-443.

Puente, R. (2011). "Vivir Bien” y decolonialización. In: Farah, I. and Vasapollo, L. (eds). ¿Vivir bien: Paradigma no Capitalista? (pp 345-365). Bolivia: CIDES-UMSA.

Quinua Nativa (2016). Retrieved July 24, 2016, from http://naturalezaypatrimonio.com/quinua-nativa/.

Ray, H.P., Anderson, S. R. (2000). The cultural creatives: How 50 million people are changing the world. New York, NY: Harmony Books.

Reason, P., Bradbury, H. (2001). Handbook of action research. Participative inquiry \& practice. Sage: London.

Rees, W. (1995). Economic development and environmental protection: An ecological economics perspective. Environmental Monitoring and Assessment, 86(1), 29-45.

Rifkin, J. (2005). The European dream: How Europe's vision of the future is quietly eclipsing the American dream. New York, NY: Penguin Group.

Rodríguez-Magda, R.M. (2004). Transmodernidad. Barcelona: Anthropos

Rodríguez-Magda, R.M. (2011). Transmodernidad: un nuevo paradigma. Transmodernity: Journal of peripheral cultural production of the Luso-Hispanic World 1(1): 1-13.

Sánchez, F. (2008). Elementos para una geopolítica de los megaproyectos. Revista Colombiana de Geografía, 17, 7-21.

Scott, J. C., (1998). Seeing like a state: how certain schemes to improve the human condition have failed. New Haven, CT: Yale University Press.

Seyfang, G., \& Haxeltine, A. (2012). Growing grassroots innovations: exploring the role of community-based initiatives in governing sustainable energy transitions. Environment and Planning C: Government and Policy, 30(3), 381-400.

Sierra-Camargo, X. (2014). Derecho, minería y (neo) colonialismo. Una aproximación crítica a la regulación de la minería de oro a gran escala en Colombia. OPERA, 14(14), 161-191.

Singleton, J. (2010). Head, heart and hands model for transformative learning: place as context for changing sustainability values. Journal of Sustainability Education, 9. 
Sipos, Y., Battisti, B., \& Grimm, K. (2008). Achieving transformative sustainability learning: engaging head, hands and heart. International Journal of Sustainability in Higher Education, 9(1), 68-86.

Sol, J., Beers, P. J., \& Wals, A. E. J. (2013). Social learning in regional innovation networks: Trust, commitment and reframing as emergent properties of interaction. Journal of Cleaner Production, 49, 35-43. doi:10.1016/j.jclepro.2012.07.041

Spry, T. (2001). Performing Autoethnography: An Embodied Methodological Praxis. Qualitative Inquiry, 7(6), 706-732. doi:10.1177/107780040100700605

Steffen, W., Persson, A., Deutsch, L., Zalasiewicz, J., Williams, M., Richardson, K., Crumley, C., Crutzen, P., Folke, C., Gordon, L., Molina, M., Ramanathan, V., Rockstrom, J., Scheffer, M., Schellnhuber, H.J., Svedin, U. (2011) The Anthropocene: from global change to planetary stewardship. Ambio, 40, 739-761.

Sterling, S. (2009). Riding the storm: Towards a connective cultural consciousness. In Wals, A.E.J. (Ed.), Social learning towards a sustainable world (pp 63-82). Wageningen: Wageningen Academic Publishers.

Stone, M. K., and Barlow, Z. (Eds.). (2005). Ecological literacy: Educating our children for a sustainable world. San Francisco: Sierra Club Books.

Strathern, M. (1991). Partial connections. Savage, MD: Rowman \& Littlefield.

Tedlock, B. (1991). From participant observation to the observation of participation: The emergence of narrative ethnography. Journal of anthropological research, 47(1), 6974.

Thompson, B. (2011). Pachakuti: indigenous perspectives, buen vivir, sumaq kawsay and degrowth. Development, 54(4), 448-454

Tidball, K. G. (2014). Trees, rebirth and resilience: Community-led reforestation and recovery in post-Katrina New Orleans. In: Tidball, K. G., Krasny, M. E. (Eds.), Greening in the Red Zone. New York City, NY: Springer,

Valkenburg, B., Baukema, L., Almekinders, C., and Tromp, C. (2009). Research in Action. In: Research in action: Theories and practices for innovation and social change (pp 15-29). C. Almekinders, L. Beukema, C. Tromp (eds). Wageningen: Wageningen Academic Publishers.

Villalba, U. (2013). Buen Vivir vs Development: a paradigm shift in the Andes? Third World Quarterly 34(8), 1427-1442.

Viveiros de Castro, E., (2015). Who's afraid of the ontological wolf: Some comments on an ongoing anthropological debate. Cambridge Anthropology, 33 (1): 2-17. 
Wals, A.E.J. (2009). Social learning towards a sustainable world. Wageningen: Wageningen Academic Publishers.

Wals, A.E.J. (2011). Learning Our Way to Sustainability. Journal of Education for Sustainable Development, 5(2), 177-186. doi:10.1177/097340821100500208

Wals, A.E.J. (2015). Beyond unreasonable doubt: learning for socio-ecological sustainability in the anthropocene. Inaugural address. Wageningen: Wageningen University.

Wals, A. E. J., and Heymann, F. (2004). Learning on the edge: exploring the change potential of conflict in social learning for sustainable living. In A. Wenden (Ed.), Educating for a Culture of Social and Ecological Peace (pp. 123-145). New York: State University of New York Press.

Wals, A. E. J., and Jickling, B. (2002). "Sustainability" in higher education: from doublethink and newspeak to critical thinking and meaningful learning. International Journal of Sustainability in Higher Education, 3(3), 221-232.

Wals, A.E.J., van der Hoeven, N. and Blanken, H. (2009). The acoustics of social learning: designing learning processes that contribute to a more sustainable world. Utrecht/Wageningen: SenterNovem/Wageningen Academic Publishing.

Wals, A.E.J. \& van der Waal, M.E. (2014) Sustainability-Oriented Social Learning in Multicultural Urban Areas: The Case of the Rotterdam Environmental Centre. In: Krasny, M. \& Dillon, J. (Eds.) Greening in the Red Zone: Disaster, Resilience and Community Greening. Frankfurt a.m.: Springer, pp 379-396.

Walsh, C. (2010). Development as Buen Vivir: Institutional arrangements and (de)colonial entanglements. Development 53(1), p.p. 15-21.

Walsh, C. (2012). Interculturalidad y (de)colonialidad: Perspectivas críticas y políticas. XII Congreso da Association pour la Recherche Interculturelle. Florianópolis: UFSC, Brasil.

Wilson, E. O. (1984). Biophilia. Cambridge: Harvard University Press.

Witteveen L. (2009) The voice of the visual: visual learning strategies for problem analysis, social dialogue and mediated participation. Delft: Eburon Academic Publishers.

Witteveen, L., Lie, R. (2009) Learning about "wicked" problems in the Global South. Creating a film-based learning environment with "Visual Problem Appraisal". MedieKultur: Journal of media and communication research, 28(52), 18.

Woods, M. (2007). Engaging the global countryside: globalization, hybridity and the reconstitution of rural place. Progress in Human Geography, 31(4), 485-507. 


\section{Summary}

For the first time in history, one single species has succeeded in transforming planet Earth to such an extent that major natural systems are being disrupted, placing ever-greater strains on the environment and mankind. In response to the age of the 'anthropocene,' as some authors are calling this epoch (Steffen et al 2011), new social movements of the networked society are developing autonomous networks of horizontal communication and action with a view to achieve socio-ecological justice (Castells, 2012). At the same time, there is increasing recognition that more awareness and connectedness does not necessarily lead to greater sustainability outcomes. There are thus calls for more radical, learning-based sustainability that generates deep transformations in individuals and communities so as to transition towards a more reflexive and process-oriented society (Wals 2009, Sterling 2009).

The principal contention of this thesis is that new social movements (NSM), based on integrated visions of sustainability, provide platforms for bringing about transformative learning. Through new forms of collective action centered on a plurality of ideas and practices, and with a strong focus on reflection and personal development, such NSM are articulating new paradigms of alternative development.

This thesis is based on empirical research (2012-2016) into one such NSM named the Council of Sustainable Settlements of Latin America (C.A.S.A.). Established in 2012, C.A.S.A has embarked on a self-directed and self-organized process of articulating and promoting more regenerative and sustainable lifestyles across cultural groups in Colombia. Comprising Indigenous pueblos, neo-rural settlements (ecovillages), Hare Krishna communities, campesino farmers and urban peoples and initiatives, the C.A.S.A. network organizes workshops and intercultural exchanges between members. The flagship event is El Llamado de la Montaña (The Call of the Mountain), which is an annual intercultural event which brings together up to 400 people for five days of shared living, workshops, conferences, Indigenous ceremonies and dancing. Interviewing members of C.A.S.A, visiting member communities, and participating in network events such as El Llamado de la Montaña forms the basis of this research. 
This thesis is divided into an introduction and seven chapters. In the introduction I begin by giving an overview of the research problem and the background of the C.A.S.A. network. This is followed by the research objective, the research questions, and an overview of the chapters.

In chapter 2, I outline the key concepts and theories used in the thesis. This begins with the key characteristics of NSM and how they relate to the C.A.S.A. network. This is followed by the endogenous Latin American concept of buen vivir (the good life), which represents as alternative narrative to development based on a community-centric, ecologically balanced and culturally sensitive values. This concept is important to my research because it represents an important narrative to C.A.S.A. as a network, as well as its members in how they are attempting to construct socio-ecological good lives. Fundamental to buen vivir is the next concept I address which is the ontological turn and its politics. With a strong focus on decolonization, buen vivir demands that we address the power relations between the dominant ontology (ways of being) of modernity, and other marginalized cosmologies such as those of Indigenous Andean communities. The last set of theories I employ are those of social learning where I am interested in the importance of plurality (fundamental to the two concepts above) in creating 'dissonance' which posits that people on the boundaries of their comfort zones are more receptive to transformational learning.

In chapter 3, I outline the methodology of Participatory Action Research (PAR), which is an interactive inquiry process that balances problem-solving actions implemented in a collaborative context together with the active voice of the researcher. This methodology has allowed me to address the objective-subjective and expert-subject divides by attempting to decolonize the power relations between the two. I address the objective-subjective divide by engaging in autoethnography whereby giving my own voice and emotions to the narrative being written. The expert-subject divide is addressed by joining with co-researchers to co-produce the knowledge of this research. I have also taken an active role in the C.A.S.A. network, partaking in network decisions and organizing events. I finish the chapter by reflecting on this methodology, my role as a researcher, and the difficulties encountered in the field.

In chapter 4, I present the first empirical case of the community Atlántida, which explores the role of social learning in bringing about transformative sustainability processes among individuals and communities. Drawing on 12 months of action-oriented research, including interviews and community-reflection meetings, and with contributions by two co-researchers 
from the community, I show how the process of triple-loop learning took place in the community. Disruptions in the community provided the opportunity for members to enter into a process of deep learning, whereby they reflected collectively on their process of community building and the subsequent unraveling of its social fabric. I argue that dissonance must be present to catalyse transformative learning processes, but that for these processes to lead to actual learning, there must be significant levels of self-reflection and flexibility, and to be aware that such processes are never easy and always take a human toll.

In chapter 5, I move away from the community setting towards exploring the visions and practices of buen vivir in the C.A.S.A. network, and its potential for acting as a platform for alternatives to develop. Based on methods such as participant observation, participatory photography and discussion circles, my results highlight that despite the challenges and contradictions of enacting endogenous ideas of a good life or buen vivir, the practices of attempting to do so can bring about deep personal and collective transformations by developing new relations with territory and society.

In chapter 6, I move to the network event El Llamado de la Montaña where I explore how intercultural encounters between different ontological positions can lead to more radically confronting and overcoming our unsustainable habits. Important in this respect is the negotiation process involved in 'ontological politics' (the power relations between different ontological positions). Results show how encounters between different ontologies can result in transformative and potentially 'transgressive' learning in terms of disrupting stubborn routines, norms and hegemonic powers which tend to accelerate unsustainablity. I conclude, however, that such learning environments also lead to conflicts as inflexible, rigid ontologies and power relations within and between communities must be addressed if sustained learning is to take place. Crucial to this process is therefore the role of facilitating spaces for discussion and reflection, whereby such encounters bring about an ontological politics generative of novel perspectives and potentially transformative learning processes.

In chapter 7, I move towards a more conceptual look at the nature of transformative learning through spaces created in socio-ecological and civic ecology practices. Based on empirical research and theory, I present some 'design principles' for creating spaces that facilitate boundary crossing and transformative learning for socio-ecological sustainability. The five principles are: 1) experiencing a good story; 2) collaborative leadership; 3) embracing organic 
processes; 4) employing passions and emotions; and 5) promoting plurality for change. This chapter also poses the question as to what extent such practices help people develop the reflexive capacities needed to transform and transgress resilient patterns and systems that contribute to 'glocal' systemic dysfunction. It then finishes with strategies for upscaling and outscaling these capacities through bioregional and national networks, one of which is the C.A.S.A. Colombia network and its annual gathering El Llamado de la Montaña.

In chapter 8, I summarize my main findings, highlighting that experiencing different ways of thinking and being has the power to change points of reference in our worldviews, whereby new social movements such as C.A.S.A. provide a means of articulating and forging alliances between people and communities attempting to live more responsibly within the limits of the earth. However, such learning processes are incredibly complex, and the value-action gap remains substantial in many cases. It is one thing to talk about wanting to live in harmonious relations with people, nature and Mother Earth, but quite another to put this into practice; for example, by living in an intentional community, growing your own food, and inviting non-human actors such as spirits into one's life. What this thesis has shown, however, is that by putting into practice principles of buen vivir such as reconnecting to ancestral wisdom, questioning values of competition and individuality, and forming new relations to place and territory, one begins to question one's own set of norms, and those of society.

Ultimately, the C.A.S.A. network's struggles, negotiations and learning processes remind us that global sustainability entails more than 'menus' of good practices but a plurality of solutions which include humans and non-humans, different ontologies, and even a multiplicity of worlds, in what is a tough but rewarding aula. More future research is needed, however, into the relations between NSM such as C.A.S.A. and the state, as well as how such alternative paradigms play out in urban settings. 


\section{Resumen}

Por primera vez en la historia, una sola especie ha logrado transformar el planeta Tierra hasta el punto de interrumpir los principales sistemas naturales, colocando cada vez mayores presiones sobre el medio ambiente y la humanidad. En respuesta a la época del "Antropoceno", como algunos autores llaman a estos tiempos (Steffen et al 2011), los Nuevos Movimientos Sociales (NMS), están desarrollando configuraciones autónomas de red con comunicación y accionar horizontal, con el fin de lograr más justicia socio-ecológica (Castells, 2012). Al mismo tiempo, hay un creciente reconocimiento de que una mayor conciencia o una mayor interconexión, por sí solas, no conducen necesariamente a mayores resultados de sustentabilidad. Por lo tanto, hay una llamada a generar un tipo sustentabilidad más radical, basada en el aprendizaje que genera profundas transformaciones en los individuos y las comunidades, con el fin de impulsar la transición hacia una sociedad más reflexiva y orientada en procesos (Wals 2009, Sterling 2009).

Esta tesis argumenta principalmente que los Nuevos Movimientos Sociales (NMS), basados en visiones integradas de sustentabilidad, proporcionan plataformas para producir un aprendizaje transformador. A través de nuevas formas de acción colectiva, centrada en una pluralidad de ideas y prácticas, y con un fuerte enfoque en la reflexión y el desarrollo personal, tales NMS están articulando nuevos paradigmas de desarrollo alternativo.

Esta tesis está basada en una investigación empírica de cuatro años (2012-2016) de seguimiento de un NMS llamado el Consejo de Asentamientos Sustentables de América Latina (C.A.S.A.). Establecido en 2012, C.A.S.A se ha embarcado en un proceso auto-dirigido y autoorganizado para articular y promover estilos de vida sustentables y regenerativos en diferentes grupos culturales en Colombia: pueblos indígenas, asentamientos neo-rurales (ecoaldeas), comunidades Hare Krishna, agricultores campesinos y habitantes de las ciudades. La red C.A.S.A. organiza talleres de intercambio cultural entre sus miembros y un encuentro intercultural anual llamado El Llamado de la Montaña, que reúne hasta 400 personas durante cinco días para convivir en comunidad, compartir conocimientos, talleres, conferencias, ceremonias indígenas y baile. A través de entrevistas a miembros de C.A.S.A, visita a comunidades y participación en los eventos y organización de la red, esta investigación se basó en una metodología de Investigación-Acción Participativa y Etnografía. 
Esta tesis se divide en una introducción y siete capítulos. En la introducción se da una visión general del problema de investigación y el contexto de la red C.A.S.A. Luego se presentan los objetivos de la investigación, las preguntas de investigación, y un resumen de los capítulos.

En el capítulo 2, se esbozan los principales conceptos y teorías utilizados en la tesis. Comenzando por las características más claves de los Nuevos Movimientos Sociales (NMS) y explicando cómo estas se relacionan con la red C.A.S.A. A continuación se presenta el concepto latinoamericano endógeno del buen vivir como una narrativa que propone una alternativa al desarrollo convencional, y que está basada en valores culturalmente sensibles que se centran en la comunidad y el equilibrio ecológico. Este concepto es esencial para esta investigación ya que influye la forma en que los miembros de la red C.A.S.A. están tratando de construir formas de vida socio-ecológicas. Fundamental para el buen vivir es el concepto del giro ontológico y su política. Con un fuerte enfoque en la descolonización, buen vivir demanda que abordemos las relaciones de poder entre la ontología dominante (formas de ser de la modernidad), y otras cosmologías marginadas, como las de las comunidades indígenas de los Andes. El último conjunto de teorías que se emplearon son las de aprendizaje social, enfocándose en la importancia de la pluralidad (fundamental para los dos conceptos anteriores), y en la generación de "disonancia" que postula la necesidad de sacar a las personas de sus 'zonas de confort' para inducirlos a ser más receptivos a experimentar un aprendizaje transformativo.

En el capítulo 3 se trata a profundidad la metodología de investigación-acción participativa (PAR), que es un proceso de consulta interactiva que equilibra las acciones implementadas para resolver problemas en un contexto de colaboración, manteniendo una voz activa del investigador. Esta metodología ha permitido hacer frente a las dicotomías de objetividadsubjetividad y de experto-sujeto investigado al descolonializar las relaciones de poder existentes entre las mismas. Se asume la brecha entre objetividad-subjetividad mediante la utilización de la auto-etnografía, que da voz propia al autor y expone sus emociones en la narrativa del texto. Se hace frente a la brecha experto-sujeto investigado con la invitación de co-investigadores de la red C.A.S.A para coproducir el conocimiento de esta investigación. El autor también ha tomado un papel activo en la red C.A.S.A., participando en las decisiones de la red y la organización de eventos. Este capítulo termina reflexionando sobre ésta metodología, el rol del investigador, y las dificultades encontradas en el campo. 
En el capítulo 4, se presenta el primer caso empírico sobre la Ecoaldea Atlántida, en el que se explora el papel del aprendizaje social en los procesos de sustentabilidad y transformación de los individuos y la comunidad. Sobre la base de 12 meses de investigación de campo orientada en la investigación acción, incluyendo entrevistas y la participación en las reuniones de reflexión de la comunidad, y con las contribuciones de dos co-investigadores miembros de la comunidad, se muestra cómo se llevó a cabo el proceso de aprendizaje de triple circuito en la comunidad. Las disrupciones en la comunidad proporcionaron la oportunidad para que los miembros entraran en un proceso de aprendizaje profundo, reflexionando colectivamente en su proceso de construcción de la comunidad y la posterior desintegración de su tejido social. Se argumenta que la disonancia es primordial para catalizar los procesos de aprendizaje transformativo, pero que para que estos procesos conlleven a un aprendizaje real, tiene que haber importantes niveles de auto-reflexión y de flexibilidad, y se debe ser consciente de que estos procesos nunca son fáciles y siempre afectan profundamente las relaciones humanas.

En el capítulo 5, la investigación se aleja del contexto de comunidad para explorar las visiones y prácticas de buen vivir de la red C.A.S.A., y su potencial para actuar como plataforma de alternativas al desarrollo convencional. Con base en métodos tales como la observación participativa, la fotografía participativa y la discusión en círculos, los resultados ponen de manifiesto que a pesar de los desafíos y contradicciones de las ideas endógenas de una vida satisfactoria o un buen vivir, el hecho de intentar llevarlas a la práctica pueden dar lugar a profundas transformaciones personales y colectivas al desarrollar nuevas relaciones con los territorios y la sociedad.

En el capítulo 6, se explora el encuentro de la red: El Llamado de la Montaña, donde se investiga cómo los encuentros interculturales entre diferentes posiciones ontológicas pueden conducir a afrontar y superar más radicalmente nuestros hábitos no sustentables. Importante en este respecto es el proceso de negociación que conlleva la "política ontológica" (las relaciones de poder entre diferentes posiciones ontológicas). Los resultados muestran cómo los encuentros entre diferentes ontologías pueden dar lugar a aprendizajes transformativos y potencialmente 'transgresivos' en términos de interrumpir obstinadas rutinas no sustentables, normas y poderes hegemónicos que tienden a acelerar la degradación socio-ambiental. Se llega a la conclusión, sin embargo, que este tipo de entornos de aprendizaje también conducen a conflictos, sobretodo si las ontologías rígidas e inflexibles, y las relaciones de poder dentro y entre las comunidades no se abordan, sólo así puede darse paso a que ocurra el aprendizaje. 
Por lo tanto, es crucial para este proceso el papel de facilitar espacios para la discusión y la reflexión, de tal forma que tales encuentros lleven a políticas ontológicas generativas de nuevas perspectivas y procesos de aprendizaje potencialmente transformativos.

En el capítulo 7, se da una mirada más conceptual al aprendizaje transformativo en el ámbito de las prácticas socio-ecológicas y de ecología cívica. Basándose en investigación teórica y empírica, se presentan algunos "principios de diseño" para la creación de espacios que faciliten el cruce de límites y el aprendizaje transformativo para la sustentabilidad socio-ecológica. Los cinco principios son: 1) experimentar una buena historia; 2) liderazgo colaborativo; 3) promover procesos orgánicos; 4) emplear las pasiones y emociones; y 5) promover la pluralidad para el cambio. En este capítulo también se plantea la cuestión de hasta qué punto estas prácticas ayudan a las personas a desarrollar las capacidades reflexivas necesarias para transformar y transgredir patrones resilientes y sistemas que contribuyen a la disfunción sistémica "glocal". El capítulo finaliza entonces presentando estrategias para escalar y multiplicar estas capacidades, a través de redes bio-regionales y nacionales, una de las cuales es la red C.A.S.A y su encuentro nacional El Llamado de la Montaña.

En el capítulo 8, se resumen las principales conclusiones, destacando que el experimentar diferentes formas de pensar y de ser tiene el poder de cambiar puntos de referencia en nuestra visión del mundo, con lo que los Nuevos Movimientos Sociales como C.A.S.A., proporcionan un medio de articulación estableciendo alianzas entre las personas y comunidades que tratan de vivir de manera más responsable dentro de los límites de la tierra. Sin embargo, tales procesos de aprendizaje son increíblemente complejos, y la brecha entre los valores (éticos) y la acción sigue siendo considerable amplia en muchos casos. Una cosa es hablar sobre el deseo de vivir en relaciones armoniosas con las personas, la naturaleza y la Madre Tierra, pero otra muy distinta es poner esto en práctica; por ejemplo, a través de vivir en una comunidad intencional, de cultivar nuestra propia comida, y de invitar actores no humanos, tales como espíritus, a convivir con uno. Lo que esta tesis ha demostrado, sin embargo, es que al poner en práctica los principios del buen vivir, como el volver a conectarse con la sabiduría ancestral, cuestionar los valores de la competencia y la individualidad, y la formación de nuevas relaciones de lugar y con el territorio, genera procesos de cuestionamiento del conjunto de normas y supuestos propios, y los de la sociedad. 
En última instancia, las luchas, las negociaciones y los procesos de aprendizaje de la red C.A.S.A. nos recuerdan que la sustentabilidad global implica más que "menús" de buenas prácticas, sino una pluralidad de soluciones que incluyen seres humanos y no humanos, diferentes ontologías, e incluso una multiplicidad de mundos, en lo que es una difícil, pero gratificante, aula de vida. Sin embargo, se necesita más investigación sobre las relaciones entre los Nuevos Movimientos Sociales (NSM) como C.A.S.A. y el Estado, así como el rol que dichos paradigmas alternativos juegan en los entornos urbanos. 


\section{Samenvatting}

Voor het eerst in de geschiedenis heeft een enkele soort het voor elkaar gekregen om onze planeet dusdanig te veranderen dat belangrijke natuurlijke systemen worden verstoord, wat leidt tot een steeds grotere belasting van het milieu en de mensheid. Als reactie op dit tijdperk, door sommige auteurs aangemerkt als 'het Antropoceen' (Steffen et al 2011), worden autonome netwerken gerealiseerd door nieuwe sociale bewegingen uit de netwerksamenleving met als doel het bewerkstelligen van socio-ecologische gerechtigheid (Castells, 2012). Tegelijkertijd heerst het besef dat een toenemend bewustzijn en een sterkere binding met de sociale en fysieke omgeving niet noodzakelijkerwijs bijdraagt aan een duurzamere uitkomst. De urgentie om iets fundamenteels te doen aan mondiale duurzaamheidsvraagstukken vraagt om een meer radicale, op leren gebaseerde, duurzaamheid die vergaande veranderingen in individuen en gemeenschappen bewerkstelligd om een transitie naar een meer wederkerige en procesgeoriënteerde samenleving te kunnen realiseren (Wals 2009, Sterling 2009).

De hoofdstelling van dit proefschrift is dat nieuwe sociale bewegingen (NSM), gebaseerd op een geïntegreerde duurzaamheidsvisie, een platform bieden voor transformatief leren. Door nieuwe vormen van collectief handelen te creëren die gebaseerd zijn op een breed scala aan ideeën en gewoontes en met een sterke focus op reflectie en persoonlijke ontwikkeling, articuleren deze NSMs nieuwe paradigma's van alternatieve ontwikkeling.

Dit proefschrift is gebaseerd op empirisch onderzoek (2012-2016) in een zo'n NSM: Council of Sustainable Settlements of Latin America (C.A.S.A.). C.A.S.A, opgericht in 2012, is begonnen met een zelfgestuurd en zelf georganiseerd proces van het benadrukken en bevorderen van meer regeneratieve en duurzame leefstijlen door culturele groepen in Colombia. Het C.A.S.A netwerk, bestaande uit inheemse pueblos, neo-rurale nederzettingen (ecovillages), Hare Krishna gemeenschappen, campesino boeren en stedelijke groepen en initiatieven, organiseert workshops en interculturele uitwisselingen tussen de leden. Het belangrijkste evenement is El Llamado de la Montaña (De Roep van de Berg), een jaarlijks intercultureel evenement waarin tot 400 mensen gedurende 5 dagen samenleven en zich bezighouden met workshops, dialogische interacties, traditionele ceremonies en dansen. Dit onderzoek is gebaseerd op interviews met C.A.S.A-leden, diverse bezoeken aan C.A.S.A gelieerde gemeenschappen en deelname aan netwerkbijeenkomsten zoals El llamado de la Montaña. 
Dit proefschrift is verdeeld in een introductie en zeven hoofdstukken. De introductie start biedt een overzicht van het onderzoeksprobleem en de achtergrond van het C.A.S.A. netwerk, gevolgd door het onderzoeksdoel, de onderzoeksvragen en een overzicht van de hoofdstukken.

In hoofdstuk 2 introduceer worden de belangrijkste concepten en theorieën die in dit proefschrift een rol spelen uiteengezet. Ik begin met het beschrijven van de belangrijkste eigenschappen van NSM en hoe deze gerelateerd zijn aan het C.A.S.A netwerk. Daarna volgt een introductie van het inheems Latijns Amerikaanse concept van 'buen vivir' (het goede leven). 'Buen vivir' suggereert een vorm van ontwikkeling die gebaseerd is op waarden die gekenmerkt worden door ecologische en culturele sensitiviteit en gemeenschapszin.. Dit concept is cruciaal voor C.A.S.A en haar leden omdat het een leidraad is bij het het opbouwen van een sociaalecologisch goed bestaan. Fundamenteel voor 'buen vivir' is de zogenaamnde 'ontologische draai' en de daarbij behorende politiek. Met een sterke focus op dekolonisatie vereist 'buen vivir' dat we de machtsrelatie tussen de dominante ontologie (manier van zijn in de wereld) tussen de moderne wereld en die van gemarginaliseerde samenlevingen zoals die van inheemse gemeenschappen. De laatste groep theorieën die ik behandel zijn gerelateerd aan sociaal leren waarin het belang van pluraliteit (fundamenteel voor de hierboven genoemde concepten) en in het creëren van 'dissonantie' wordt benadrukt. Sociaal leren veronderstelt dat mensen die op de grens van hun comfortzone leven ontvankelijker zijn voor transformatief leren dan mensen die daarbinnen blijven.

In hoofdstuk 3 beschrijf ik methodologie van participerend aktie-onderzoek. Dit is, een interactieve en handelingsgerichte bevragingsmethode waarin de balans tussen probleemoplossende acties in een collaboratieve context en de actieve stem van de onderzoeker wordt nagestreefd. Deze methodologie heeft $\mathrm{mij}$ in staat gesteld om de kunstmatige scheiding tussen objectief-subjectief en expert-subject in elk geval deels te doorbreken door de machtsrelatie tussen beide partijen (de onderzoeker en de onderzochten) proberen te doorbreken. De tegenstelling objectief-subjectief vervaagt door hantering van het gebruik van auto-etnografie waarbij ik mijn eigen stem en emoties in de geschreven verhaallijn verwerk. De expert-subject tegenstelling vervaagt door te streven naar coproductie van de kennis niet over de gemeenschap maat met en voor de gemeenschap. Het hoofdstuk eindigt met een reflectie op de methodologie, mijn rol als onderzoeker en de dilemma's die ik tegenkwam in het veld. 
Hoofdstuk 4 behandelt de eerste empirische casus van de Atlántida gemeenschap, waarin ik de rol van sociaal leren bij de totstandkoming van transformatieve duurzaamheidsprocessen tussen individuen en gemeenschappen onderzoek. Het participerend aktie-onderzoek dat in een periode van 12 maanden plaatsvond laat zien hoe het proces van triple-loop leren plaatsvond in de gemeenschap. Verstoringen in de gemeenschap vormden kansen voor de leden om blootgesteld te worden aan een proces van diep reflexief leren, waarbij ze collectief reflecteerden op het proces van gemeenschapsvorming en het daaropvolgende uiteenvallen van de sociale structuur. Op basis van de bevindingen beargumenteer ik dat dissonantie transformatief lerenmogelijk maakt zolang er sprake is van een significant niveau van zelfreflectie en flexibiliteit, alsook de erkenning dat veranderingsprocessen nooit makkelijk zijn en altijd een menselijke tol eisen.

In hoofdstuk 5, verschuift de aandacht naar het exploreren van de visie en gebruiken van buen vivir in het C.A.S.A. netwerk en haar vermogen om als platform te dienen voor de ontwikkeling van alternatieven. Gebaseerd op onderzoeksmethoden zoals deelnemer-observatie, participatieve fotografie en discussiekringen laten de resultaten zien dat de uitdagingen en tegenstellingen van het aannemen van endogene ideeën over een goed leven of buen vivir kunnen leiden tot diepe persoonlijke en collectieve transformaties door het ontwikkelen van nieuwe relaties met het de fysieke omgeving en de samenleving.

In hoofdstuk 6 staat het netwerk-evenement El Llamado de la Montaña centraal om te zicht te krijgen op hoe interculturele ontmoetingen tussen verschillende ontologische posities kunnen leiden tot meer radicale confrontaties en het doorbreken van niet-duurzame gewoonten. Belangrijk in dit verband is het onderhandelingsproces dat plaatsvindt in het kader van de 'ontologische politiek' ofwel de machtsverhoudingen tussen de verschillende ontologische posities. De resultaten laten zien hoe ontmoetingen tussen verschillende ontologieën kunnen resulteren in transformatief en mogelijk 'grensoverschrijdend' leren op het gebied van het doorbreken van hardnekkige routines, normen en overheersend en bepalende krachten die de neiging hebben om niet-duurzaamheid te versnellen. Ik concludeer echter dat dergelijke beladen leeromgevingen ook leiden tot destructieve conflicten door inflexibele, rigide ontologieën en machtsverhoudingen binnen en tussen gemeenschappen. Deze moeten worden aangepakt om duurzaam leren te laten plaatsvinden. Cruciaal voor dit proces is dan ook het faciliteren van ruimte voor discussie en reflectie, waarbij deze ontmoetingen leiden tot een 
ontologische politiek die leidt tot nieuwe perspectieven en potentieel van meer constructieve transformatieve leerprocessen.

In hoofdstuk 7 gaat over de aard van transformatief leren zoals dat tot stand komt in de ruimtes gecreëerd in socio-ecologische en maatschappelijke ecologisch praktijken. Op basis van empirisch onderzoek en theorie presenteer ik een aantal ontwerpprincipes voor het creëren van ruimtes die grensdoorbrekend en transformatieve leren voor sociaal-ecologische duurzaamheid bevorderen. Deze vijf principes zijn: 1) het ervaren van een goed verhaal; 2) samenwerkend leiderschap; 3) het omarmen van organische processen; 4) het gebruiken van passies en emoties; en 5) het bevorderen van pluralisme voor verandering. In dit hoofdstuk stel ik ook de vraag in hoeverre deze praktijken mensen helpen in het ontwikkelen van de reflexieve capaciteiten die nodig zijn om veerkrachtige patronen en systemen te doorbreken die bijdragen aan 'glokale' systemische disfunctie. Het eindigt dan met strategieën voor opschaling en verspreiden deze capaciteiten door middel van bioregionale en nationale netwerken, waar El Llamado de la Montaña deel van uitmaakt.

In hoofdstuk 8 worden de belangrijkste bevindingen van deze studie samengevat. Een belangrijke uitkomstis dat het ervaren van verschillende manieren van denken en zijn ons referentiepunt en wereldbeeld kan doen veranderen. Nieuwe sociale bewegingen zoals C.A.S.A. kunnen een rol spelen bij het beschrijven en smeden van allianties tussen mensen en gemeenschappen in een poging om meer verantwoord te leven binnen de ecologische grenzen van de aarde. Echter, dergelijke leerprocessen zijn ongelooflijk complex, en de kloof tussen de waarden die worden nagestreefd en het handelen dat daar uit voort zou moeten komen blijft aanzienlijk in veel gevallen. Het is één ding om te praten over de wens om in harmonie te leven met mensen, de natuur en Moeder Aarde, maar dit in de praktijk brengen is een ander verhaal; bijvoorbeeld, door te leven in een moedwillige gemeenschap, het verbouwen van je eigen voedsel en het uitnodigen van niet-menselijke actoren zoals geesten en de andere soorten in je eigen leven. Wat dit proefschrift echter laat zien, is dat door de principes van buen vivir zoals het zoeken van verbinding met oude wijsheden, het betwijfelen van waardes als competitie en individualiteit en het vormen van nieuwe relaties met tijd en plek, men kan beginnen met een herijken van de eigen normen en die van de samenleving vanuit een meer sociaal-ecologisch perspectief. 
Uiteindelijk laat de worsteling van het C.A.S.A. netwerk, haar onderhandelingen en leerprocessen zien dat wereldwijde duurzaamheid meer is dan een 'menu' van goede gewoonten, maar vraagt om een meervoud aan oplossingen die zowel mensen als nietmensen, verschillende ontologische perspectieven en zelfs een meerderheid aan werelden bevatten. Meer onderzoek is echter nodig naar de relaties tussen nieuwe sociale bewegingen zoals C.A.S.A. en de overheid en naar de toepasbaarheid van deze bewegingen in een stedelijke omgeving. 


\section{About the Author}

Martha C. Chaves was born in Bogotá D.C., Colombia on the 28th of January 1979. She obtained her Bachelor Degree in Biology, specializing in Entomology at the Faculty of Natural Science at the Universidad del Valle, Cali, Colombia, in 2004. She worked as a Young Researcher (through the Colciencias program) at the Research Group Biology, Ecology and Management of Ants, Universidad del Valle. In 2008, she obtained her Master degree in Forest and Nature Conservation, at Wageningen University, the Netherlands, sponsored by the ALBAN Scholarship for high level students of Latin America.

In January 2012, she enrolled in a PhD program with the chair group Sociology of Development and Change, in cooperation with the Education and Competence Studies, both at Wageningen University, the Netherlands. This was funded by the Scholarship Program Francisco José de Caldas for PhD studies abroad, and granted by the Colombian Institute for the Development of Science and Technology, COLCIENCIAS. Currently she is working on the international project Transgressive Social learning for Social-Ecological Sustainability in Times of Climate Change $T$ Learning (see http://www.worldsocialscience.org/activities/transformations/t-learning/), funded by the International Social Science Council (ISSC) as Coordinator and researcher of the Colombian case study. 
The research described in this thesis was financially supported by the Administrative Department of Science, Technology and Innovation of Colombia, COLCIENCIAS. 


\section{Propositions}

1. 'Transgressive' forms of learning, which disrupt stubborn routines, norms and hegemonic powers, are needed to address 'wicked' challenges of sustainability (this thesis).

2. Taking the notion of multiple-worlds seriously encourages the rethinking of our own assumptions (this thesis).

3. Research is performative and thus requires self-reflection so as to address the partial role of the researcher, and the implications of this.

4. Instead of scientific research being read by 10 academic peers, it should be used by 100 agents of change.

5. The age of different scientific fields has passed: we have entered the era of transdisciplinary research where natural and social sciences melt into one with a view to engage with the inter-related web of life.

6. In our everyday lives we continue to perpetuate hierarchical power structures in society that we wish to change.

7. We need to place more attention to critically researching the elite, consumerist, mainstream society and its systemic effects on people and nature, while voicing the alternatives to this with the same passion we currently deploy when studying 'poor', marginalized people and their effects on nature.

Propositions belonging to the thesis, entitled

Answering the 'Call of the Mountain': Co-creating sustainability through networks of change in Colombia

Martha Cecilia Chaves

Wageningen, 22 November 2016 